\title{
Measured short-term subsurface ground displacements from EPBM tunnelling in London Clay
}

\author{
M. S. P. WAN* J. R. STANDING $\dagger$, D. M. POTTS $\uparrow$ and J. B. BURLAND $\dagger$
}

\begin{abstract}
Subsurface ground displacements from the construction of the twin-bore Crossrail tunnels in London Clay by earth pressure balance machines (EPBMs) are presented and discussed, complementing a companion paper by the authors that focused on the surface response. Both papers report vertical and horizontal displacements, in this case measured using comprehensive arrays of instruments installed within boreholes in Hyde Park, London. The Crossrail tunnels are deeper than those cited in most UK case histories concerning tunnelling in stiff clay. Clear insights were gained into subsurface displacement mechanisms: an 'inward' displacement field was observed around the Crossrail tunnel construction, in contrast to the 'outward' displacement field that developed around the shallower Channel Tunnel Rail Link tunnels constructed east of London using similar EPBMs in London Clay. This has important implications when estimating subsurface displacements using currently available empirical methods. Appraisal of the EPBM operational variables suggests that the relative magnitude of face and tail grout pressures to overburden stress is the key factor contributing to the opposing senses of the observed displacement fields. Earlier tunnelling-induced strain softening of the London Clay is evident from greater subsurface incremental volume losses and settlement trough width parameters relating to subsequent tunnel construction.
\end{abstract}

KEYWORDS: field instrumentation; ground movements; monitoring; settlement; tunnels \& tunnelling

\section{BACKGROUND}

Using earth pressure balance machines (EPBMs) to construct tunnels in urban environments has become increasingly popular because they can be effectively controlled to minimise resulting ground settlements. There are only a limited number of comprehensive case histories presenting subsurface ground response to EPBM tunnelling in stiff clay. The ground response to Channel Tunnel Rail Link (CTRL) tunnel construction (where EPBMs were also used in London Clay) described by Standing \& Selemetas (2013) involved an outward displacement field in the close vicinity of the new tunnels; that is, the resultant vectors of displacement were directed away from the new tunnel. In this situation, existing empirical methods for estimating subsurface displacements are not valid (e.g. Mair et al., 1993). This has important implications when assessing potential damage to underground structures such as existing tunnels and services. The results from subsurface field monitoring described in this paper relate to the twin-bore Crossrail tunnel construction at an instrumented research site in Hyde Park, London. The observed surface displacements are presented in a companion paper (Wan et al., 2017). Subsurface ground displacements were measured with borehole rod extensometers and inclinometers in conjunction with surface monitoring by precise levelling and micrometer stick measurements to provide absolute displacements. These monitoring results were studied and correlated to a number of EPBM operation variables recorded by the tunnelling contractor. By doing

Manuscript received 6 February 2017; revised manuscript accepted 13 June 2017. Published online ahead of print 18 July 2017.

Discussion on this paper closes on 1 February 2018, for further details see p. ii.

* Geotechnical Consulting Group LLP, London, UK (Orcid:0000-0001-5290-8449).

$\uparrow$ Imperial College, London, UK. so, it was possible to establish the characteristics and mechanisms of the near-tunnel ground responses induced by construction with earth pressure balance (EPB) tunnel boring machines (TBMs). In this paper, where relevant, comparisons are made with other case histories where subsurface tunnelling-induced displacements were measured in London Clay, notably those reported by Attewell \& Farmer (1974), Barratt \& Tyler (1976), New \& Bowers (1994), Dean \& Bassett (1995), Macklin \& Field (1998), Nyren (1998), Van der Berg et al. (2003), Clayton et al. (2006) and Standing \& Selemetas (2013).

The material presented in this paper forms part of an extensive research project investigating the effect of tunnelling on existing tunnels. Information concerning the overall project, involving field monitoring, structural testing of bolted cast-iron segments, numerical analyses and advanced laboratory soil testing, is summarised by Standing et al. (2015). The intention of the current paper is to provide sufficient background information such that it can be read and understood independently of the companion paper by the authors (Wan et al., 2017). In order to avoid needless repetition, many of the details relating to the Crossrail project, site geology, instrumentation layout and the EPBMs used are omitted in this paper; where necessary, the reader is directed to appropriate sections in the companion paper.

\section{CROSSRAIL TUNNELLING WORK AND SITE GEOLOGY}

The research site at Hyde Park was set up in the vicinity of where the Crossrail tunnels pass beneath the existing tunnels of the London Underground Limited (LUL) Central Line. The exact location of the intersection is beneath Bayswater Road, which runs alongside the northern boundary of Hyde Park, just east of Lancaster Gate. The relative position of the tunnels is shown in Fig. 1 and their respective axis depths are about $24 \mathrm{~m}$ (Central Line) and $34.5 \mathrm{~m}$ (Crossrail) below ground level. 


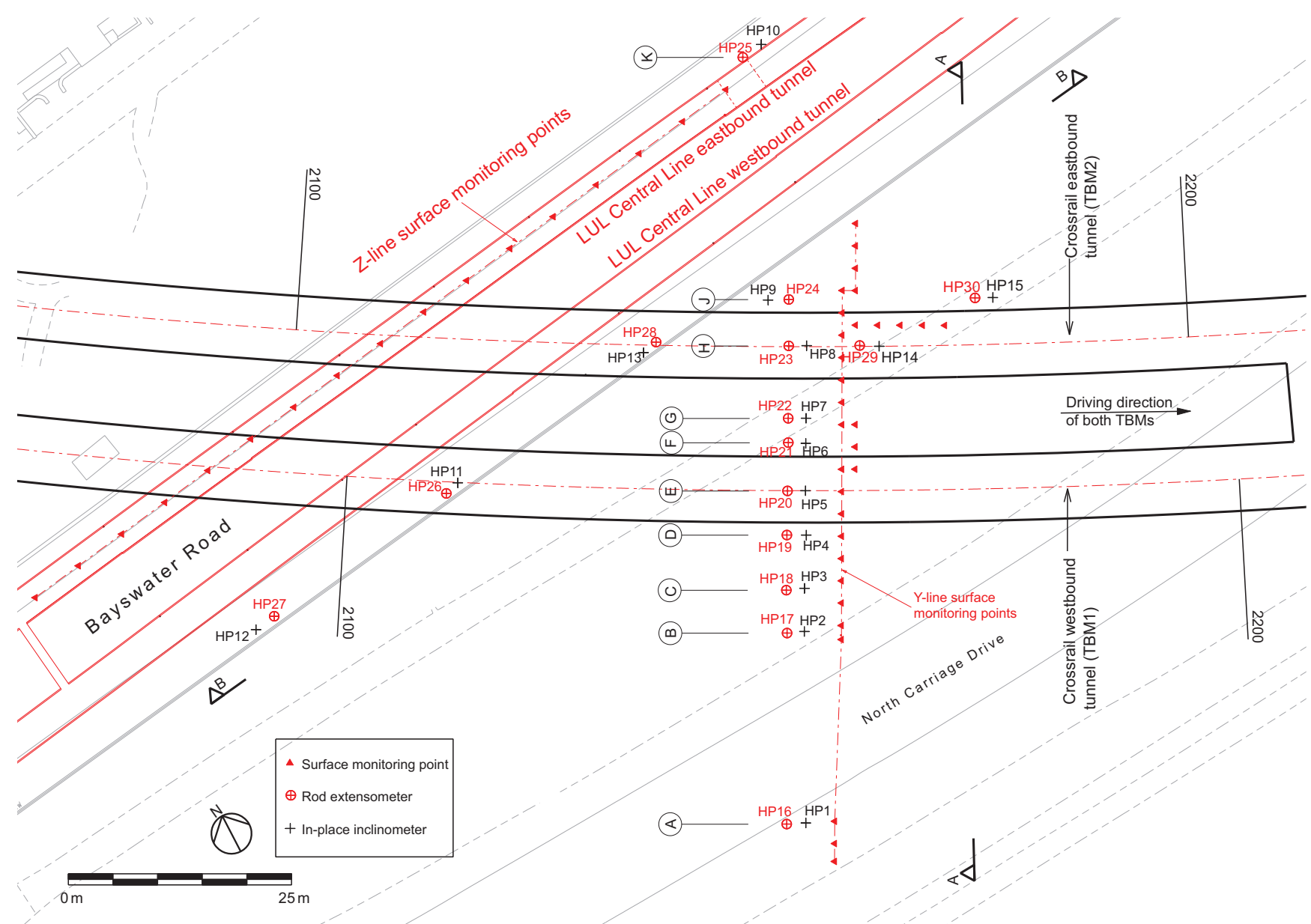

Fig. 1. Instrumentation layout plan

A typical London Basin stratigraphy is found at the Hyde Park site with made ground and Terrace Gravels overlying the descending sequence of the London Clay Formation (LCF), Lambeth Group, Thanet Sand and Chalk bedrock. The detailed stratigraphy is shown and described by Wan et al. (2017: figure 2) and is also shown in some of the key figures of this paper. The tunnels of the Central Line are within unit B2 of the LCF, while the deeper Crossrail tunnels have their crown in unit B2 and invert just within the more permeable A3ii unit (see King (1981) for a description of the units).

The EPB TBMs used to construct the Crossrail tunnels were $7 \cdot 1 \mathrm{~m}$ in diameter with a tapered shield length of $11 \mathrm{~m}$. Spoil produced from the rotating cutter-head passed into a plenum chamber from which it was removed by an Archimedes screw. The precast concrete lining rings, formed of seven segments and a key-piece, were erected within the shield body and had inner and outer diameters of $6.2 \mathrm{~m}$ and $6.8 \mathrm{~m}$, respectively, and a nominal length of $1600 \mathrm{~mm}$. The annulus void between the tunnel lining extrados and the excavated ground was filled using a two-part grout injection system. A comprehensive system of instrumentation allowed various operational variables to be monitored continuously and the TBM controlled effectively. Details of the TBMs used are given by Wan et al. (2017: figure 5; pp. 423, 424).

\section{INSTRUMENTATION LAYOUT}

The instrumentation layout shown in Fig. 1 was designed specifically to monitor the subsurface ground displacements induced by the passage of both TBMs. There were 30 boreholes in total, each accommodating either an inclinometer casing or a rod extensometer. Surface ground displacements were monitored on three instrumentation lines (X, Y and $\mathrm{Z}$ ); the $\mathrm{X}$-line (not shown in Fig. 1) was about $100 \mathrm{~m}$ away from the Y-line (see Wan et al. (2017: figure 3; p. 422)). Of these, the Y-line was where most of the subsurface instruments were installed. Extensometer and inclinometer boreholes were paired (about $2.5 \mathrm{~m}$ apart) so that both vertical and horizontal ground displacements could be obtained at the same locations: useful when determining resultant displacement vectors and ground strains. The positions of the installed rod extensometer anchors and in-place inclinometers along the main array (section A-A of Fig. 1) are presented in Figs 2(a) and 2(b), respectively. A maximum of eight rod extensometer anchors for measuring subsurface vertical displacements could be installed within each borehole and these were largely distributed around the Crossrail tunnels (Fig. 2(a)). There was a similar arrangement for the inclinometer MEMS (micro-electro-mechanicalsystem) sensors, 16 of which could be installed in each borehole (Fig. 2(b)). The measurement principles, installation procedures and measurement techniques of the instruments are described by Wan (2014) and Wan \& Standing (2014a). On the southern pavement of Bayswater Road, there was another borehole instrument array running parallel to the existing Central Line tunnels as shown in Fig. 2(c) (section B-B of Fig. 1). These boreholes were positioned as close as possible to the Central Line tunnels to observe how their presence affects the ground response, compared with the 'greenfield' ground response. 


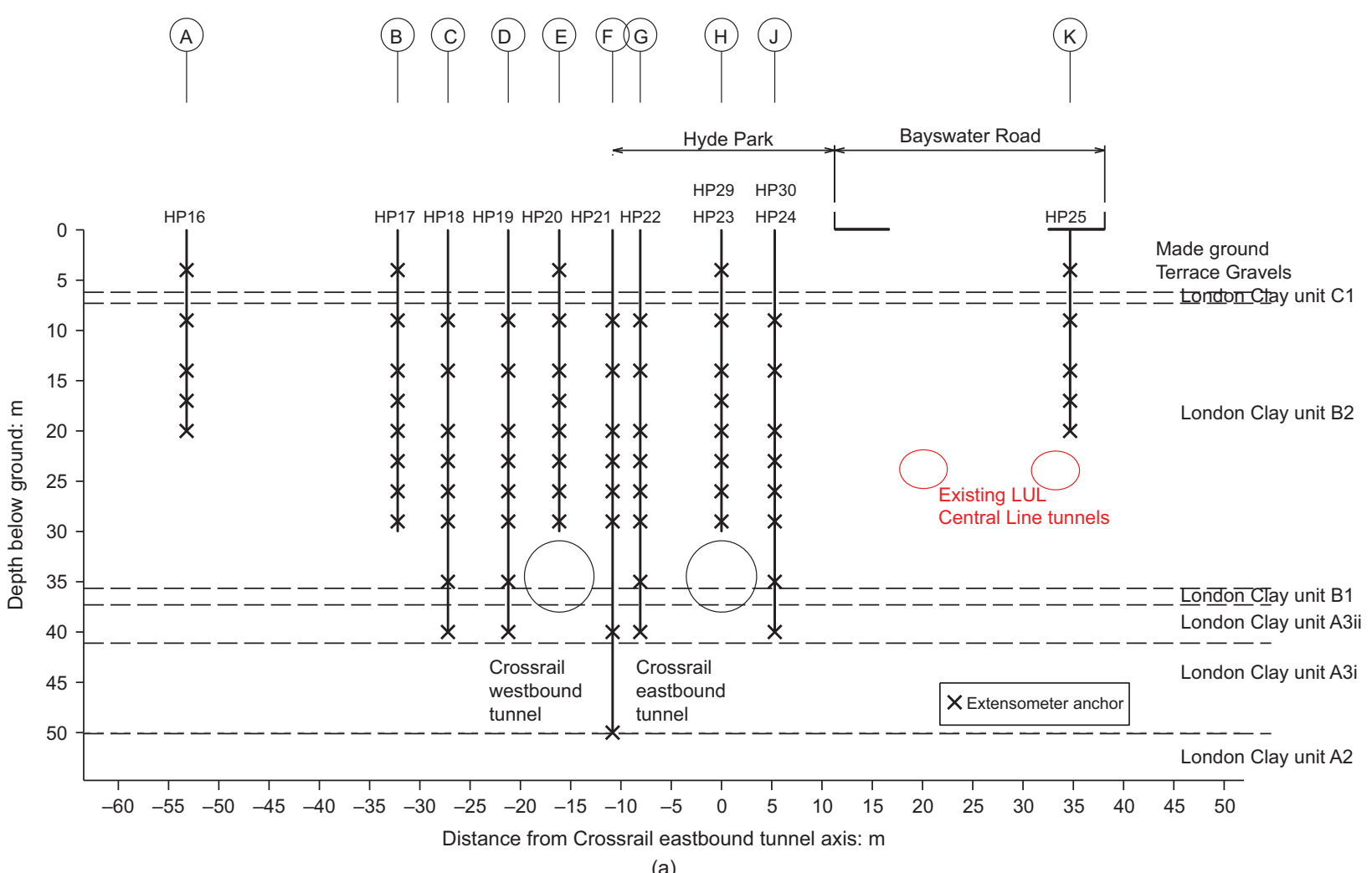

(a)

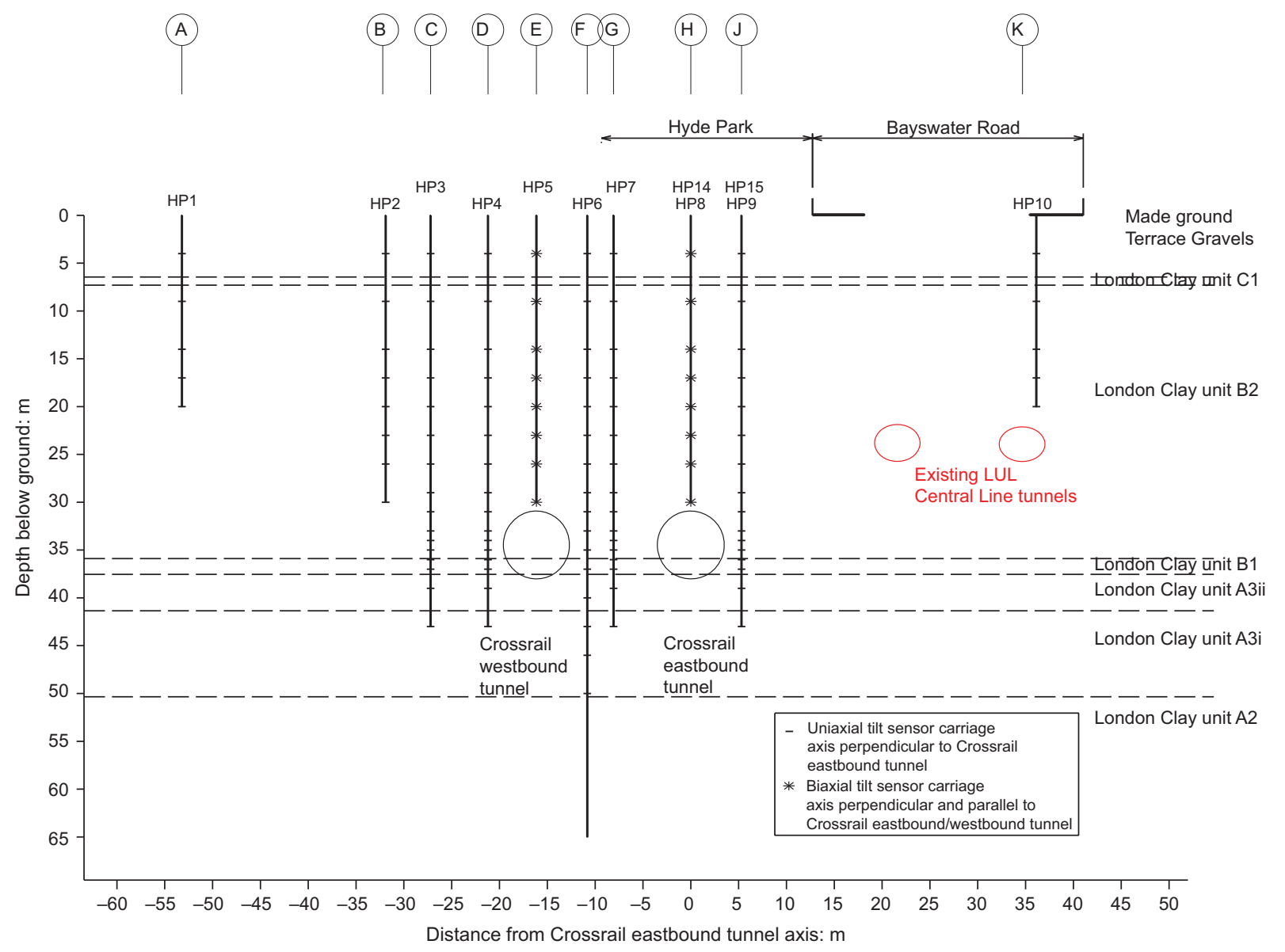

(b)

Fig. 2. (a) Cross-section of Y-line rod extensometers (section A-A). (b) Cross-section of Y-line in-place inclinometers (section A-A). (c) Cross-section of borehole instruments in Bayswater Road (section B-B) (continued on next page) 


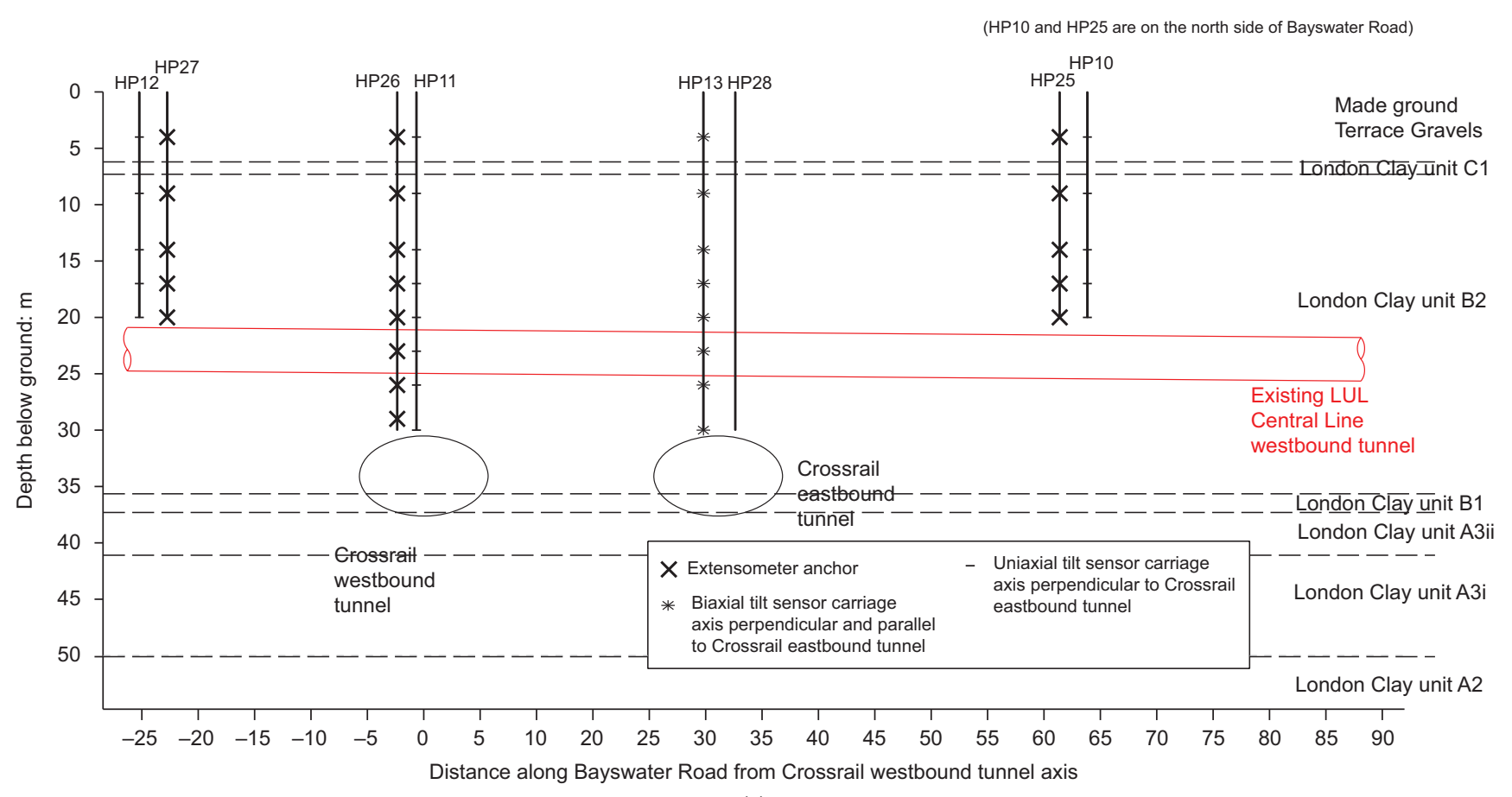

(c)

Fig. 2. Continued

\section{SUBSURFACE MONITORING RESULTS}

The monitoring data were divided into the same five distinct periods used in the companion paper for the surface monitoring results

period 1: pre-construction (12 October 2011 to 19 November 2012)

period 2: construction of the westbound tunnel by TBM1 (19 November 2012 to 30 November 2012)

period 3: interim phase before TBM2 arrived (30 November 2012 to 03 February 2013)

period 4: construction of the eastbound tunnel by TBM2 (03 February 2013 to 12 February 2013)

period 5: long-term monitoring (12 February 2013 onwards).

Data from the base-line monitoring during period 1 are discussed by Fearnhead et al. (2014) and Wan (2014); this paper concentrates on the short-term responses observed during periods 2 and 4 .

The sign conventions for presentation of the monitoring results are as follows.

(a) Positive $(+) x$ means the longitudinal distance ahead of the TBM cutter-head.

(b) $x_{\mathrm{f}}$ is the longitudinal horizontal distance between the cutter-head and the monitoring point/line in question. Negative (-) $x_{\mathrm{f}}$ means the cutter-head is in front of and approaching the monitoring point/line while positive $x_{\mathrm{f}}$ means the cutter-head is progressing beyond the monitoring point/line.

(c) Positive $y$ means the transverse horizontal distance from the tunnel axis to the left-hand side when looking in the direction of tunnel advancement.

(d) Negative $z$ means the downwards vertical distance from the ground surface.

(e) $u, v$ and $w$ are the displacements in the directions and senses of $x, y$ and $z$, respectively.

$(f)$ The depth of the tunnel axis below ground surface is denoted $z_{0}$ (a positive value).
More than 80 sets of manual dial gauge measurements were taken on the rod extensometers during periods 1 to 5 . Typically, it took about $2 \mathrm{~h}$ to take a measurement set on all extensometers while the inclinometers were logged automatically. The times and dates at which the rod extensometer measurements were made correspond to those when precise surveys were carried out for the surface measurements and are given by Wan et al. (2017: figure 6; p. 426). In this paper, the surveys are related either to time or to the distance, $x_{\mathrm{f}}$, of the EPBM cutter-head in relation to the monitoring line.

Subsurface vertical displacements from rod extensometers Short-term response to westbound tunnel construction (TBM1, period 2). The subsurface vertical displacements measured at the anchors of extensometer HP20 above the centre-line (grid line E, $y=0.0 \mathrm{~m}$ in Fig. 1) are presented in Fig. 3, which shows how displacements typically developed as TBM1 passed beneath the extensometer line. TBM1 was stopped for $31 \mathrm{~h}$, when the cutter-head was directly beneath the extensometers, because of problems with the spoil muck-away system. As shown in Fig. 3(a), negligible settlement occurred at the anchors during this period. A maximum settlement of $16 \cdot 2 \mathrm{~mm}$ was measured at the deepest anchor $(z=-29.0 \mathrm{~m}), 2 \mathrm{~m}$ above the tunnel crown, once TBM1 had passed about $40 \mathrm{~m}$ beyond the instrumentation line.

Significant ground settlements started developing after about $x_{\mathrm{f}}=-10 \mathrm{~m}$, as shown in Fig. 3(b). When the shield body of TBM1 was beneath extensometer HP20 (i.e. $0 \mathrm{~m}<x_{\mathrm{f}}<10 \mathrm{~m}$ ), the rate of settlement of the deeper anchors reduced while the ground was supported by the shield. At the $29 \mathrm{~m}$ anchor, an upward displacement of $0.8 \mathrm{~mm}$ was measured at about $x_{\mathrm{f}}=7 \mathrm{~m}$, probably from the ground being pushed up by the tail-skin grouting. Although it might be expected that the greatest heave from tail-skin grouting would occur when the rear of the TBM passed beneath the section, it should be noted that, because of the 

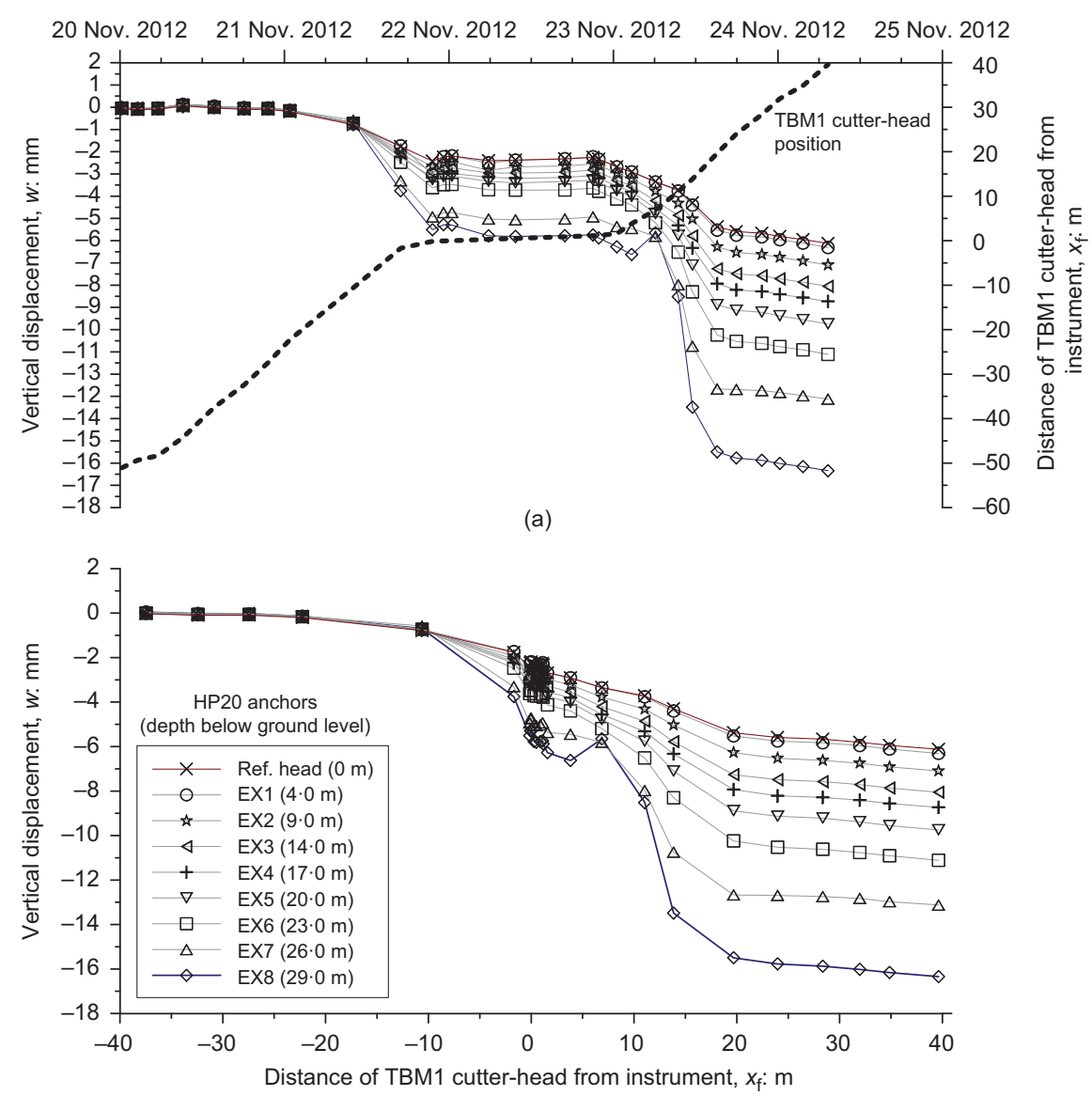

(b)

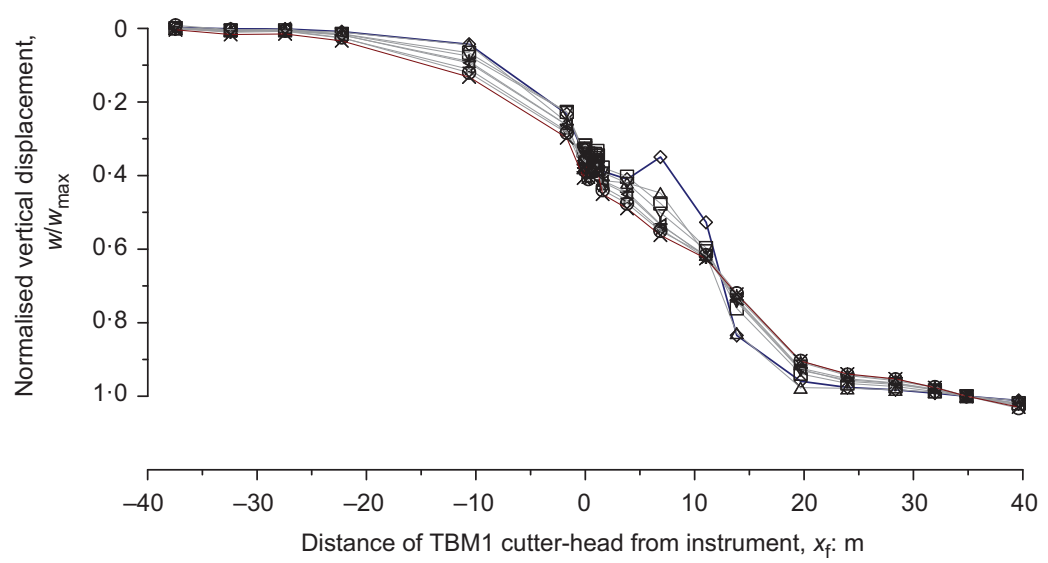

(c)

Fig. 3. Vertical displacements of grid line $E$ rod extensometer HP20 during westbound construction (period 2) (a) plotted against time and (b) plotted against TBM1 cutter-head distance. (c) Normalised incremental vertical displacements

frequency of the manual measurements, the next reading taken corresponded to when the rear of the TBM had passed the section. It seems likely that a greater magnitude of heave occurred between these two sets of measurements. This is corroborated by the outward displacements that were also observed from the inclinometers adjacent to TBM1 (HP6) and TBM2 (HP9) when the shield tails were approaching the instruments at a range of $7 \mathrm{~m}<x_{\mathrm{f}}<11 \mathrm{~m}$ (discussed later with reference to Figs 10, 12 and 13). Subsequently $\left(x_{\mathrm{f}}>10 \mathrm{~m}\right)$, the ground settled more rapidly as the tail void began to close. Further settlement beyond $x_{\mathrm{f}}>20 \mathrm{~m}$ is attributed to deformation of the newly erected tunnel linings.

Normalised longitudinal profiles of vertical displacement at different depths are plotted in Fig. 3(c). The profiles show very similar patterns, apart from that of the deepest anchor. The trough length factors, $i_{x}$, were obtained by considering the normalised longitudinal profiles as a series of cumulative probability curves, for which, theoretically, at the point of inflexion, $50 \%$ of the total displacements would occur (i.e. $x_{50 \%}$ ) and at one $i_{x}$ distance either side of the point of inflexion, $15 \cdot 9 \%$ and $84 \cdot 1 \%$ of the total displacements would occur (i.e. $x_{16 \%}$ and $x_{84 \%}$ ). The $i_{x}$ values were taken as $\left(x_{84 \%}-x_{16 \%}\right) / 2$, and range from $9.7 \mathrm{~m}$ at the depth $z=-29 \cdot 0 \mathrm{~m}$ to $13.4 \mathrm{~m}$ at the surface. These $i_{x}$ values, together with the trough length parameters $\left(K_{x z}=i_{x} /\left(z_{0}+z\right)\right)$, are summarised in Table 1. As expected for closed-face shield tunnelling, less than $50 \%$ of the maximum settlements was measured when the cutter-head was directly beneath the instrument $\left(x_{\mathrm{f}}=0 \mathrm{~m}\right)$. 
Table 1. Vertical displacement longitudinal trough characteristics determined from extensometer HP20 measurements during the westbound construction (period 2)

\begin{tabular}{|c|c|c|c|c|c|c|}
\hline Anchor & $\begin{array}{l}\text { Depth below } \\
\text { ground: } m\end{array}$ & $\begin{array}{c}\text { Relative displacement } \\
\text { when } x_{\mathrm{f}}=0 \mathrm{~m}, w / w_{\max }: \%\end{array}$ & $x_{50 \%}: \mathrm{m}$ & $\begin{array}{l}\text { Trough length } \\
\text { factor, } i_{x}: \mathrm{m}\end{array}$ & $\begin{array}{l}\text { Trough length } \\
\text { parameter, } K_{x z}\end{array}$ & $\begin{array}{c}\text { Maximum vertical } \\
\text { displacement, } w: \mathrm{mm}\end{array}$ \\
\hline Ref. head & 0 & 37 & $4 \cdot 3$ & $13 \cdot 4$ & $0 \cdot 39$ & $-6 \cdot 0$ \\
\hline EX1 & 4 & 36 & $4 \cdot 8$ & $13 \cdot 1$ & $0 \cdot 43$ & $-6 \cdot 1$ \\
\hline EX2 & 9 & 35 & $5 \cdot 1$ & $12 \cdot 8$ & $0 \cdot 50$ & $-6 \cdot 9$ \\
\hline EX3 & 14 & 35 & $5 \cdot 6$ & $12 \cdot 2$ & 0.59 & $-7 \cdot 9$ \\
\hline EX4 & 17 & 35 & $5 \cdot 8$ & $12 \cdot 0$ & 0.68 & $-8 \cdot 6$ \\
\hline EX5 & 20 & 32 & $6 \cdot 8$ & $11 \cdot 3$ & $0 \cdot 77$ & $-9 \cdot 6$ \\
\hline EX6 & 23 & 32 & $7 \cdot 7$ & $11 \cdot 0$ & 0.95 & $-10 \cdot 9$ \\
\hline EX7 & 26 & 36 & $8 \cdot 2$ & $10 \cdot 1$ & $1 \cdot 17$ & $-13 \cdot 0$ \\
\hline EX8 & 29 & 33 & $10 \cdot 4$ & $9 \cdot 7$ & $1 \cdot 73$ & $-16 \cdot 2$ \\
\hline
\end{tabular}

Profiles of vertical displacement with depth at different times and relative positions of the TBM1 cutter-head are presented in Figs 4(a) and 4(b) from the extensometers along the Y-line and Bayswater Road, respectively. The four extensometers on Bayswater Road were all located within $5 \mathrm{~m}$ of the Central Line tunnels. Vertical displacements decreased with increasing transverse distance from the TBM1 axis (grid line E), as would be expected. From grid lines D to $\mathrm{F}(-4.9 \mathrm{~m}<y<5.4 \mathrm{~m})$, maximum subsurface settlements occurred at $z=-29 \mathrm{~m}, 2 \mathrm{~m}$ above the TBM crown, while the ground heaved by up to $3.5 \mathrm{~mm}$ at $z=-40 \mathrm{~m}$ just below the TBM invert level $(z=-38.2 \mathrm{~m})$ at grid lines $\mathrm{D}$ and $\mathrm{F}$, from stress relief due to tunnel excavation. At transverse offset distances beyond $10 \mathrm{~m}$ either side of TBM1, the profiles are almost vertical above the TBM crown, indicating constant vertical displacements and hence negligible strains above this level. Only very small subsurface settlements $(<1 \mathrm{~mm})$ occurred at the furthest extensometers HP16 $(y=-37 \cdot 4 \mathrm{~m})$ and HP25 $(y=48 \cdot 5 \mathrm{~m})$, suggesting that they were outside the zone of influence of TBM1.

Extensometers HP26 (Bayswater Road) and HP20 (Hyde Park) were both located directly above the axis of TBM1 $(y=0 \mathrm{~m}), 38 \mathrm{~m}$ apart (see Fig. 1). The developing profiles of subsurface vertical displacement with depth as TBM1 passed beneath them are very similar, with magnitudes of settlement increasing towards the TBM crown (Figs 4(a) and 4(b)). However, settlements were larger at HP20 compared with the corresponding anchors at HP26. This may reflect the tighter construction control applied when TBM1 passed beneath the Central Line tunnels near HP26 and may also be partly due to the existing tunnels shielding the ground directly above them from the effects of the new tunnel construction. This shielding effect potentially counteracts the ground softening induced by the much earlier construction of the Central Line tunnels (which may also have been partly reduced by subsequent ageing of the ground). The same trend was observed for the surface settlements along the Z-line, which were smaller than along the Y-line, and a similar response can also be observed when comparing the displacement profiles of HP27 and HP17 (both $y \approx-16 \mathrm{~m}$ ) and HP28 and HP23 (both $y \approx 16 \mathrm{~m}$ ).

Individual transverse settlement troughs at various depths along the Y-line at the end of period 2 are presented in Fig. 5. As with the surface settlements (Wan et al., 2017), Gaussian distribution curves were fitted to the subsurface settlement troughs for points with $w / w_{\max }>0.36$ (i.e. those closer to the TBM centre-line) and values of the transverse trough width factor, $i_{y}$, and volume loss, $V_{\mathrm{L}}$, for both southern and northern halves are given in the figure. The $V_{\mathrm{L}}$ values presented were not determined from the area above the measurement points but from the area above the best-fit
Gaussian curves. Troughs were asymmetric about the TBM centre-line, with the northern half-troughs being wider at all depths. This probably reflects a softening of the ground from construction of the Central Line tunnels (albeit more than a century ago). The troughs are clearly Gaussian and become narrower and deeper with depth down to elevation $z=-29 \mathrm{~m}$ $(0.4 \mathrm{~m}$ below the TBM axis level). Settlements up to $3.5 \mathrm{~mm}$ occurred either side of the TBM axis at $z=-35 \mathrm{~m}$, while there was up to $3.5 \mathrm{~mm}$ heave at $z=-40 \mathrm{~m}$. The heave profile at $z=-40 \mathrm{~m}$ appears to be asymmetric, but this is probably due to the fact that no measurements were possible directly beneath the new tunnel, where the greatest heave would have been expected.

Profiles of the main trough characteristics $\left(i_{x}, i_{y}, K_{x z}, K_{y z}\right.$, and $V_{\mathrm{L}}$ values) determined from the Y-line extensometers in Hyde Park are plotted with depth down to TBM crown elevation for period 2 in Fig. 6 and the numerical values given in Tables 1 and 2. Generally, trough width factors $\left(i_{y}\right)$ and trough length factors $\left(i_{x}\right)$ decreased with increasing depth (Fig. 6(a)); that is, both transverse and longitudinal troughs became narrower with depth. In addition, the $i_{y}$ values for the southern half-troughs ('greenfield', with little influence from the existing tunnels) were smaller at most depths than those for the northern half-troughs, reflecting the influence of the existing Central Line tunnels. The increase with depth of the subsurface trough width and trough length parameters $\left(K_{y z}\right.$ and $\left.K_{x z}\right)$ is shown in Fig. 6(b). The measured $K_{y z}$ values for both half-troughs are slightly smaller than those from the relationship proposed by Mair et al. (1993). Most of the case histories and the centrifuge test results used by Mair et al. (1993) involve tunnel depths considerably shallower than at the current instrumentation site, indicating that deeper tunnels have slightly narrower subsurface settlement troughs than shallower tunnels. Moh et al. (1996) proposed an expression for determining subsurface trough width factors, based on a power function involving the depth to the tunnel axis, which can be adjusted and tied to the observed surface trough width factor. Moh et al. also recommended a value of the power parameter $m=0.8$ for tunnelling in silty clays, although this was only based on one case history. Two profiles of $K_{y z}$ values determined from the expression proposed by Moh et al. (1996) with $m=0.4$ and $m=0.8$ are also shown in Fig. 6(b). It can be seen that the measured $K_{y z}$ values are much greater than those based on $m=0.8$ but agree very well with those using $m=0 \cdot 4$.

Profiles of volume loss $\left(V_{\mathrm{L}}\right)$ with depth, as determined from the best-fit Gaussian curves, are shown in Fig. 6(c). Volume loss values generally increased slightly with depth for both the southern and northern half-troughs $\left(0.46 \%<V_{\mathrm{L}}<0.66 \%\right.$ and $0.49 \%<V_{\mathrm{L}}<0.69 \%$, respectively), 

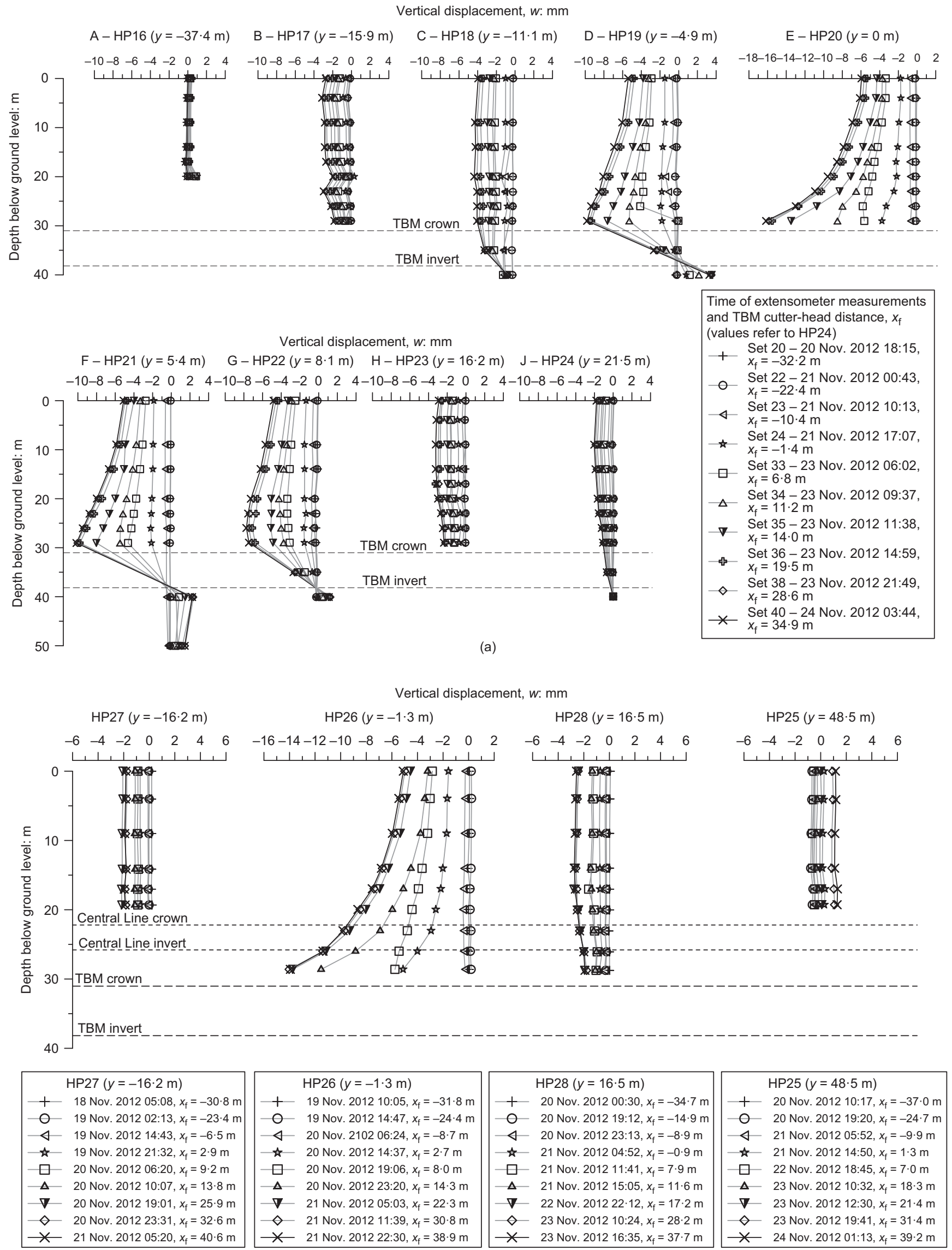

(b)

Fig. 4. Vertical displacements of rod extensometer anchors in (a) Hyde Park and (b) Bayswater Road during westbound construction (period 2) 

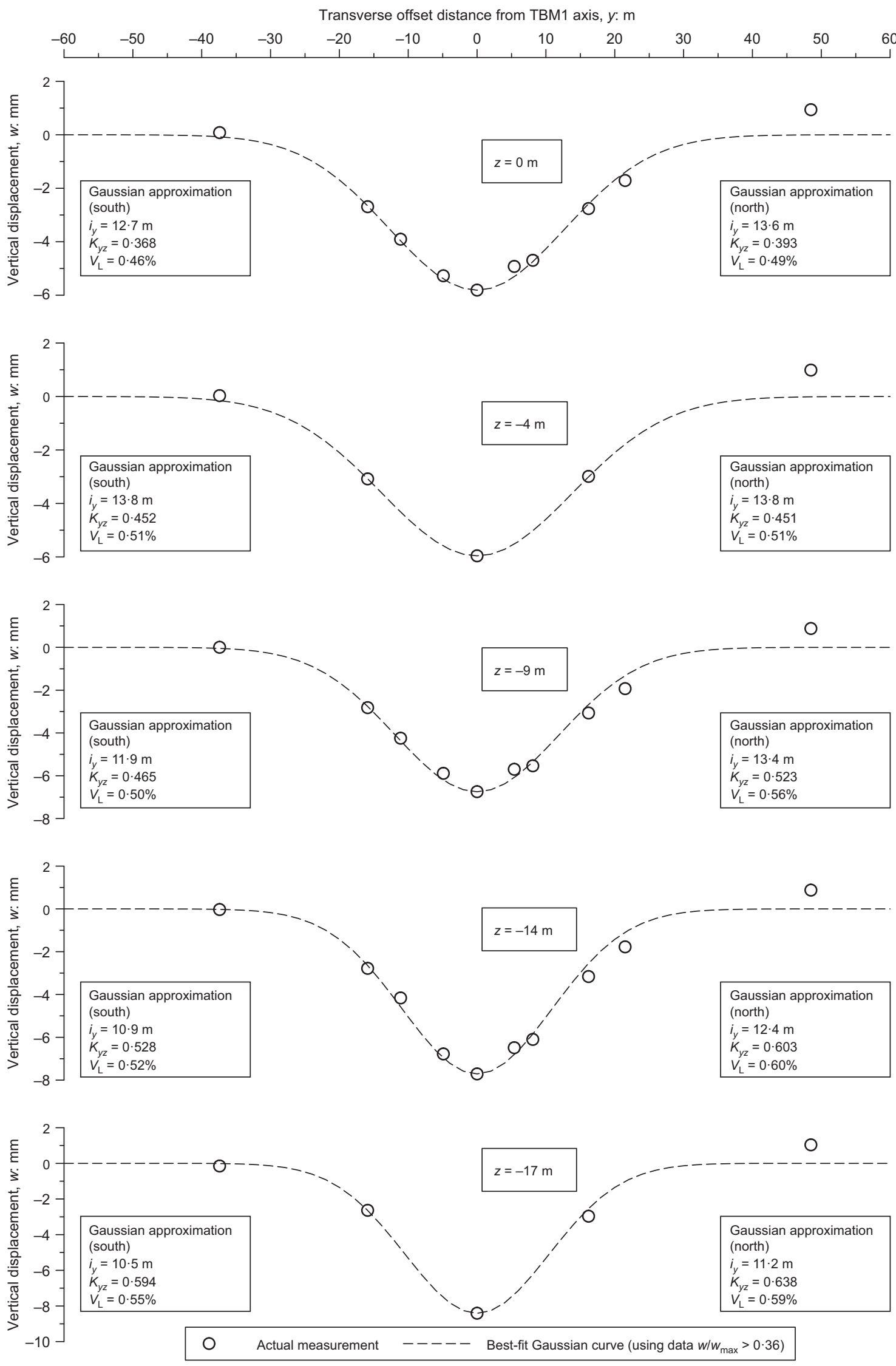

(a)

Fig. 5. Subsurface settlement troughs at various depths, $z$, at end of period 2 (continued on next page)

which does not agree with the frequently accepted assumption that the immediate ground response to tunnelling in London Clay is undrained (with zero volume change). Given the relatively high average advance rate of the TBM, this suggests that the ground permeability was higher than usually expected for London Clay and 

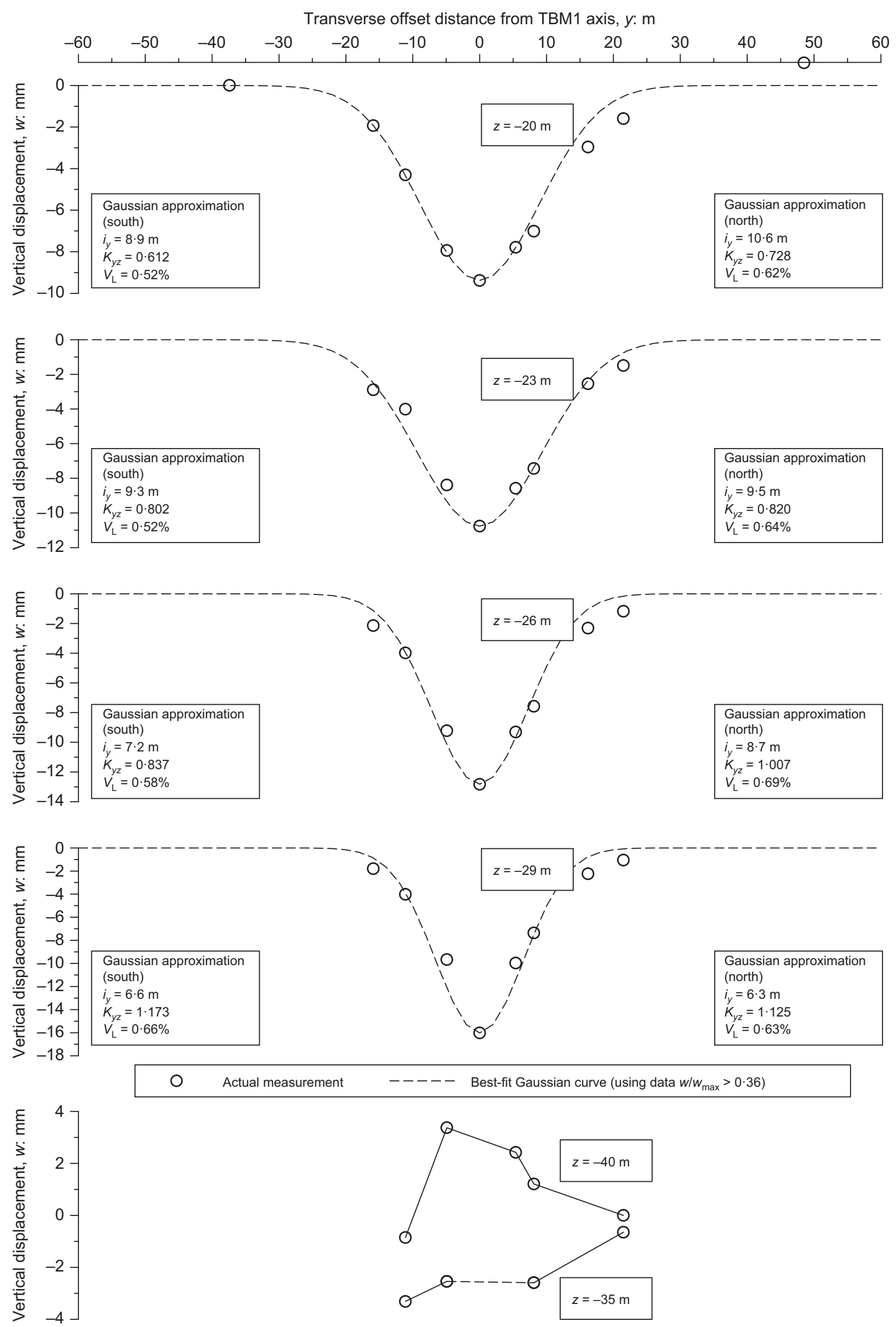

(b)

\section{Fig. 5. Continued}

therefore the ground response was partially drained. This correlates well with the fact that the lower part of the tunnel is located in the London Clay sub-units B1 and A3ii, which are much more permeable than unit B above them (Standing \& Burland, 2006; Hight et al., 2007; Wan \& Standing, 2014b). Other features specific to the site, such as the 


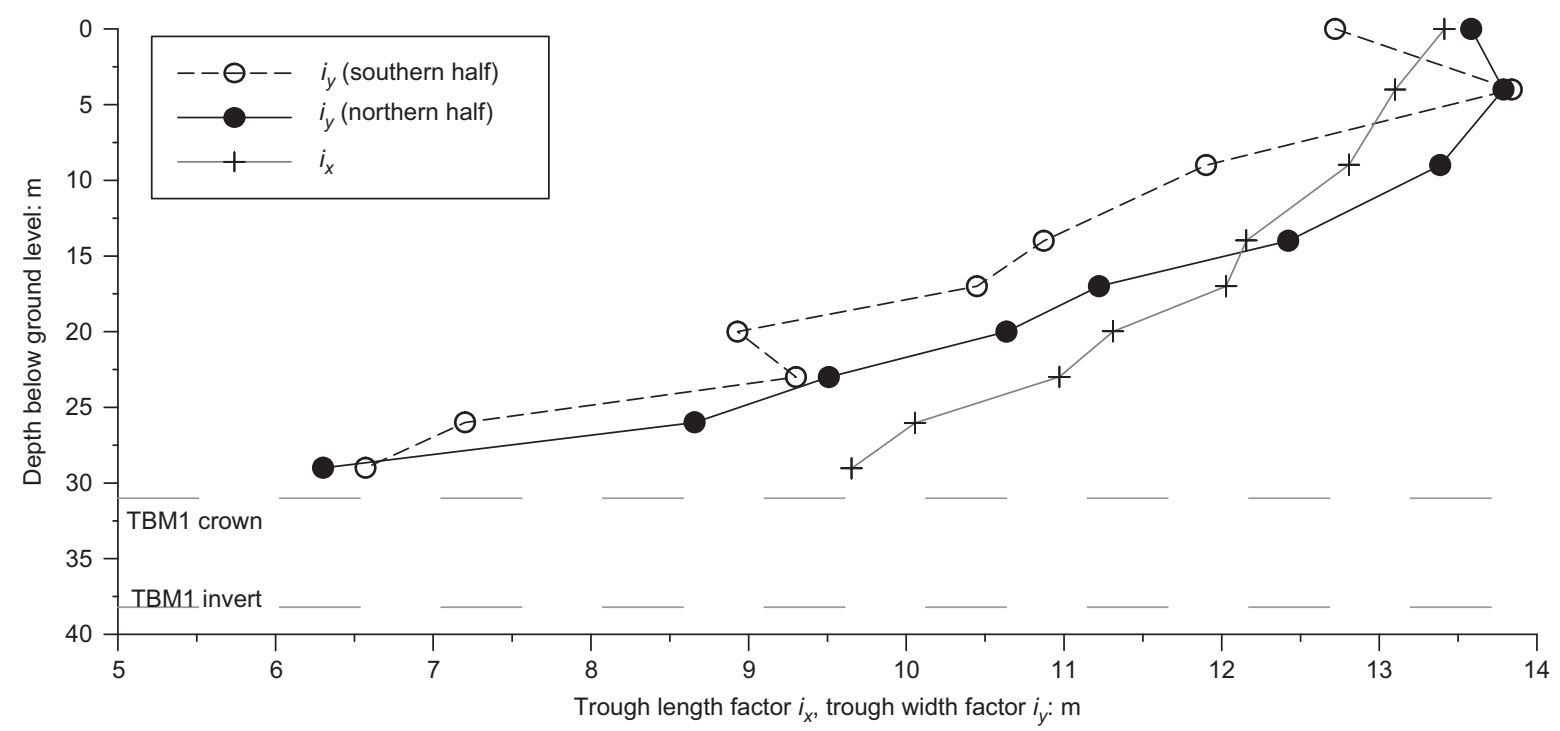

(a)

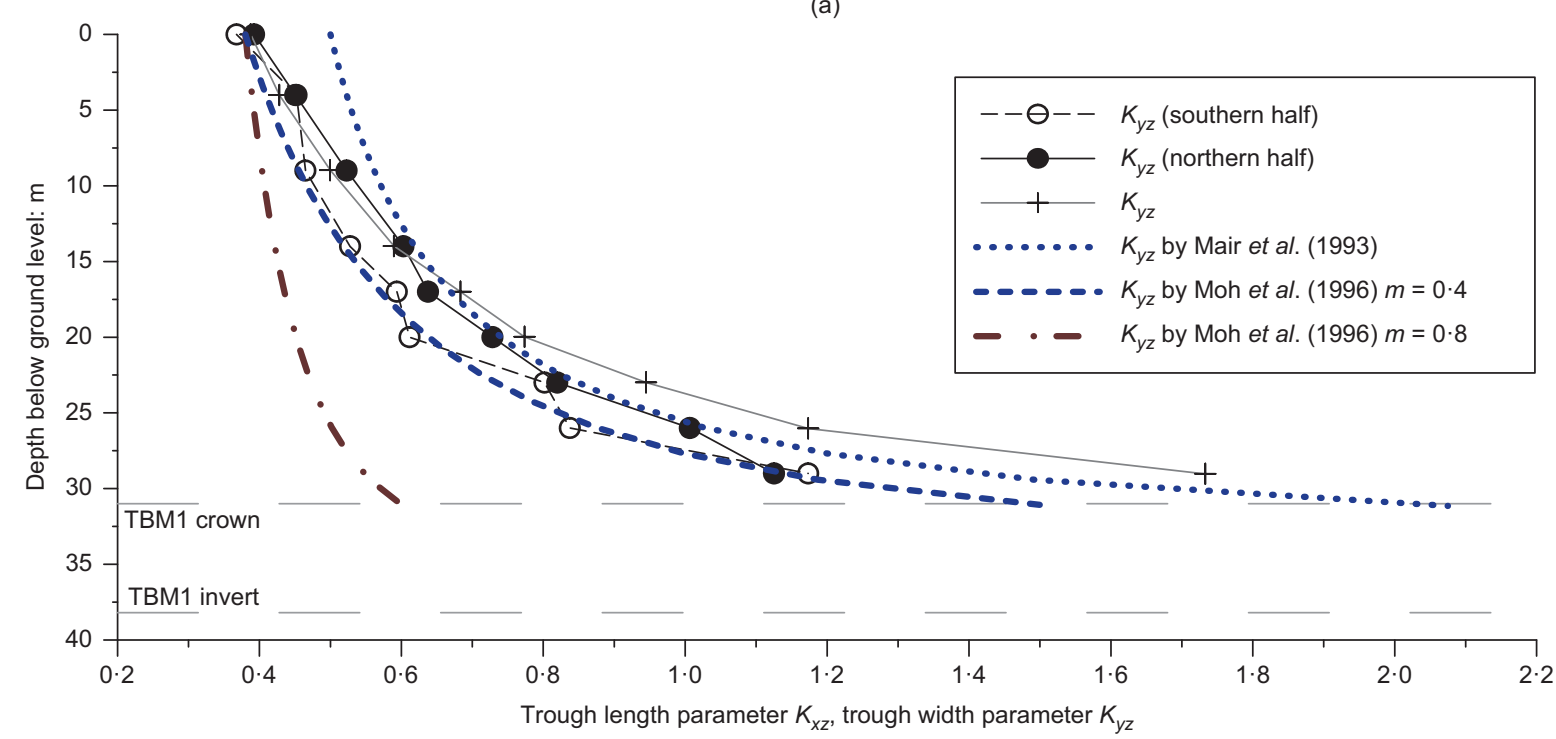

(b)

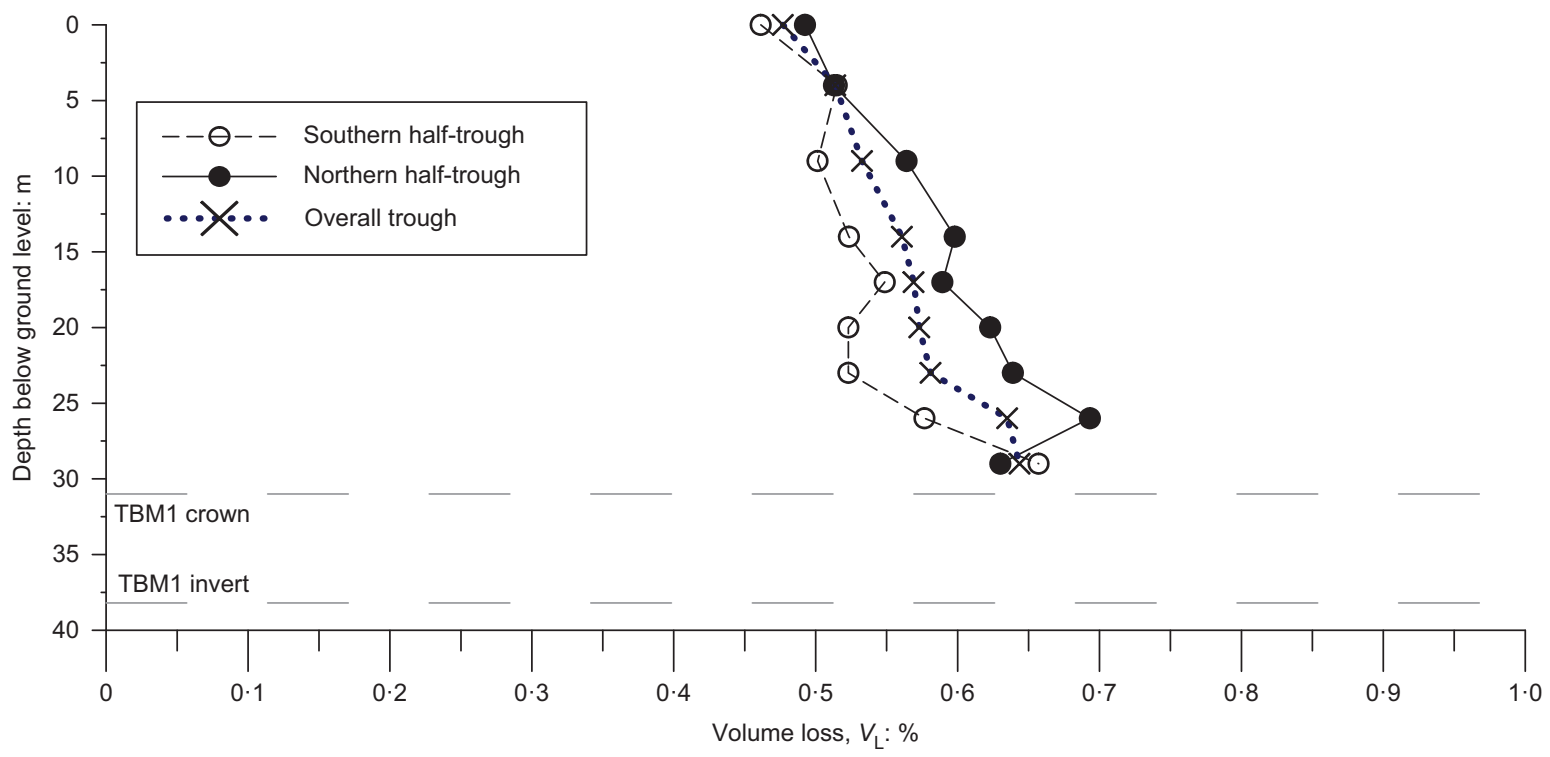

(c)

Fig. 6. Subsurface vertical displacement trough characteristics from the measurements in Y-line extensometers (end of period 2): (a) trough width and length factors; (b) trough width and length parameters; (c) volume loss 
Table 2. Vertical displacement transverse trough characteristics determined from Y-line extensometer measurements in response to the westbound construction (end of period 2)

\begin{tabular}{|c|c|c|c|c|c|c|c|c|}
\hline \multirow[t]{2}{*}{ Depth below ground: $\mathrm{m}$} & \multicolumn{2}{|c|}{$\begin{array}{l}\text { Trough width factor, } \\
\qquad i_{y}: \mathrm{m}\end{array}$} & \multicolumn{2}{|c|}{$\begin{array}{l}\text { Trough width } \\
\text { parameter, } K_{y z}\end{array}$} & \multirow{2}{*}{$\begin{array}{c}\text { Percentage } \\
\text { difference } \\
\text { north/south: } \%\end{array}$} & \multicolumn{3}{|c|}{ Volume loss, $V_{\mathrm{L}}: \%$} \\
\hline & South & North & South & North & & South & North & Overall \\
\hline 0 & $12 \cdot 7$ & $13 \cdot 6$ & $0 \cdot 37$ & 0.39 & $5 \cdot 4$ & $0 \cdot 46$ & $0 \cdot 49$ & 0.48 \\
\hline 4 & $13 \cdot 8$ & $13 \cdot 8$ & $0 \cdot 45$ & $0 \cdot 45$ & $0 \cdot 0$ & 0.51 & $0 \cdot 51$ & 0.51 \\
\hline 9 & $11 \cdot 9$ & $13 \cdot 4$ & 0.47 & $0 \cdot 52$ & $10 \cdot 6$ & $0 \cdot 50$ & $0 \cdot 56$ & 0.53 \\
\hline 14 & $10 \cdot 9$ & $12 \cdot 4$ & 0.53 & $0 \cdot 60$ & $13 \cdot 2$ & 0.52 & $0 \cdot 60$ & 0.56 \\
\hline 17 & $10 \cdot 5$ & $11 \cdot 2$ & 0.59 & 0.64 & $8 \cdot 5$ & 0.55 & 0.59 & 0.57 \\
\hline 20 & $8 \cdot 9$ & $10 \cdot 6$ & 0.61 & 0.73 & $19 \cdot 7$ & 0.52 & $0 \cdot 62$ & 0.57 \\
\hline 23 & $9 \cdot 3$ & $9 \cdot 5$ & $0 \cdot 80$ & $0 \cdot 82$ & $2 \cdot 5$ & 0.52 & 0.64 & 0.58 \\
\hline 26 & $7 \cdot 2$ & $8 \cdot 7$ & $0 \cdot 84$ & $1 \cdot 01$ & $20 \cdot 2$ & 0.58 & 0.69 & 0.63 \\
\hline 29 & $6 \cdot 6$ & $6 \cdot 3$ & $1 \cdot 17$ & $1 \cdot 13$ & $-3 \cdot 4$ & 0.66 & 0.63 & 0.64 \\
\hline
\end{tabular}

presence of claystones (Wan \& Standing, 2014b) and fissures in the London Clay, may also contribute to more rapid drainage.

Short-term response to eastbound tunnel construction (TBM2, period 4). Responses from the construction of the eastbound tunnel in period 4 were broadly very similar to those for the westbound tunnel in period 2. Three extensometers (HP28, HP23 and HP29) were located directly above the TBM2 alignment (grid line H, see Fig. 1). However, the focus here is on HP23, which forms part of the Y-line (observations from the other two extensometers were very similar). Subsurface incremental vertical displacements measured from HP23 are shown in Figs 7(a) and 7(b) and can be compared with the results in Figs 3(a) and 3(b). In this case, response to TBM2 started when $-20 \mathrm{~m}<x_{\mathrm{f}}<-10 \mathrm{~m}$, sooner than for TBM1 in greenfield ground, indicating ground softening from the westbound tunnel construction. During the approach of TBM2, until $x_{\mathrm{f}}=-5 \mathrm{~m}$, settlements decreased slightly with depth; that is, the shallower ground settled a little more than the ground nearer the TBM crown. This trend reversed once the TBM cutter-head had moved about $5 \mathrm{~m}$ in front of the extensometers $\left(x_{\mathrm{f}}>-5 \mathrm{~m}\right)$, with the deeper anchors, closer to the tunnel construction, experiencing larger settlements than the shallower ones. By the end of period 4, a maximum incremental settlement of about $23 \mathrm{~mm}$ at $z=-29 \mathrm{~m}$ was measured. It should be noted that apparently no upward displacement at any anchor of HP23 (or HP28, HP29) was observed when the TBM2 shield tail was approaching the instrument line (as was observed for the approach of TBM1). Manual measurements on the rod extensometers were taken in conjunction with precise levelling every 4 to $5 \mathrm{~h}$ : in this period the TBM had travelled more than $5 \mathrm{~m}$ and thus observations of any upward displacement induced by the tail grout pressure could have been missed.

Longitudinal profiles of normalised incremental vertical displacements at different depths of HP23 are plotted in Fig. 7(c). The same trend as in Fig. 7(b) can be seen, with initially smaller normalised settlements at deeper anchors before the TBM2 cutter-head reached the Y-line and the trend subsequently reversing. Trough length factors $\left(i_{x}\right)$ determined from HP23 ranged from $9.6 \mathrm{~m}$ at $z=-29.0 \mathrm{~m}$ to $14.8 \mathrm{~m}$ at the surface. The $i_{x}$ values, together with the trough length parameters $\left(K_{x z}\right)$, are given in Table 3 .

Profiles of incremental vertical displacement with depth, as measured by way of the other Y-line extensometers, are presented in Fig. 8(a) and can be seen to reduce in magnitude with increasing distance from the axis of TBM2, as was the case for TBM1 (Fig. 4(a)). At distances further than about $25 \mathrm{~m}$ from TBM2, incremental vertical displacements down to tunnel crown level were more or less constant, suggesting negligible vertical strains over this depth. Again, heave of about $3 \mathrm{~mm}$ was observed at $z=-40 \mathrm{~m}$, either side of TBM2 (note that the TBM2 invert level was at $z=-38.2 \mathrm{~m}$ ). Subsurface settlements of less than $1 \mathrm{~mm}$ were measured at all depths in the furthest extensometers $\operatorname{HP} 16(y=-53.6 \mathrm{~m})$ and HP25 $(y=32.5 \mathrm{~m})$ on the southern and northern sides, respectively, suggesting that they were outside the zone of influence of TBM2.

Extensometers HP28 (Bayswater Road) and HP23 (Hyde Park), both located directly above the axis of TBM2 (see Fig. 1), showed the same developing profiles of subsurface vertical displacement with depth as TBM2 passed beneath them, with magnitudes of settlement increasing towards the TBM crown (Figs 8(a) and 8(b)). However, settlements at HP23 were slightly larger compared with the corresponding anchors at HP28. This, as in the case of TBM1, may reflect the tighter construction control applied when TBM2 passed beneath the Central Line tunnels near HP28 as well as the shielding effect of the existing tunnels.

As with the case for the ground response to the westbound tunnel construction, incremental transverse settlement troughs at various depths along the Y-line resulting from the passage of TBM2 could be fitted well with Gaussian curves. The profiles (not presented here) were asymmetric about the TBM2 centre-line and so it was necessary to fit different Gaussian curves to each side of the settlement troughs. The southern half-troughs were wider for all depths, opposite to what was observed for the ground response to the passage of TBM1, where the troughs were wider on the northern side. This indicates that construction of the westbound Crossrail tunnel had a more dominant effect than the existing Central Line tunnels, which is logical given that the westbound tunnel is larger in diameter, closer to the eastbound tunnel and the ground disturbance is more recent. Numerical values of the incremental vertical displacement trough characteristics $\left(i_{x}, i_{y}, K_{x z}, K_{y z}\right.$ and $\Delta V_{\mathrm{L}}$ values) are given in Tables 3 and 4 . As with the values relating to westbound tunnel construction, the trough width and length factors $\left(i_{y}\right.$ and $\left.i_{x}\right)$ decreased with depth, with $i_{y}$ values being greater for the southern half-troughs. Correspondingly, subsurface trough width and length parameters $\left(K_{y z}\right.$ and $\left.K_{x z}\right)$ increased with depth. As with the ground response to the westbound tunnel construction, incremental volume losses determined from the best-fit Gaussian curves increased slightly with depth for both the southern and northern half-troughs $\left(0 \cdot 96 \%<\Delta V_{\mathrm{L}}<1 \cdot 13 \%\right.$ and $0.70 \%<\Delta V_{\mathrm{L}}<0.83 \%$ for the southern and northern 


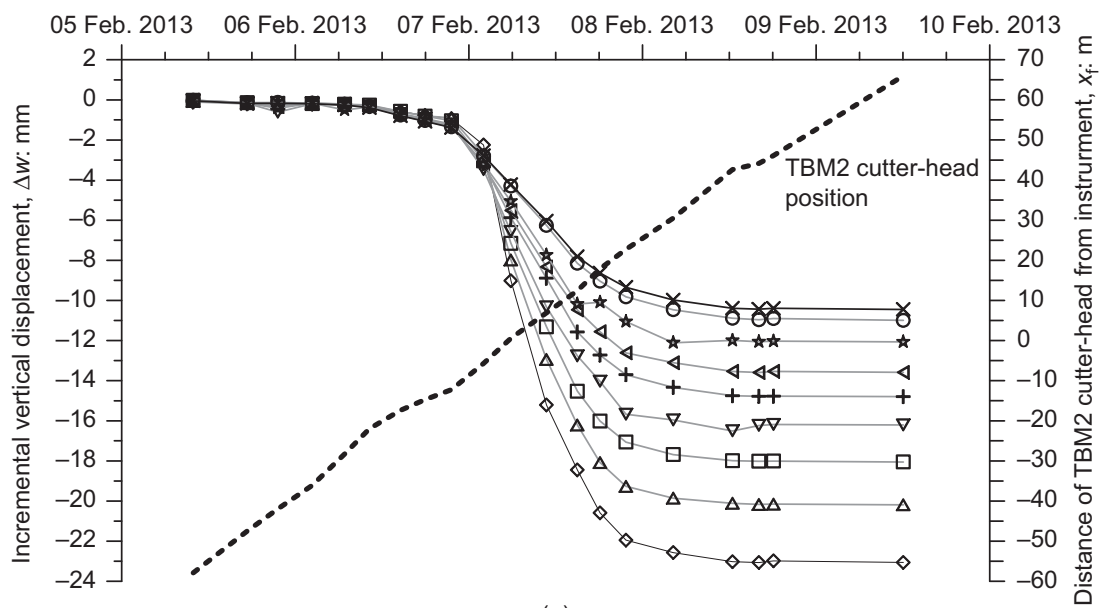

(a)

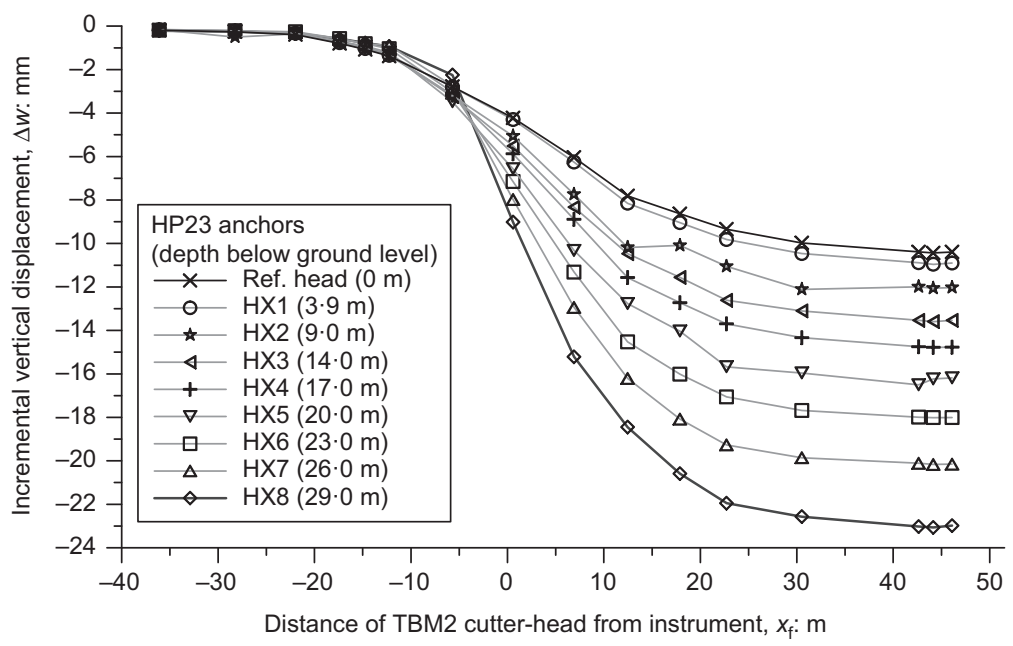

(b)

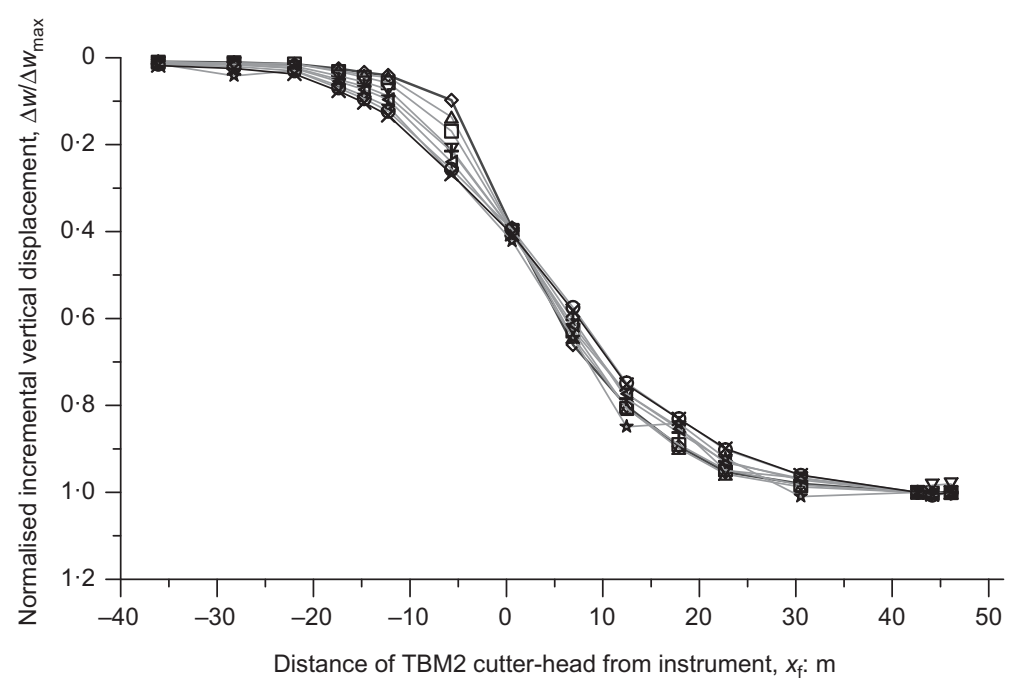

(c)

Fig. 7. Incremental vertical displacements of grid line $\mathbf{H}$ rod extensometer HP23 during eastbound construction (period 4) (a) plotted against time and (b) plotted against TBM2 cutter-head distance. (c) Normalised incremental vertical displacements

half-troughs, respectively). As with TBM1, this contradicts the assumption that the immediate ground response to tunnelling in London Clay is undrained with negligible volumetric strains.

By examining the derived trough width factors of the southern and northern half-troughs for each of the TBM1 and TBM2 passages, the degrees of influence of the existing
Central Line tunnels and the recently constructed westbound tunnel can be compared. At the end of period 2 (TBM1 passage), the percentage differences in trough width factors of the northern half-troughs and the southern counterparts were only up to $20 \%$ (Table 2). At the end of period 4 (TBM2 passage), these percentage differences ranged from about $20 \%$ to $30 \%$ (Table 4 ). The influence of the existing Central 
Table 3. Incremental vertical displacement longitudinal trough characteristics determined from extensometer HP23 measurements during the eastbound construction ( period 4)

\begin{tabular}{|c|c|c|c|c|c|c|}
\hline Anchor & $\begin{array}{l}\text { Depth below } \\
\text { ground: } \mathrm{m}\end{array}$ & $\begin{array}{c}\text { Relative incremental } \\
\text { displacement when } x_{\mathrm{f}}=0 \mathrm{~m} \text {, } \\
\Delta w / \Delta w_{\max }: \%\end{array}$ & $\begin{array}{c}x_{50 \%}: \\
\mathrm{m}\end{array}$ & $\begin{array}{l}\text { Trough length } \\
\text { factor, } i_{x}: \mathrm{m}\end{array}$ & $\begin{array}{l}\text { Trough length } \\
\text { parameter, } K_{x z}\end{array}$ & $\begin{array}{c}\text { Maximum incremental } \\
\text { vertical displacement, } \Delta w \text { : } \\
\text { mm }\end{array}$ \\
\hline $\begin{array}{l}\text { Ref. } \\
\text { head }\end{array}$ & 0 & 41 & $4 \cdot 0$ & $14 \cdot 8$ & $0 \cdot 43$ & $-10 \cdot 4$ \\
\hline HX1 & 4 & 40 & $4 \cdot 3$ & $14 \cdot 5$ & $0 \cdot 47$ & $-10 \cdot 9$ \\
\hline HX2 & 9 & 42 & $2 \cdot 8$ & $14 \cdot 2$ & $0 \cdot 55$ & $-12 \cdot 0$ \\
\hline HX3 & 14 & 40 & $3 \cdot 4$ & $13 \cdot 2$ & $0 \cdot 64$ & $-15 \cdot 5$ \\
\hline HX4 & 17 & 40 & $3 \cdot 7$ & $12 \cdot 5$ & $0 \cdot 71$ & $-14 \cdot 8$ \\
\hline HX5 & 20 & 40 & $3 \cdot 4$ & $12 \cdot 7$ & $0 \cdot 87$ & $-16 \cdot 5$ \\
\hline HX6 & 23 & 40 & $3 \cdot 4$ & $10 \cdot 5$ & $0 \cdot 90$ & $-18 \cdot 0$ \\
\hline HX7 & 26 & 40 & $3 \cdot 2$ & $9 \cdot 8$ & $1 \cdot 15$ & $-20 \cdot 1$ \\
\hline HX8 & 29 & 39 & $3 \cdot 1$ & $9 \cdot 6$ & $1 \cdot 72$ & $-23 \cdot 0$ \\
\hline
\end{tabular}

Line tunnels should be reflected more strongly in the ground response to the eastbound tunnel construction than the westbound tunnel due to their closer proximity to the eastbound tunnel. However, the greater percentage differences between the northern and southern trough width factors for TBM2 suggest that there was a much stronger influence from the more recently constructed westbound tunnel than from the existing Central Line tunnels.

Comparison of short-term ground responses measured in periods 2 and 4 . The subsurface transverse and longitudinal troughs induced by westbound and eastbound tunnel construction can be compared in terms of the characteristics summarised in Tables 5-9. Maximum surface settlements from westbound and eastbound tunnel construction were $6.0 \mathrm{~mm}$ and $10.4 \mathrm{~mm}$, respectively, representing an increase of about $73 \%$. The percentage increase was fairly constant with depth to $z=-20 \mathrm{~m}$, at about $70 \%-80 \%$, but then reduced to $42 \%$ at $z=-29 \mathrm{~m}$. TBM operation variables (e.g. face pressures, tail grout pressures and volumes) were similar in magnitude for both TBM1 and TBM2 near the Y-line extensometers, again indicating the influence of the westbound tunnel construction disturbing and softening the ground.

In terms of the longitudinal incremental settlement trough characteristics, the trough length factors, $i_{x}$, from the ground surface down to the elevation $z=-20 \mathrm{~m}$ increased by about $10 \%$, but were almost identical for elevations from $-23 \mathrm{~m}<z<-29 \mathrm{~m}$. The trough width factors, $i_{y}$, of the southern half-troughs for the eastbound tunnel construction were always larger (by up to $24 \%$ ) than those for the westbound tunnel as a consequence of ground softening from the passage of TBM1. Conversely, the $i_{y}$ values for the northern half-troughs were always 20-30\% smaller from the passage of TBM2 compared with the passage of TBM1. This can be explained by the influence of the westbound construction diminishing with transverse distance from its axis and the fact that the influence of the recently built westbound tunnel was much stronger than the influence of the pre-existing Central Line tunnels. The softening effect from the westbound tunnel construction resulted in overall incremental volume losses at all depths increasing from eastbound tunnel construction with fairly constant percentage increases of $66-73 \%$ from elevations $-23 \mathrm{~m}<z<0 \mathrm{~m}$, reducing to about $41 \%$ below $z=-23 \mathrm{~m}$. This observation indicates that the ground softening effect extended upwards from the tunnel crown to $z=-20 \mathrm{~m}$, suggesting an associated development of normal and shear strains in the London Clay over the same zone (about $1 \cdot 5 \mathrm{D}$ above the tunnel crown, $D$ being the tunnel diameter). This is discussed further and corroborated later in terms of contours of shear strain around the tunnels derived from combined extensometer and inclinometer measurements.

Cumulative settlements induced by westbound and eastbound construction. The cumulative subsurface ground settlement troughs at the end of periods 2, 3 and 4 are shown in Fig. 9. During the rest period between the passage of TBM1 and TBM2 (period 3, about 70 days), the ground settled relatively uniformly across the transverse cross-section by up to about $1.5 \mathrm{~mm}$. In general, asymmetry of the cumulative settlement troughs was observed after the construction of both tunnels, with larger settlement towards the TBM2 side. The peak cumulative settlement always occurred between the TBM1 and TBM2 centre-lines for the shallower ground $(z>-17 \mathrm{~m})$, while the same always occurred at the location of the TBM2 centre-line for the deeper ground above the tunnel crown $(-29 \mathrm{~m} \leq z \leq-17 \mathrm{~m})$.

\section{Subsurface horizontal displacements from in-place inclinometers}

In-place MEMS tilt devices installed within inclinometer casings measured changes in rotation in the plane transverse to the TBM alignments. Their operation and the determination of horizontal displacements from them are explained by Wan \& Standing (2014a). Details concerning the raw rotation output are given by Wan (2014); the focus in this paper is on the interpreted horizontal displacements.

Short-term response to westbound tunnel construction (TBM1, period 2). In determining transverse horizontal displacements, measured rotations are integrated over appropriate gauge lengths starting from a point of known horizontal displacement. Along the Y-line, it was assumed that the top of the casing experienced the same horizontal displacements as the surface monitoring points (SMPs) at corresponding transverse distances $(y)$ from the TBM axis as measured by a micrometer stick (Wan et al., 2017). Where no micrometer stick measurements were available (e.g. HP1 and HP10), it was assumed the base of the casing was fixed and horizontal displacements were summed from this point. It is important to note that, since displacement profiles are determined by summing incremental displacements over individual gauge lengths, any measurement error in one gauge length would be accumulated in the profile below that gauge length in question. The data presented here were 


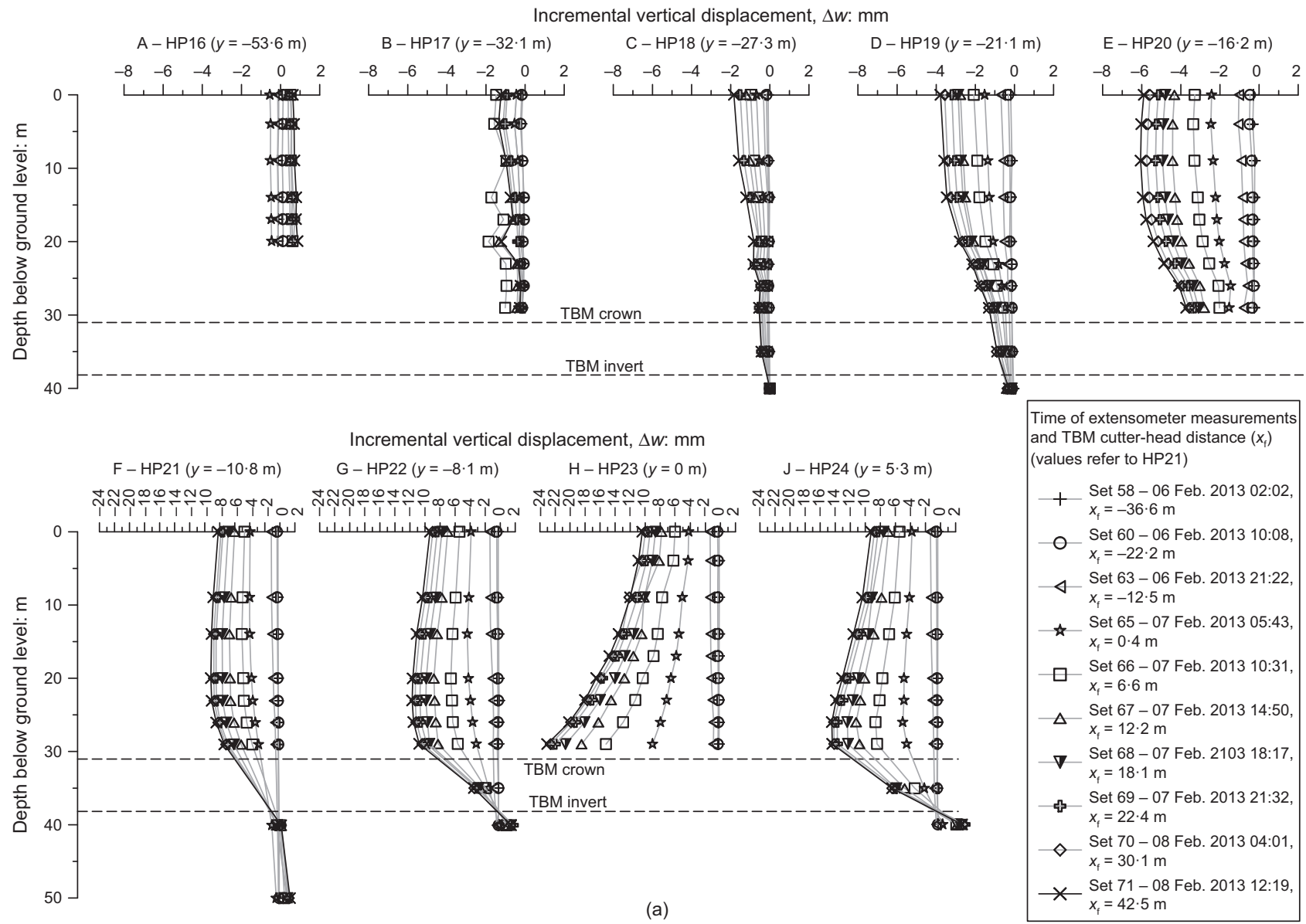

Incremental vertical displacement, $\Delta w: \mathrm{mm}$

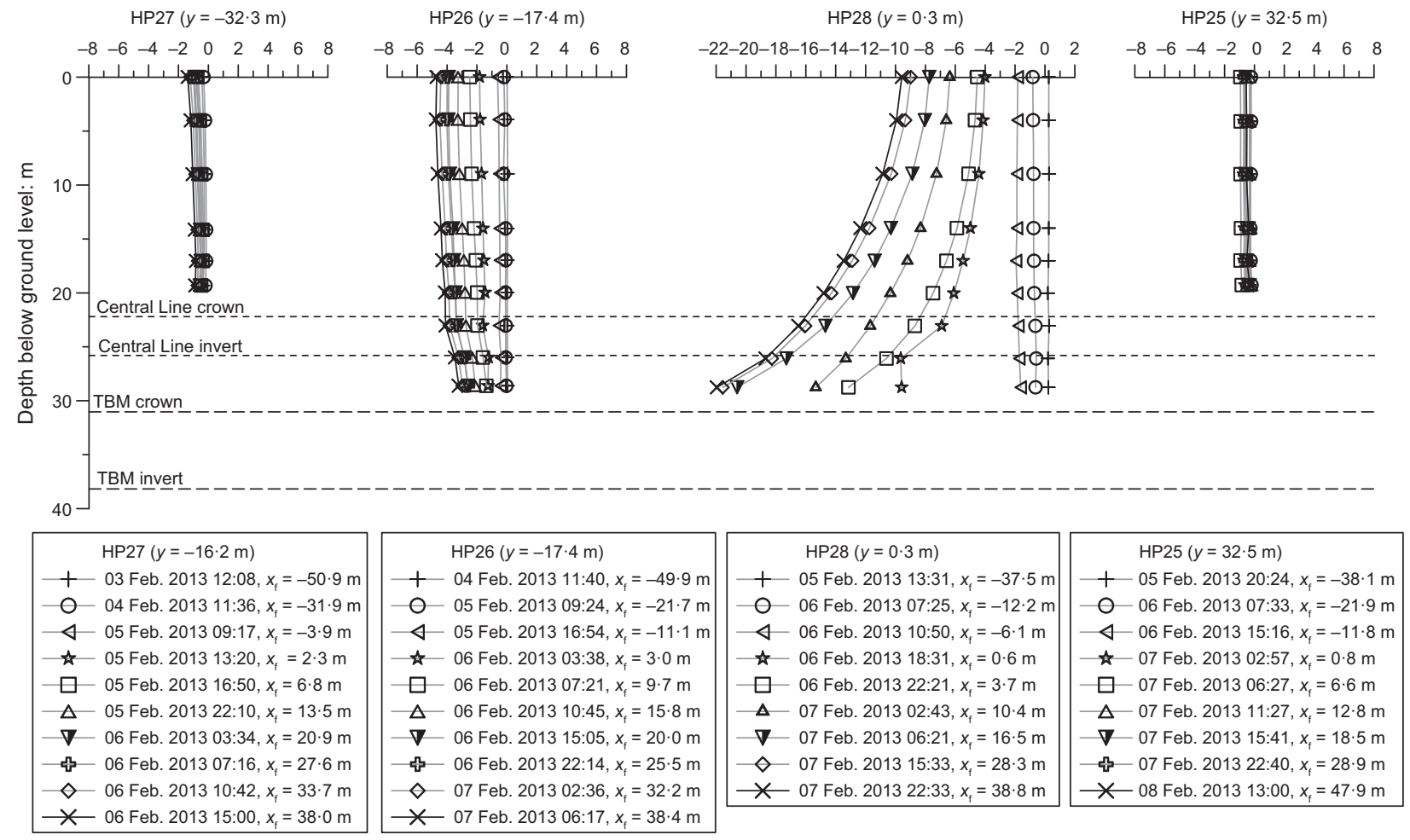

(b)

Fig. 8. Incremental vertical displacements of rod extensometer anchors in (a) Hyde Park and (b) Bayswater Road during eastbound construction (period 4) 
Table 4. Incremental vertical displacement transverse trough characteristics determined from Y-line extensometer measurements in response to the eastbound construction (end of period 4)

\begin{tabular}{|c|c|c|c|c|c|c|c|c|}
\hline \multirow[t]{2}{*}{ Depth below ground: $\mathrm{m}$} & \multicolumn{2}{|c|}{$\begin{array}{l}\text { Trough width factor, } \\
\qquad i_{y}: \mathrm{m}\end{array}$} & \multicolumn{2}{|c|}{$\begin{array}{l}\text { Trough width } \\
\text { parameter, } K_{y z}\end{array}$} & \multirow{2}{*}{$\begin{array}{c}\text { Percentage } \\
\text { difference } \\
\text { north/south: } \%\end{array}$} & \multicolumn{3}{|c|}{ Incremental volume loss, $\Delta V_{\mathrm{L}}: \%$} \\
\hline & South & North & South & North & & South & North & Overall \\
\hline 0 & $14 \cdot 8$ & $10 \cdot 9$ & $0 \cdot 43$ & $0 \cdot 31$ & $-27 \cdot 9$ & 0.96 & $0 \cdot 70$ & $0 \cdot 83$ \\
\hline 4 & $14 \cdot 9$ & N/A & $0 \cdot 49$ & N/A & N/A & $1 \cdot 01$ & N/A & N/A \\
\hline 9 & $13 \cdot 7$ & $9 \cdot 9$ & 0.54 & $0 \cdot 39$ & $-27 \cdot 8$ & $1 \cdot 02$ & $0 \cdot 74$ & 0.88 \\
\hline 14 & $12 \cdot 7$ & $9 \cdot 5$ & 0.62 & $0 \cdot 46$ & $-25 \cdot 8$ & $1 \cdot 07$ & $0 \cdot 80$ & 0.94 \\
\hline 17 & $11 \cdot 8$ & N/A & 0.67 & N/A & N/A & $1 \cdot 09$ & N/A & N/A \\
\hline 20 & $11 \cdot 0$ & $7 \cdot 7$ & $0 \cdot 75$ & 0.53 & $-29 \cdot 3$ & $1 \cdot 13$ & $0 \cdot 80$ & 0.97 \\
\hline 23 & $9 \cdot 8$ & $7 \cdot 4$ & $0 \cdot 85$ & 0.63 & $-25 \cdot 9$ & $1 \cdot 10$ & $0 \cdot 83$ & 0.96 \\
\hline 26 & $8 \cdot 8$ & $6 \cdot 5$ & $1 \cdot 03$ & $0 \cdot 76$ & $-26 \cdot 2$ & $1 \cdot 11$ & $0 \cdot 82$ & 0.96 \\
\hline 29 & $7 \cdot 0$ & $5 \cdot 5$ & $1 \cdot 25$ & 0.98 & $-21 \cdot 6$ & $1 \cdot 01$ & $0 \cdot 79$ & $0 \cdot 90$ \\
\hline
\end{tabular}

Note: The northern half-troughs for elevations $z=-4 \mathrm{~m}$ and $z=-17 \mathrm{~m}$ do not have data points with $\Delta w / \Delta w_{\max }>0 \cdot 36$.

Table 5. Comparison of maximum incremental ground settlements in response to the westbound and eastbound construction

\begin{tabular}{|c|c|c|c|}
\hline \multirow[t]{2}{*}{$\begin{array}{l}\text { Depth below } \\
\text { ground: } m\end{array}$} & \multicolumn{2}{|c|}{$\begin{array}{l}\text { Maximum incremental } \\
\text { settlement above TBM } \\
\text { axis: mm }\end{array}$} & \multirow[t]{2}{*}{$\begin{array}{c}\text { Ratio } \\
\text { (TBM2/TBM1) }\end{array}$} \\
\hline & $\begin{array}{l}\text { TBM1 } \\
\text { (HP20) }\end{array}$ & $\begin{array}{l}\text { TBM2 } \\
\text { (HP23) }\end{array}$ & \\
\hline 0 & $-6 \cdot 0$ & $-10 \cdot 4$ & 1.73 \\
\hline 4 & $-6 \cdot 1$ & $-10 \cdot 9$ & $1 \cdot 79$ \\
\hline 9 & $-6 \cdot 9$ & $-12 \cdot 0$ & 1.74 \\
\hline 14 & $-7 \cdot 9$ & $-13 \cdot 5$ & $1 \cdot 71$ \\
\hline 17 & $-8 \cdot 6$ & $-14 \cdot 8$ & $1 \cdot 72$ \\
\hline 20 & $-9 \cdot 6$ & $-16 \cdot 5$ & 1.72 \\
\hline 23 & $-10 \cdot 9$ & $-18 \cdot 0$ & 1.65 \\
\hline 26 & $-13 \cdot 0$ & $-20 \cdot 1$ & $1 \cdot 55$ \\
\hline 29 & $-16 \cdot 2$ & $-23 \cdot 0$ & 1.42 \\
\hline
\end{tabular}

Table 6. Comparison of incremental settlement trough length factors in response to the westbound and eastbound construction

\begin{tabular}{l|c|c|c}
\hline \multirow{2}{*}{$\begin{array}{l}\text { Depth below } \\
\text { ground: } \mathrm{m}\end{array}$} & \multicolumn{2}{|c|}{$\begin{array}{c}\text { Incremental settlement } \\
\text { trough length factor, } i_{x}:\end{array}$} & $\begin{array}{c}\text { Ratio } \\
\text { (TBM2/TBM1) }\end{array}$ \\
\cline { 2 - 3 } & \multicolumn{2}{|c}{ TBM1 } & TBM2 \\
& (HP20) & (HP23) & \\
\hline 0 & $13 \cdot 4$ & $14 \cdot 8$ & $1 \cdot 10$ \\
4 & $13 \cdot 1$ & $14 \cdot 5$ & $1 \cdot 11$ \\
9 & $12 \cdot 8$ & $14 \cdot 2$ & $1 \cdot 11$ \\
14 & $12 \cdot 2$ & $13 \cdot 2$ & $1 \cdot 08$ \\
17 & $12 \cdot 0$ & $12 \cdot 5$ & $1 \cdot 04$ \\
20 & $11 \cdot 3$ & $12 \cdot 7$ & $1 \cdot 12$ \\
23 & $11 \cdot 0$ & $10 \cdot 5$ & $0 \cdot 95$ \\
26 & $10 \cdot 1$ & $9 \cdot 8$ & $0 \cdot 97$ \\
29 & $9 \cdot 7$ & $9 \cdot 6$ & $0 \cdot 99$ \\
\hline
\end{tabular}

carefully checked to identify such errors using redundancy and interpolation, although this was only necessary in two cases.

The response to the westbound tunnel construction by TBM1 measured by the inclinometers was most prominent at HP6 (grid line F, $y=5.3 \mathrm{~m}$ ). Developing transverse horizontal displacements determined along HP6 as TBM1 passed are presented in Fig. 10. Maximum horizontal displacement always occurred at $z=-36 \mathrm{~m}$, near the TBM axis level, as expected. The profiles of displacements with depth before the
Table 7. Comparison of incremental settlement trough width factors (southern half-troughs) in response to the westbound and eastbound construction

\begin{tabular}{l|c|c|c}
\hline $\begin{array}{l}\text { Depth below } \\
\text { ground: } \mathrm{m}\end{array}$ & \multicolumn{2}{|c|}{$\begin{array}{c}\text { Incremental settlement } \\
\text { trough width factor, } i_{y}: \mathrm{m}\end{array}$} & $\begin{array}{c}\text { Ratio } \\
\text { (TBM2/TBM1) }\end{array}$ \\
\cline { 2 - 3 } & $\begin{array}{c}\text { South half, } \\
\text { TBM1 }\end{array}$ & $\begin{array}{c}\text { South half, } \\
\text { TBM2 }\end{array}$ & \\
\hline 0 & $12 \cdot 7$ & $14 \cdot 8$ & $1 \cdot 17$ \\
4 & $13 \cdot 8$ & $14 \cdot 9$ & $1 \cdot 08$ \\
9 & $11 \cdot 9$ & $13 \cdot 7$ & $1 \cdot 15$ \\
14 & $10 \cdot 9$ & $12 \cdot 7$ & $1 \cdot 17$ \\
17 & $10 \cdot 4$ & $11 \cdot 8$ & $1 \cdot 13$ \\
20 & $8 \cdot 9$ & $11 \cdot 0$ & $1 \cdot 24$ \\
23 & $9 \cdot 3$ & $9 \cdot 8$ & $1 \cdot 05$ \\
26 & $7 \cdot 2$ & $8 \cdot 8$ & $1 \cdot 22$ \\
29 & $6 \cdot 6$ & $7 \cdot 0$ & $1 \cdot 06$ \\
\hline
\end{tabular}

Table 8. Comparison of incremental settlement trough width factors (northern half-troughs) in response to the westbound and eastbound construction

\begin{tabular}{l|c|c|c}
\hline \multirow{2}{*}{$\begin{array}{l}\text { Depth below } \\
\text { ground: } \mathrm{m}\end{array}$} & \multicolumn{2}{|c|}{$\begin{array}{c}\text { Incremental settlement } \\
\text { trough width factor, } i_{y}: \mathrm{m}\end{array}$} & $\begin{array}{c}\text { Ratio } \\
\text { (TBM2/TBM1) }\end{array}$ \\
\cline { 2 - 3 } & $\begin{array}{c}\text { North half, } \\
\text { TBM1 }\end{array}$ & $\begin{array}{c}\text { North half, } \\
\text { TBM2 }\end{array}$ & \\
\hline 0 & $13 \cdot 6$ & $10 \cdot 9$ & $0 \cdot 80$ \\
4 & $13 \cdot 8$ & N/A & N/A \\
9 & $13 \cdot 4$ & $9 \cdot 9$ & $0 \cdot 74$ \\
14 & $12 \cdot 4$ & $9 \cdot 5$ & $0 \cdot 77$ \\
17 & $11 \cdot 2$ & N/A & N/A \\
20 & $10 \cdot 6$ & $7 \cdot 7$ & $0 \cdot 73$ \\
23 & $9 \cdot 5$ & $7 \cdot 4$ & $0 \cdot 78$ \\
26 & $8 \cdot 7$ & $6 \cdot 5$ & $0 \cdot 75$ \\
29 & $6 \cdot 3$ & $5 \cdot 5$ & $0 \cdot 87$ \\
\hline
\end{tabular}

TBM cutter-head reached HP6 $\left(x_{\mathrm{f}}=0.2 \mathrm{~m}\right)$ show that the horizontal displacement was about $3 \mathrm{~mm}$ at the TBM1 axis level (Fig. 10(a)) and is associated with ground movements ahead of the cutter-head (i.e. inward movement towards the TBM face). Horizontal displacements increased as TBM1 progressed further, being about $8 \mathrm{~mm}$ at $x_{\mathrm{f}}=5.0 \mathrm{~m}$, with the ground moving radially towards the TBM1 shield body (into the gap formed by face over-excavation and tail-skin diameter tapering). The displacement then reduced to about 
Table 9. Comparison of overall incremental volume loss values in response to the westbound and eastbound construction

\begin{tabular}{l|c|c|c}
\hline \multirow{2}{*}{$\begin{array}{l}\text { Depth below } \\
\text { ground: } m\end{array}$} & \multicolumn{2}{|c|}{$\begin{array}{c}\text { Overall incremental } \\
\text { volume loss, } \Delta V_{\mathrm{L}}\end{array}$} & $\begin{array}{c}\text { Ratio } \\
\text { (TBM2/TBM1) }\end{array}$ \\
\cline { 2 - 3 } & TBM1: \% & TBM2: \% & \\
\hline 0 & 0.48 & 0.83 & 1.73 \\
4 & 0.51 & N/A & N/A \\
9 & 0.53 & 0.88 & 1.66 \\
14 & 0.56 & 0.94 & 1.68 \\
17 & 0.57 & N/A & N/A \\
20 & 0.57 & 0.97 & 1.70 \\
23 & 0.58 & 0.96 & 1.66 \\
26 & 0.63 & 0.96 & 1.52 \\
29 & 0.64 & 0.90 & 1.41 \\
\hline
\end{tabular}

$5 \mathrm{~mm}$ at $x_{\mathrm{f}}=10 \cdot 9 \mathrm{~m}$ as the tail grout pressure pushed the ground back radially outwards (Fig. 10(b)). After the TBM shield tail had passed, the surrounding ground continued to displace radially inwards as a result of grout and lining compression, reaching a maximum horizontal displacement of about $13 \mathrm{~mm}$ at $x_{\mathrm{f}}=15.8 \mathrm{~m}$. In the profiles shown in Fig. 10, a marked increase in displacement over the height of TBM1 is evident, indicating very localised ground movements. Above the TBM crown level, the displacement magnitudes reduced with distance from the TBM extrados. The final stage of the short-term horizontal displacements is shown in Fig. 10(c). Further horizontal displacements towards the TBM1 axis occurred from a combination of short-term tunnel lining deformation, tail grout shrinkage and ground consolidation, with a final maximum observed value of about $17 \mathrm{~mm}$. The final horizontal displacement at the base of the inclinometer $(z=-50 \mathrm{~m})$ was about $5 \mathrm{~mm}$ towards TBM1, indicating that the ground at a level $12 \mathrm{~m}$ $(1 \cdot 6 D)$ beneath the TBM invert was far from stationary during the westbound tunnel construction.

Transverse horizontal displacement profiles with depth measured from the Y-line inclinometers are presented in Fig. 11. MEMS sensor readings in inclinometers HP3 and HP4 were not taken during the passage of TBM1 due to faulty data loggers. These were subsequently repaired and the readings resumed, although the only reliable measurement data available are for $x_{\mathrm{f}}>170 \mathrm{~m}$, which are presented nevertheless. It is evident from the inclinometer array that the ground at all locations displaced horizontally towards the TBM1 axis, with the maximum magnitude being at TBM1 axis level on grid line F (HP6). The observed mode of horizontal displacements was that the ground in the near vicinity of TBM1 (grid lines C to $\mathrm{G},-10.9 \mathrm{~m}<y<8.1 \mathrm{~m}$ ) moved towards a point near its axis, while ground displacements above the TBM crown gradually reduced with increasing distance from the tunnel. For the inclinometers at larger offset distances (grid lines A, B, H, J and $\mathrm{K})$, the depth profiles appear to be sub-vertical, suggesting only small variations in horizontal displacement along the inclinometer casings. Transverse horizontal displacements above the TBM1 axis (HP5, grid line E, $y=0 \mathrm{~m}$ ) were expected to be zero because of symmetry, but small displacements up to about $2 \mathrm{~mm}$ were measured. This could be attributed to the installed inclinometer casing not being perfectly vertical (this type of effect is discussed and quantified by Avgerinos et al. (2017)).

Short-term response to eastbound tunnel construction (TBM2, period 4). The response to the eastbound tunnel construction by TBM 2 measured by the inclinometers was most prominent at HP9 (grid line $\mathrm{H}, y=5 \cdot 2 \mathrm{~m}$ ). Fig. 12 shows the developing transverse horizontal displacement profiles determined along HP9 as TBM2 passed. The same pattern of response as with inclinometer HP6 as TBM1 passed (Fig. 10) can be observed, albeit the magnitude of the response was larger. It is worth noting that a brief period of outward displacement was observed when the TBM shield tail was approaching the instrument (near $x_{\mathrm{f}}=10 \mathrm{~m}$ ) as a result of the tail grout pressure pushing the ground outwards. This effect of tail-grout-induced outward displacements was observed for both TBM1 and TBM2 passages, as recorded by the adjacent in-place inclinometer measurements (Fig. 13). The brief outward displacements occurred as early as $x_{\mathrm{f}}=6.5 \mathrm{~m}$ until right at the end of the shield $\left(x_{\mathrm{f}}=10.9 \mathrm{~m}\right)$, suggesting that the effect of the tail grout pressure would extend as far forward as about $4 \mathrm{~m}$ prior to the TBM shield tail reaching the instrument line.

Profiles of transverse horizontal displacement with depth in response to the eastbound tunnel construction measured along the Y-line inclinometer array are presented in Fig. 14. The ground at almost all locations displaced horizontally towards the TBM2 axis, with a maximum value of about $26 \mathrm{~mm}$ at TBM2 axis level on grid line $\mathrm{J}$ (HP9, $y=5 \cdot 2 \mathrm{~m}$ ) (compared with a maximum displacement of about $17 \mathrm{~mm}$ in HP6 $(y=5.3 \mathrm{~m})$ in response to TBM1). Small displacements, up to $4 \mathrm{~mm}$, away from TBM2 were measured below the invert level in HP6 and HP7. This could be a real response but could also be due to a measurement error in one or more sensors, as discussed above. For elevations above the TBM crown, subsurface horizontal displacements were generally larger in magnitude from the passage of TBM2 than TBM1 at corresponding offset distances. In addition, significant subsurface horizontal displacements were measured at offset distance as far as $y=-31.9 \mathrm{~m}$ (grid line B, HP2), agreeing with the general observation from all other surface and subsurface measurements that the eastbound tunnel construction induced a wider zone of influence than the westbound tunnel.

\section{INTERPRETATION OF RESULTS}

Displacements in the vertical plane transverse to the tunnel axis

Vectors of resultant incremental displacements in the transverse plane $(y-z$ plane) can be derived from the extensometer and inclinometer measurements, and are shown in Figs 15(a) and 15(b) immediately after the westbound and eastbound tunnel construction (end of periods 2 and 4), respectively. The grid points used for plotting the vectors were located at the extensometer anchor positions where the vertical displacements were taken to be those measured at the anchors, while the horizontal displacements were determined by interpolating between adjacent inclinometer gauge points. As noted earlier, horizontal displacements derived from the inclinometers on grid lines C and D (HP3 and HP4) were taken more than 10 days after the end of period 2, meaning that longer-term displacements and/or drifting of the MEMS devices may have also contributed to the resulting horizontal displacements. However, these only marginally affected two lines of vectors. Overall, immediately after tunnel construction, an 'inward' displacement field towards the region of the excavation was evident, even in the near vicinity of the excavation. This differs from observations from the instrumentation site for the CTRL project at Dagenham, where 'outward' displacement fields in the near vicinity of the EPBM excavation were observed (Standing \& Selemetas, 2013).

Reviewing the EPBM operation variables, the average face pressures at both the Hyde Park and Dagenham sites were of 

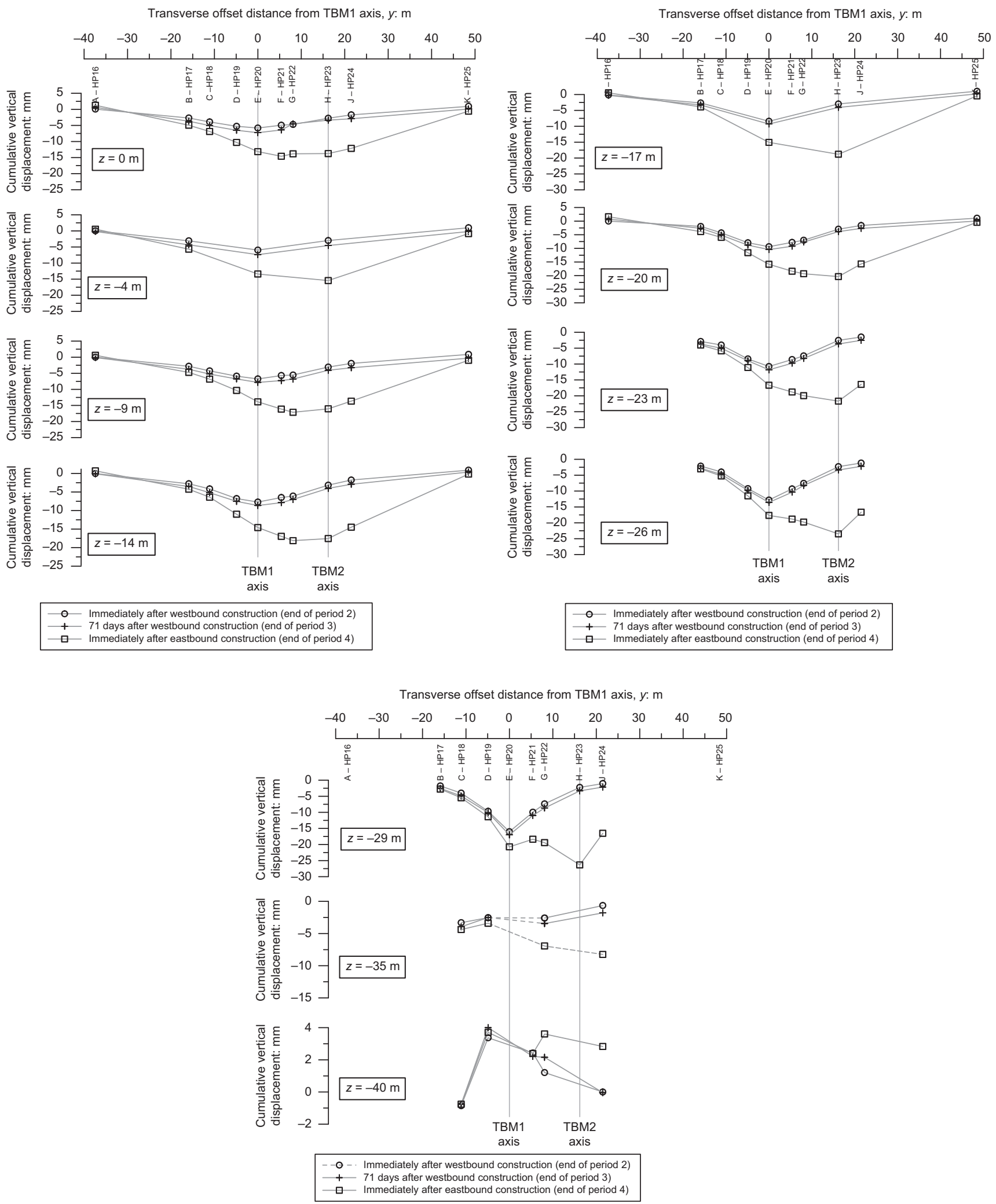

Fig. 9. Cumulative transverse settlement troughs at the end of periods 2, 3 and 4

similar magnitude $(150-200 \mathrm{kPa})$ whereas the average tail grout pressures recorded at Hyde Park were smaller than those at Dagenham. However, the Crossrail tunnel excavation beneath Hyde Park was under an overburden pressure more than twice that acting on the CTRL tunnel excavation at Dagenham, being located much deeper in the ground. The recorded EPBM pressures and estimated overburden pressures at both sites are summarised in Table 10. At the tunnel crown levels, while the face pressure and the tail grout pressure to overburden pressure ratios were at least $57 \%$ for the EPBM at Dagenham, the same pressure ratios at Hyde Park were no more than $33 \%$. This seems the most likely 


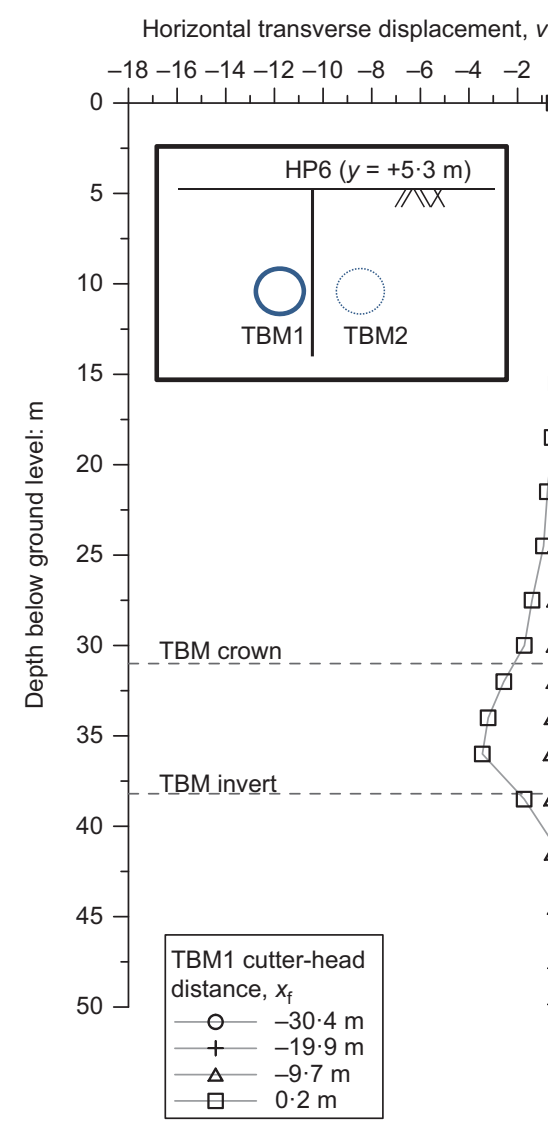

(a)
Horizontal transverse displacement, $v$ : $\mathrm{mm}$

Horizontal transverse displacement, $v$ : $\mathrm{mm}$

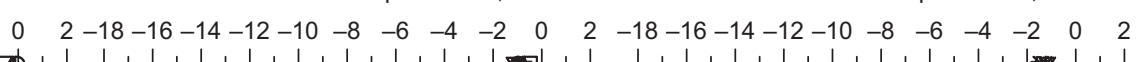

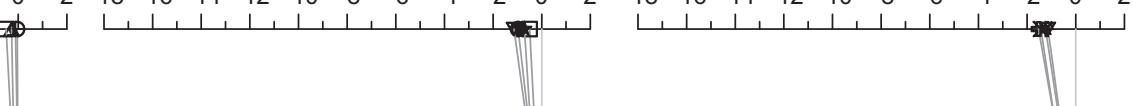
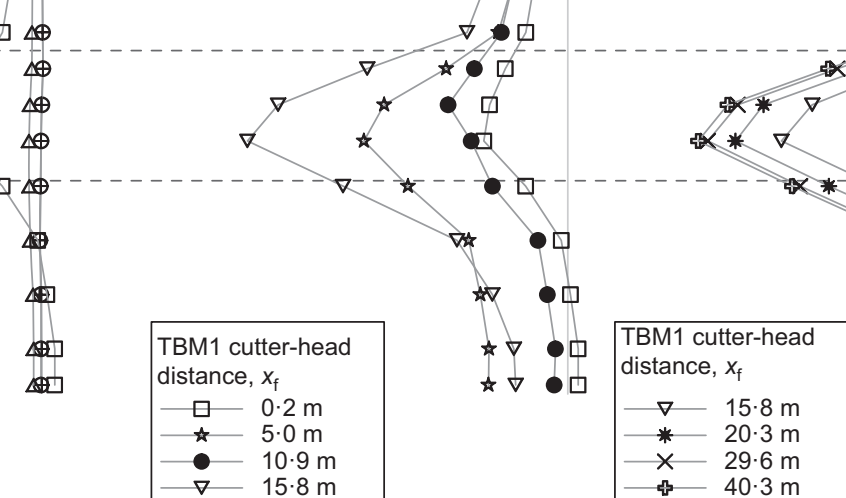

(b)

Fig. 10. Development of depth profiles of transverse horizontal displacements measured by inclinometer HP6 in response to westbound construction (period 2): (a) TBM approaching the instrument; (b) TBM passing the instrument; (c) TBM leaving the instrument

explanation for the difference in the displacement mechanisms (inward or outward) displayed by the similar type of EPBM operation at the two sites. In a discussion of the paper by Standing \& Selemetas (2013), Shirlaw argued (Standing et al., 2014) that the upward displacements above the TBM crown observed at Dagenham could also have been caused by the TBM shield being driven with an overhang (i.e. with the body of the TBM shield tilted slightly downwards).

The resultant displacement vectors immediately after tunnel construction shown for the Hyde Park site, despite the tunnels being constructed by EBPMs, resemble the mechanism of tunnelling-induced displacements that was observed at the St James's Park greenfield control site for the open-face shield tunnelling for the Jubilee Line Extension (JLE) project (Nyren, 1998). They both show an 'inward' nature of movements towards the excavation.

While the resultant displacement vectors at the ground surface mostly point to a focus in a small region roughly between $1.0 D$ and $1.5 D$ above the tunnel axis (Wan et al., 2017), the foci for subsurface displacement vectors appear to fall in a region at or below the tunnel invert. The same observation was made for the JLE tunnels constructed beneath St James's Park (Nyren, 1998).

\section{Deformation strains in the vertical plane transverse to the tunnel axis}

Normal and shear strains in the $y-z$ plane can be obtained by differentiating the measured vertical and horizontal displacements with depth. Figs 16(a) and 16(b) show the contours of incremental vertical strain $\left(\varepsilon_{z}\right)$ following construction of the westbound and eastbound tunnels, respectively (the grid points where the strains were calculated are also shown). Regions of extensional strain developed primarily above each tunnel, with the greatest magnitude occurring directly above the tunnel crowns, while there were regions of compressive strain either side of the tunnels. The boundaries between these extensional and compressive regions (i.e. contour lines of zero strain) extend roughly diagonally from the tunnel crown and invert.

The compressive vertical strains in the region between the westbound and eastbound tunnels (i.e. grid lines $F$ and $G$ in Fig. 16(a) were up to $1100 \mu \varepsilon$, or $0 \cdot 11 \%$ (within the tunnel horizon). In the region where the eastbound tunnel would be subsequently constructed (i.e. grid line $\mathrm{H}$ ), compressive vertical strains of about $400 \mu \varepsilon$, or $0.04 \%$, developed and consequently a degree of strain softening (with respect to stiffness) would have occurred after the westbound tunnel construction. Typical normalised modulus decay curves determined from undrained triaxial compression tests on London Clay samples (e.g. Hight et al., 2007) suggest that this level of vertical compressive straining could result in a $25-65 \%$ reduction in the undrained secant modulus.

Corresponding incremental transverse horizontal strains developed after the westbound and eastbound tunnel construction are presented in Figs 17(a) and 17(b), respectively. In general, compressive horizontal strains developed above and below the tunnel construction, while extensional horizontal strains developed either side of it. As with the vertical strain contours, the boundaries separating these zones of compressive and extensional strains extended 

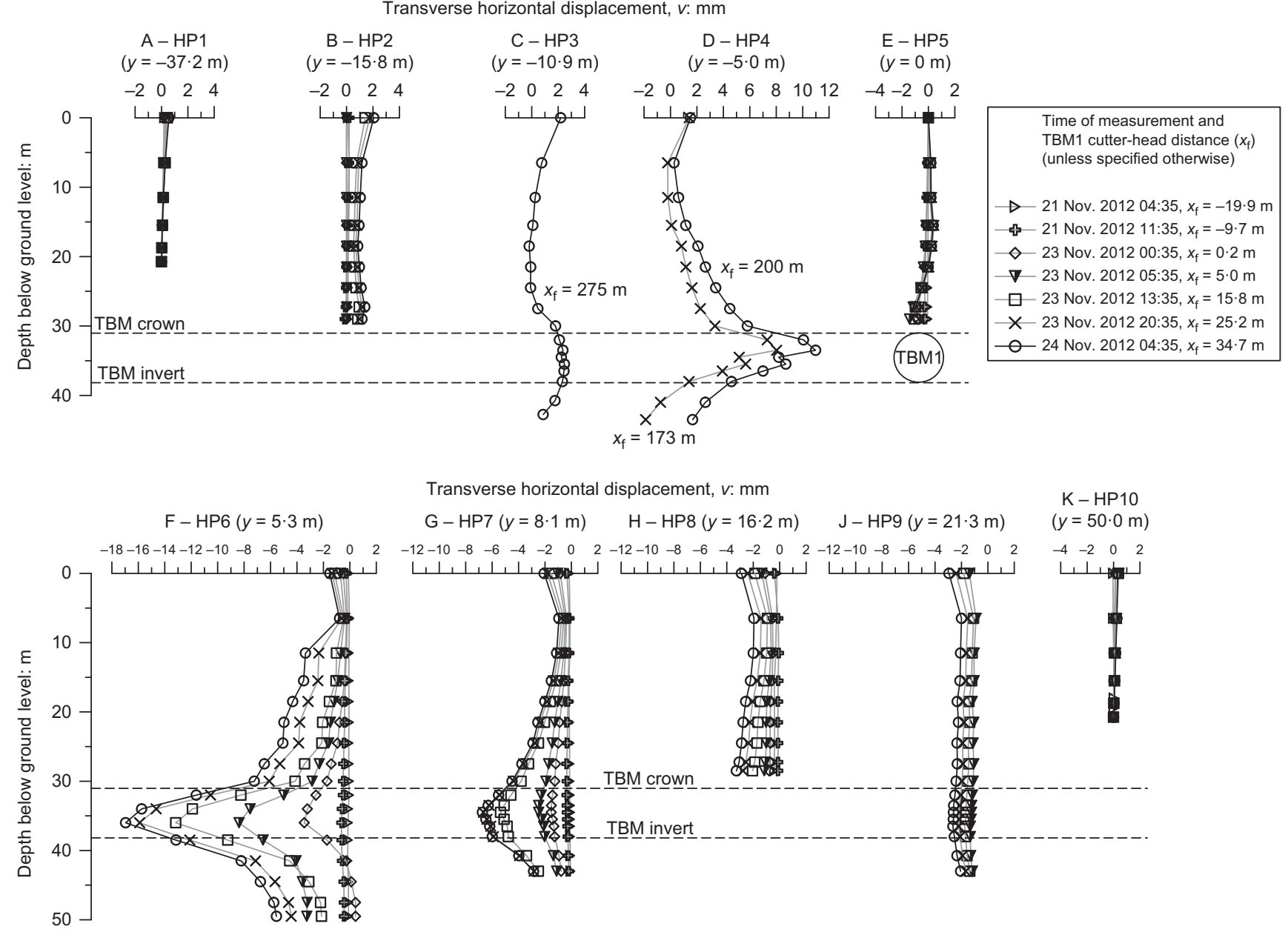

Fig. 11. Transverse horizontal displacements measured in Y-line of in-place inclinometers in Hyde Park during westbound construction (period 2)

roughly diagonally from the tunnel crown and invert. The zones of horizontal compressive strain broadly coincide with the zones of vertical extensional strain and the zones of horizontal extensional strain coincide with the zones of vertical compressive strain. Therefore, the ground surrounding a tunnel excavation with an 'inward' displacement field can be broadly divided into four quadrants of differing modes of deformation, as presented schematically in Fig. 18. This provides an insight into the likely stress paths that are followed by the ground in response to tunnel construction under plane-strain conditions.

Figures 19(a) and 19(b) show contours of incremental shear strain magnitude, $\gamma_{y z}$, induced by the construction of each tunnel. The 'butterfly wings' shape of the contour lines resembles idealised shear strain fields for a collapsing cylinder in an elastic material, indicating that concentrations of high shear strains occurred at the locations of the tunnel shoulders and knees. The directions of the shear strains in the ground around the excavation indicate that the ground deformed as if soil elements were elongating in a direction towards the excavation.

Volumetric strains and deviatoric strains can be derived from the normal and shear strains at each grid point, if the deformation is assumed to be in plane strain at the end of tunnel construction. Both the volumetric and deviatoric strains induced by the eastbound construction were significantly larger than those due to the westbound construction, as shown in Figs 20 and 21. The strains were concentrated in the ground either side of the tunnels. The volumetric strains above the tunnel crown level were small compared with those at and below the tunnel axis, but they were not zero either, agreeing with the varying volume losses derived from the subsurface troughs at different elevations above the tunnel crown (Fig. 6(c)).

Comparing Hyde Park subsurface ground displacements with other case histories

Figure 22 shows a comparison of the greenfield subsurface ground settlement trough width parameters determined for Hyde Park after construction of the first tunnel (westbound) with those found at various instrumented sites where ground response to tunnelling in clay was monitored as well as with centrifuge modelling data reported by Mair et al. (1993). As shown in the figure, the Hyde Park greenfield subsurface trough width parameters were generally lower than those of the other case histories and lower at all depth ratios than the relationship proposed by Mair et al. (1993).

\section{MECHANISMS OF GROUND RESPONSE IN THE NEAR VICINITY OF TBMS}

For the Crossrail tunnelling, the EPBM operation was monitored and controlled by a real-time computerised system that recorded a wide range of operation variables such as face pressure, tail grout pressures, tail grout volumes and weight of excavated materials. These are presented and discussed by Wan et al. (2017), in association with ground surface 


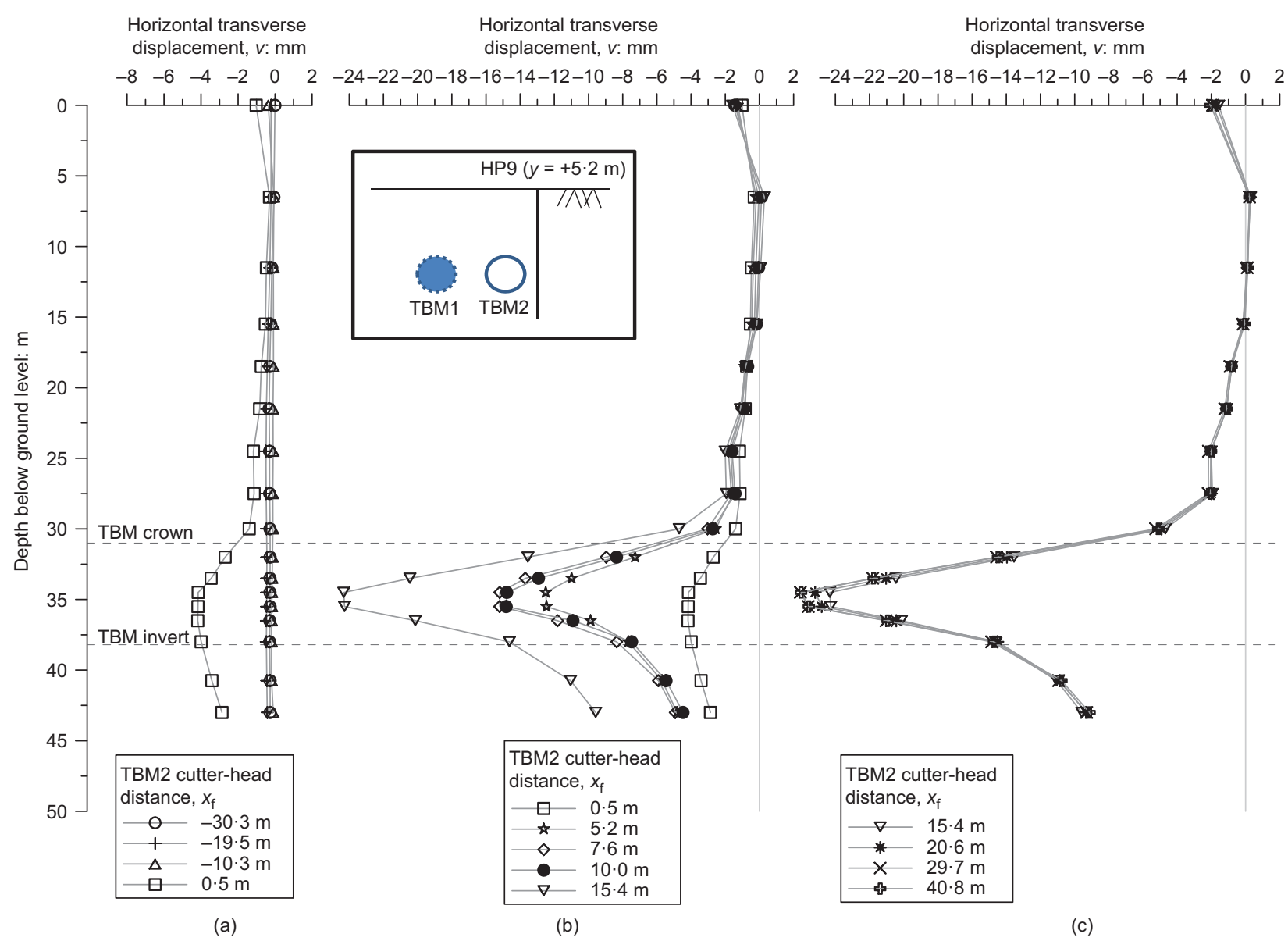

Fig. 12. Development of depth profiles of transverse horizontal displacements measured by inclinometer HP9 in response to eastbound construction (period 4): (a) TBM approaching the instrument; (b) TBM passing the instrument; (c) TBM leaving the instrument

displacements, in relation to the instrumented research site at Hyde Park. In the following, the TBM operation variables are studied more closely in relation to the response of the ground in close proximity to the tunnel construction in order to investigate where components of volume loss originate. All data from the operational variables are rolling average values over three lining rings (1.6 $\mathrm{m}$ wide each).

\section{Hypothetical components of ground loss around \\ TBM1 and TBM2}

Short-term ground loss induced by EPBM excavation can be divided into five primary components, as shown schematically in Fig. 23.

Component 1 - face movement. As the cutter-head rotates and excavates, the ground in front of the TBM face moves into the plenum chamber.

Component 2 - over-cutting by cutter-head. No over-cutting beads were present for either TBM1 or TBM2. However, both machines had cutter discs located at the end of the rotating arms, making the bore diameter $7100 \mathrm{~mm}(20 \mathrm{~mm}$ over the $7080 \mathrm{~mm}$ outer diameter of the front part of the shield) and thus over-excavating by a small degree.

Component 3 - shield body tapering. The shield body is tapered longitudinally in shape, with a diameter of $7 \cdot 10 \mathrm{~m}$ at the cutter-head, $7.08 \mathrm{~m}$ just behind it and $7.05 \mathrm{~m}$ at the rear of the shield. Therefore, there is a $25 \mathrm{~mm}$ annular gap between the cutter-head and shield tail circumferences.

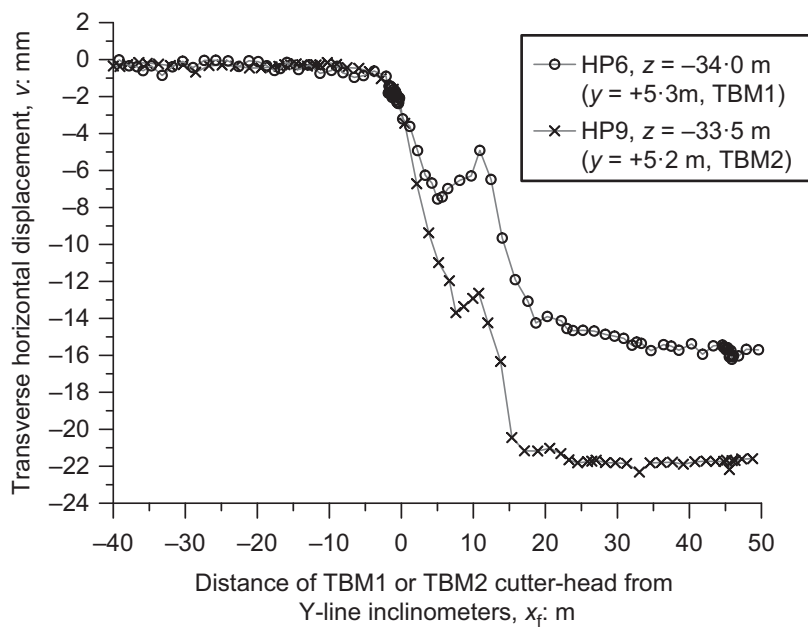

Fig. 13. Transverse horizontal displacements measured by inclinometer HP6 in response to westbound construction (period 2) and HP9 in response to eastbound construction (period 4) near the tunnel axis elevation

Component 4 - tail void closure. Precast concrete tunnel linings with an external diameter of $6.80 \mathrm{~m}$ are erected in the rear part of the shield. As the shield advances, there is a further $125 \mathrm{~mm}$ wide annular tail void between the shield tail circumference and the newly erected linings. Grout is injected through nozzles located at the shield tail as the shield advances in order to minimise the ground 

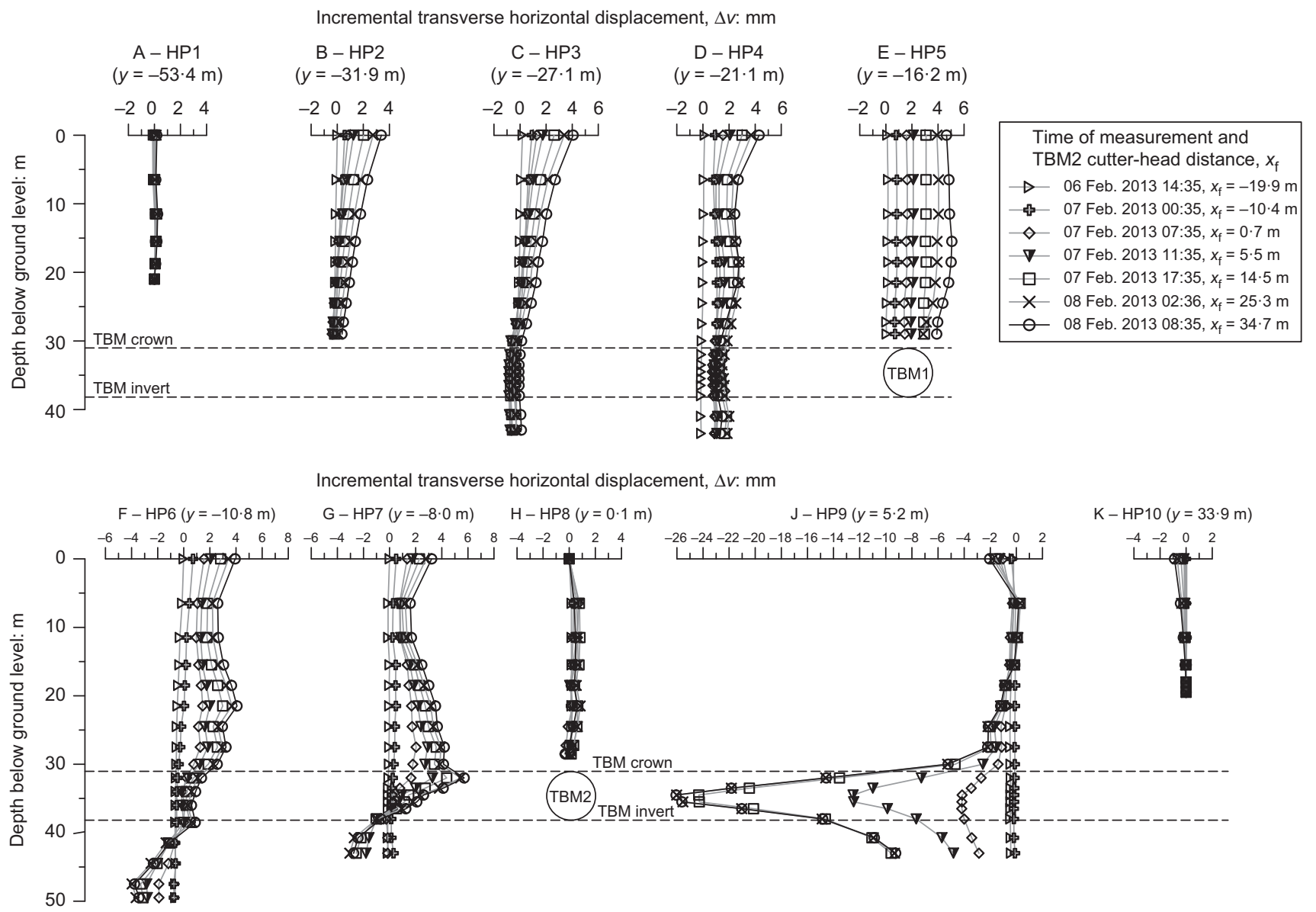

Fig. 14. Incremental transverse horizontal displacements measured in Y-line in-place inclinometers in Hyde Park during eastbound construction (period 4)

movements associated with closure of the tail void, although some volume of tail void may remain unfilled by grout and also the grout may shrink as it sets.

Component 5 - lining deformation. As the ground bears on newly erected tunnel linings, they start to deform from the overburden pressure resulting in further ground movements.

Longer-term ground movements from consolidation and creep of the ground and further shrinkage of the tail grout are not considered here.

Measured incremental volume losses above the TBM crown

The development of volume losses immediately above the crown of each TBM during its passage was investigated. At different distances of the TBM cutter-head $\left(x_{\mathrm{f}}\right)$, volume losses were determined (using Gaussian approximations) from the settlement measurements at the extensometer anchors $29 \mathrm{~m}$ below ground (i.e. $2 \mathrm{~m}$ above the TBM crown level) for the passage of both TBM1 and TBM2. The interpreted volume losses as the TBM cutter-heads approached and progressed beyond the extensometer line are shown in Figs 24(a) and 24(b). The left-hand ordinate axes in the figures represent the volume loss in terms of the percentage of the excavation volume (where the tunnel diameter, $D$, is taken as $7 \cdot 10 \mathrm{~m}$ ). The right-hand ordinate axes show the equivalent absolute volume in terms of cubic metre per metre advance of the TBM shield. By considering the relative position of the TBM shield to the instrument line, volume losses were broadly divided into four development stages - face movement, movement around the shield body, tail void closure, and lining deformation and longerterm ground settlement. Component 2, shown in Fig. 23 and discussed earlier, was grouped with component 3 because of the difficulty in isolating the two components reliably from the intermittent manual field measurements.

Face movement. Before the cutter-head arrived at the instrument line $\left(x_{\mathrm{f}}<0\right)$, volume losses were considered to be associated with the ground moving in towards the TBM face. The volume losses associated with this 'face movement' for TBM1 and TBM2 were estimated to be $0.09 \mathrm{~m}^{3} / \mathrm{m}$ and $0 \cdot 14 \mathrm{~m}^{3} / \mathrm{m}$, respectively. Since face movement starts well ahead of the cutter-head, the only EPBM variable that is expected to have some influence is the face pressure. As shown in Table 10, the measured face pressures at both TBM1 and TBM2 cutter-heads were of similar magnitude $(190-200 \mathrm{kPa})$. The larger volume of the face movement for TBM2 can be explained by the London Clay ahead of the cutter-head having been strain-softened (with respect to stiffness) from the passage of TBM1, as discussed earlier.

Movement around the shield body. The volume loss measured when the TBM shield body was beneath the instruments $\left(0 \mathrm{~m}<x_{\mathrm{f}}<10 \mathrm{~m}\right)$ was considered to be associated with the ground moving radially towards the shield circumference from over-excavation by the cutter discs at the 


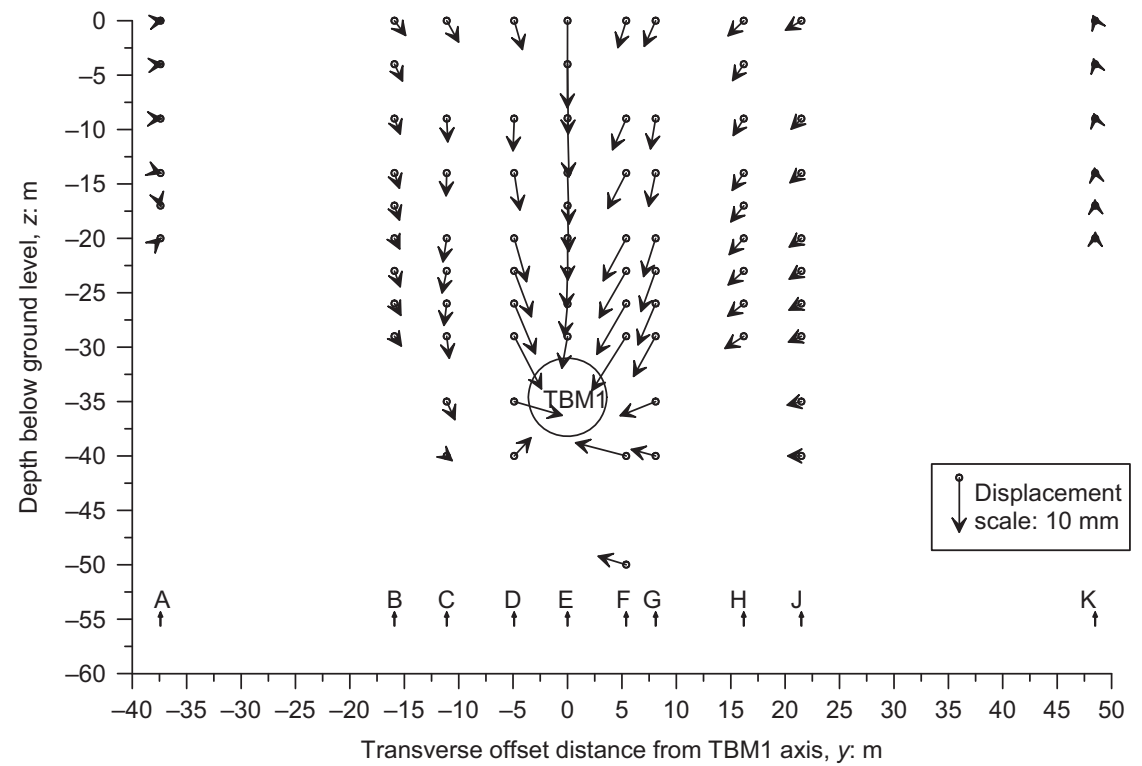

(a)

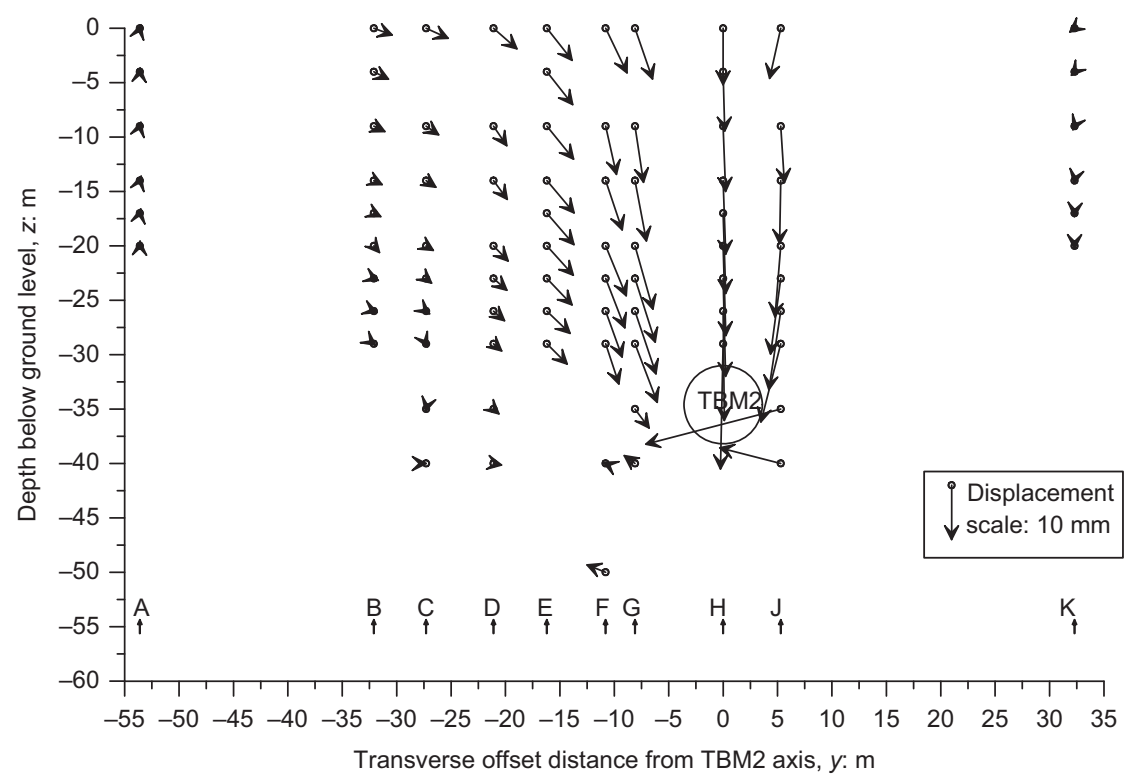

(b)

Fig. 15. Incremental displacement vectors in the vertical transverse plane in response to: (a) westbound construction at the end of period 2; (b) eastbound construction at the end of period 4

Table 10. EPBM face pressures and tail grout pressures and estimated overburden pressures at Crossrail Hyde Park and CTRL Dagenham sites

\begin{tabular}{l|c|c|c|c}
\hline \multirow{2}{*}{ Tunnel construction } & Hyde Park site & \multicolumn{2}{|c}{ Dagenham site } \\
\cline { 2 - 5 } & TBM1 & TBM2 & Up-line & Down-line \\
\hline Estimated overburden pressure at the ground at tunnel crown level: kPa & 600 & 600 & 265 & 265 \\
Average face pressure: kPa & 190 & 200 & $200^{*}$ & $150^{*}$ \\
Ratio of average face pressure to overburden pressure: \% & 32 & 33 & 75 & 57 \\
Average tail grout pressure: kPa & 90 & 140 & $160^{*}$ & $200^{*}$ \\
Ratio of tail grout pressure face pressure to overburden pressure: \% & 15 & 23 & 60 & 75 \\
\hline
\end{tabular}

*Reported by Standing \& Selemetas (2013).

ends of the rotating arms of the cutter-head and the tapering of the shield skin (components 2 and 3 in Fig. 23). The movement around the shield body component of volume loss was only about $0.05 \mathrm{~m}^{3} / \mathrm{m}$ during the passage of TBM1 and about $0 \cdot 13 \mathrm{~m}^{3} / \mathrm{m}$ for TBM2. Since the dimensions of the shield body were identical for both machines, the higher volume loss for TBM2 might originate from a larger amount of over-excavation at the cutter-head. This could be due to a reduction in stresses after the passage of TBM1 and hence a lessening of the arching effect, causing more soil to collapse 


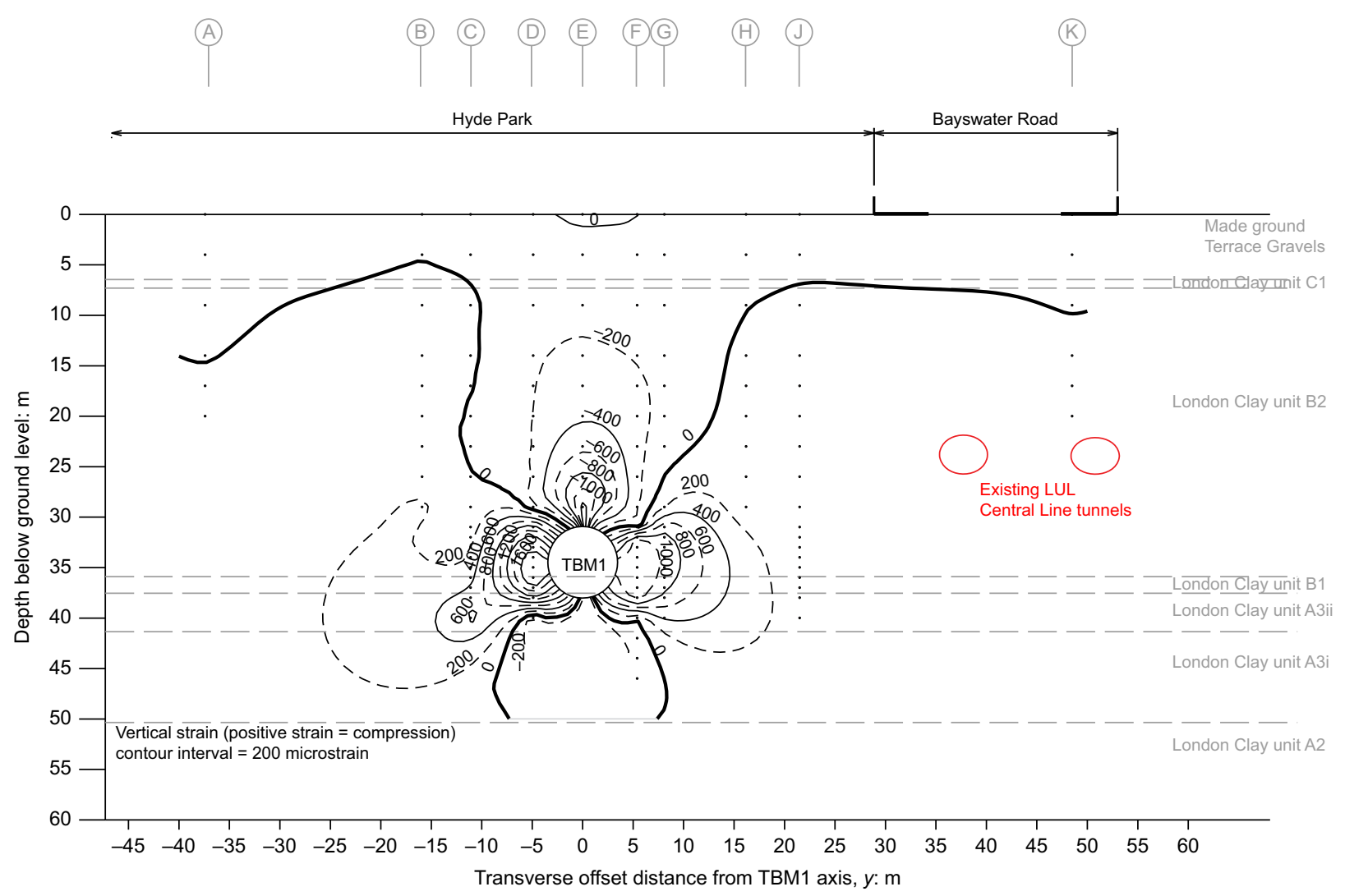

(a)

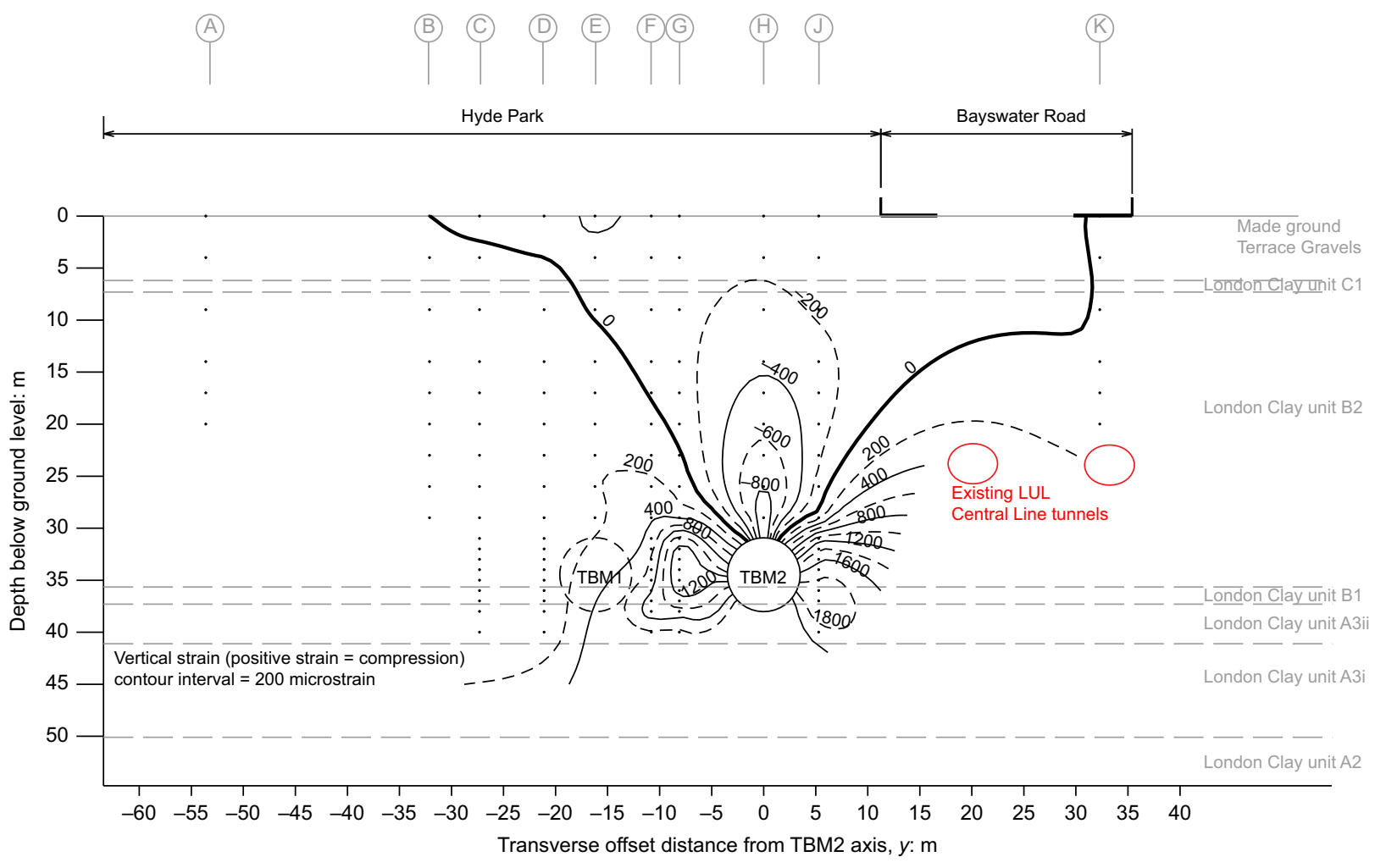

(b)

Fig. 16. Contours of incremental vertical strain in the vertical transverse plane in response to: (a) westbound construction at the end of period 2; (b) eastbound construction at the end of period 4

in towards the cutter-head. This possibility is supported by the larger weight of excavated materials per lining ring erection cycle measured for the eastbound tunnel construction (Fig. 25).
Tail void closure. After the tail of the shield body passed beyond the instrument line $\left(x_{\mathrm{f}}>10 \mathrm{~m}\right)$, volume loss was primarily associated with tail void closure (component 4 of Fig. 23). This component of volume loss was essentially the 


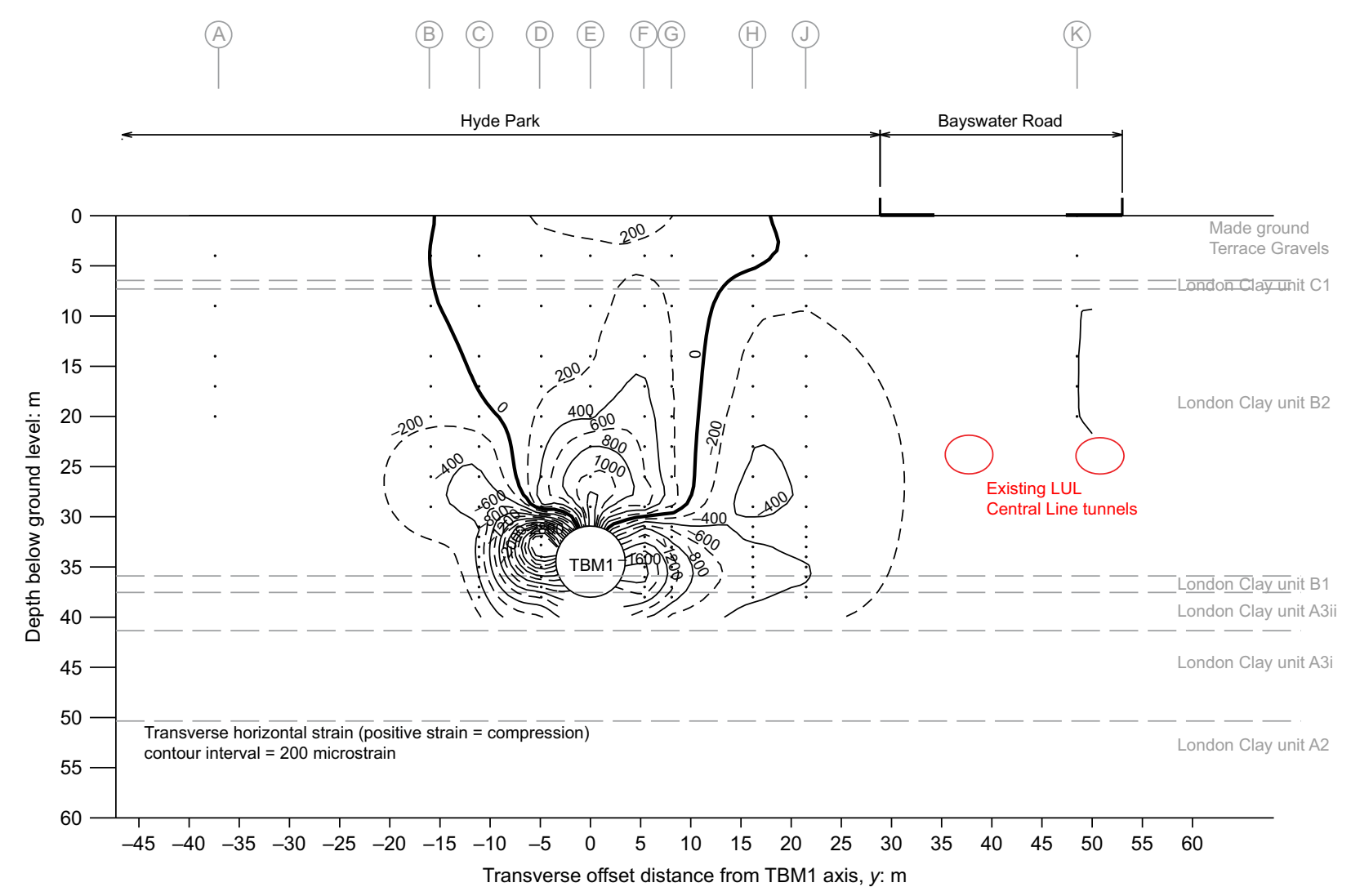

(a)

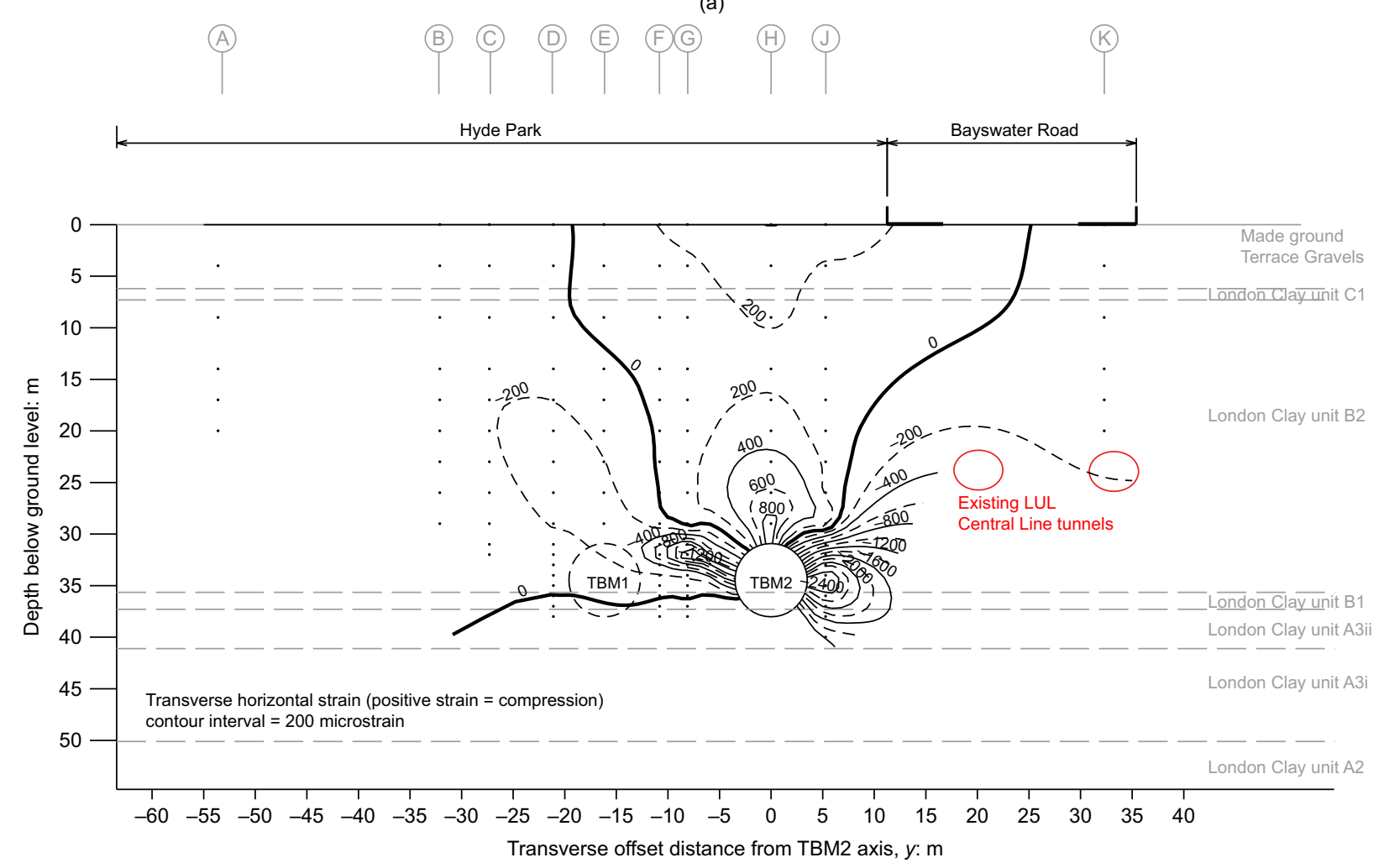

(b)

Fig. 17. Contours of incremental transverse horizontal strain in the vertical transverse plane in response to: (a) westbound construction at the end of period 2; (b) eastbound construction at the end of period 4

same $\left(0 \cdot 10 \mathrm{~m}^{3} / \mathrm{m}\right)$ for the passages of both TBM1 and TBM2. By this stage, any extra volume loss induced by overexcavation of the cutter-head should be complete and this is supported by the fact that the volume of the tail grout injected during the construction of both tunnels did not exceed the theoretical volume of the annular void beyond the tunnel lining (Fig. 26). The volume of tail grout injected during the passage of TBM2 was slightly greater than for TBM1. 


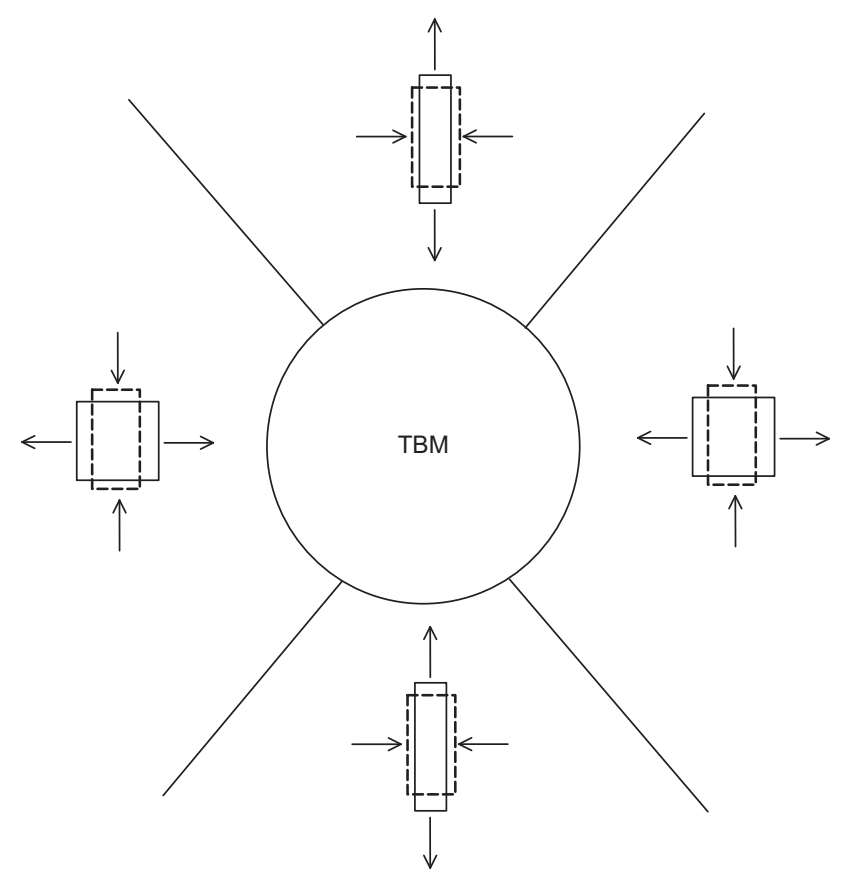

Fig. 18. Zones of different modes of deformation around tunnel excavation

Lining deformation and longer-term ground settlement. The final component of volume loss comes from the shortterm deformation of newly erected tunnel linings upon loading of the ground and, perhaps, continued shrinkage of the tail grout and time-dependent ground settlement. Since the linings for both tunnels were of the same size and type (bolted precast concrete segments), the tunnel depths were the same at the site location (hence the same overburden pressure) and the volumes of injected grout were roughly the same, this component of volume loss should be about the same for both tunnels. In fact, there was a volume loss of about $0 \cdot 020-0 \cdot 025 \mathrm{~m}^{3} / \mathrm{m}$ associated with this final component for the passage of both TBM1 and TBM2.

Having studied the development of volume losses at different stages of the TBM passages, it is evident that the greater ground loss induced from the passage of TBM2 originated mainly from the first component, relating to face movement, and cutter-head over-excavation.

\section{Total advance thrust force}

Other EPBM operation variables can provide additional information about tunnel construction and its relationship with the measured ground response. Shirlaw (Standing et al., 2014) revisited the EPBM operation variables for the CTRL tunnelling at the Dagenham site presented by Standing \& Selemetas (2013). Shirlaw argued that there was a remaining (residual) force when the total advance thrust force to drive the shield forward was countered by the reaction force provided by the pressurised muck on the excavation face (converted from the measured face pressure). This residual force is the force required to (a) provide the force on the cutting tools, (b) overcome frictional forces on the shield skin and $(c)$ drag the trailing gear. Since item $(c)$ should have roughly the same values for the passage of both TBM1 and TBM2, this suggests that the difference in the magnitude of the residual forces between the two tunnel drives was related mainly to differences in the force on the cutting tools and the frictional forces on the shield skin.
Total advance thrust forces, calculated reaction forces at the excavation face and residual forces are presented in Figs 27(a)-27(c), respectively, for when the TBM cutterheads were within $\pm 10 \mathrm{~m}$ of the Y-line extensometers. The total advance thrust force was provided by thrust cylinders within the shield tail, reacting on the newly erected tunnel lining. The total advance thrust force during the passage of TBM1 was about $24000 \mathrm{kN}$, considerably higher than that for TBM2 $(17000 \mathrm{kN})$. The reaction forces provided by the pressurised muck through the hatches of the cutter-head, estimated by multiplying the measured average face pressure by the area of the cutter-head, were about the same for both TBMs, about $7500 \mathrm{kN}$. As a result, the residual force for TBM1 was more than $50 \%$ higher than for TBM2 during the passage of their respective shields beneath the extensometer line. The difference is thought to be a result of $(a)$ the smaller forces required for the cutting tools of the TBM 2 cutter-head to cut through the ground that had been softened by the previous construction of the westbound tunnel and for the closed part of the excavation face to advance through it and $(b)$ lower frictional forces acting on the TBM2 shield skin than those acting on TBM1. An explanation for $(b)$ could be that the normal contact force on the TBM2 shield skin was significantly reduced by a larger amount of over-excavation by the cutter-head, leaving a larger volume of void between the ground and the shield skin. This corroborates the finding that the ground loss component from over-excavation and shield tapering, determined from the volume losses at $z=-29 \mathrm{~m}$, was greater for TBM2 than TBM1.

\section{SUMMARY AND CONCLUSIONS}

Monitoring results of short-term subsurface ground responses induced by the twin-bore Crossrail tunnels measured at the Hyde Park instrumentation site have been presented and discussed. The key findings from the field investigation are as follows.

(a) Subsurface transverse settlement troughs were asymmetric, with the half-troughs being essentially Gaussian in form with volume losses at various levels above the tunnel crowns ranging from $0 \cdot 48 \%$ to $0 \cdot 64 \%$ for the passage of TBM1 and $0 \cdot 83 \%$ to $0 \cdot 97 \%$ for TBM2.

(b) For the construction of the first Crossrail tunnel (westbound), the subsurface transverse settlement troughs were asymmetric about the TBM1 centre-line, with the northern half-troughs (closer to the existing tunnels of the Central Line tunnels) being wider at all depths. This suggests that the ground near the tunnels of the Central Line has been strain-softened and its stiffness was not fully recovered by their construction (even though this was more than a century ago).

(c) For the construction of the subsequent Crossrail eastbound tunnel, the subsurface transverse incremental settlement troughs were also asymmetric but, in this case, with the southern half-troughs (on which side the westbound tunnel was newly constructed) being wider at all depths. This indicates that the Crossrail westbound tunnel construction had a more dominant strain-softening effect than the existing Central Line tunnels, because the Crossrail westbound tunnel construction was of larger diameter, much closer and more recent. 


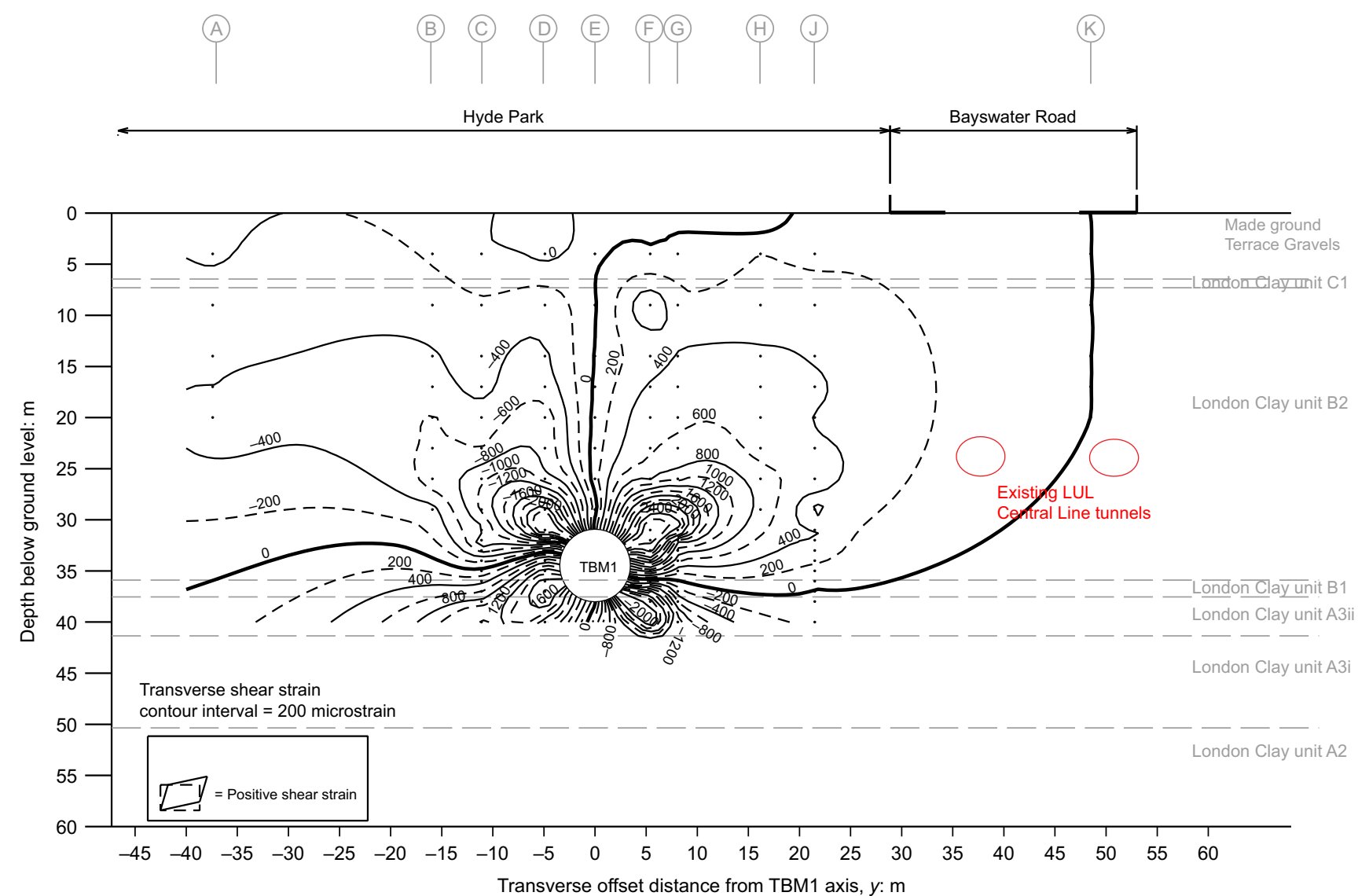

(a)

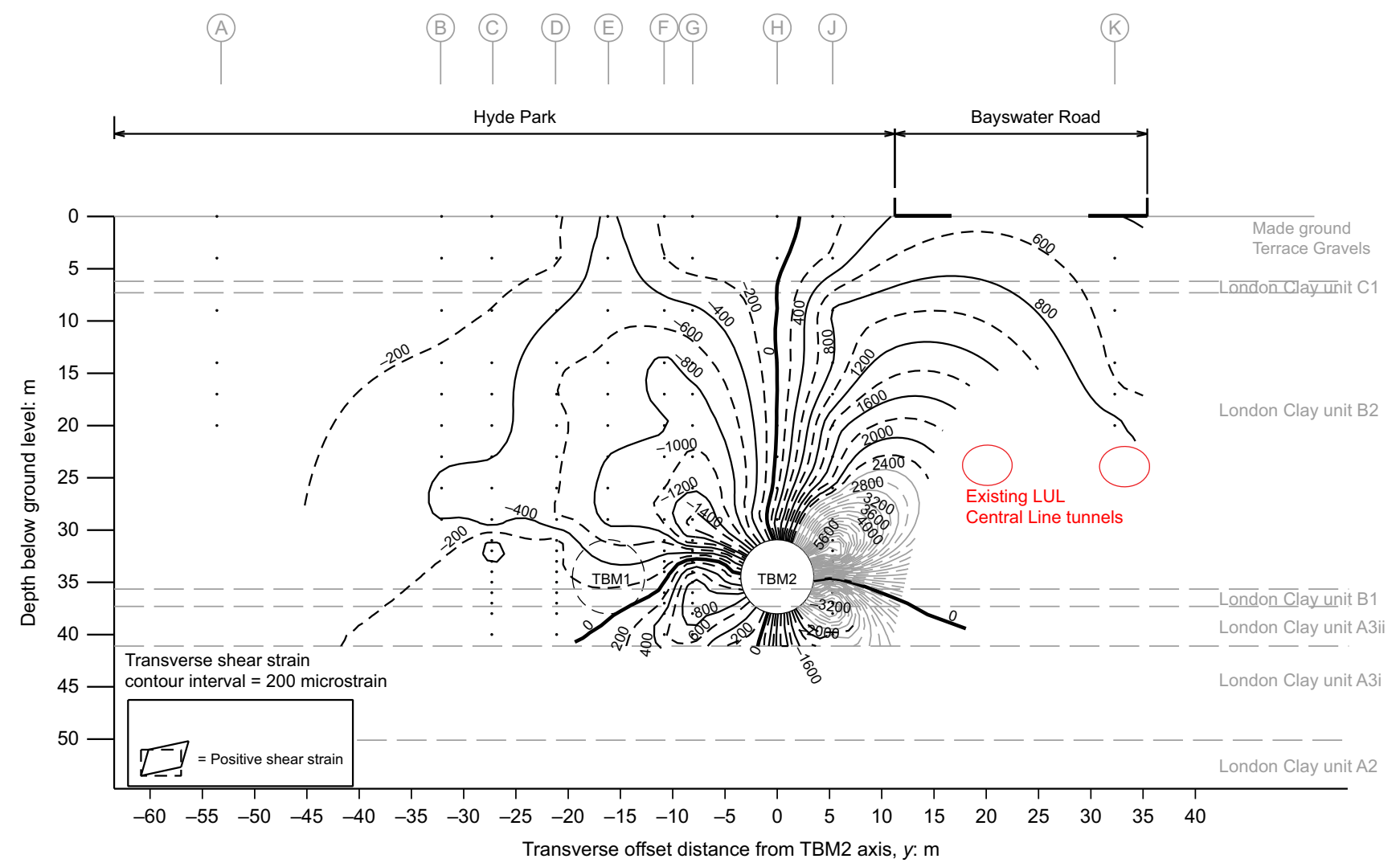

(b)

Fig. 19. Contours of incremental shear strain in the vertical transverse plane in response to: (a) westbound construction at the end of period 2; (b) eastbound construction at the end of period 4 


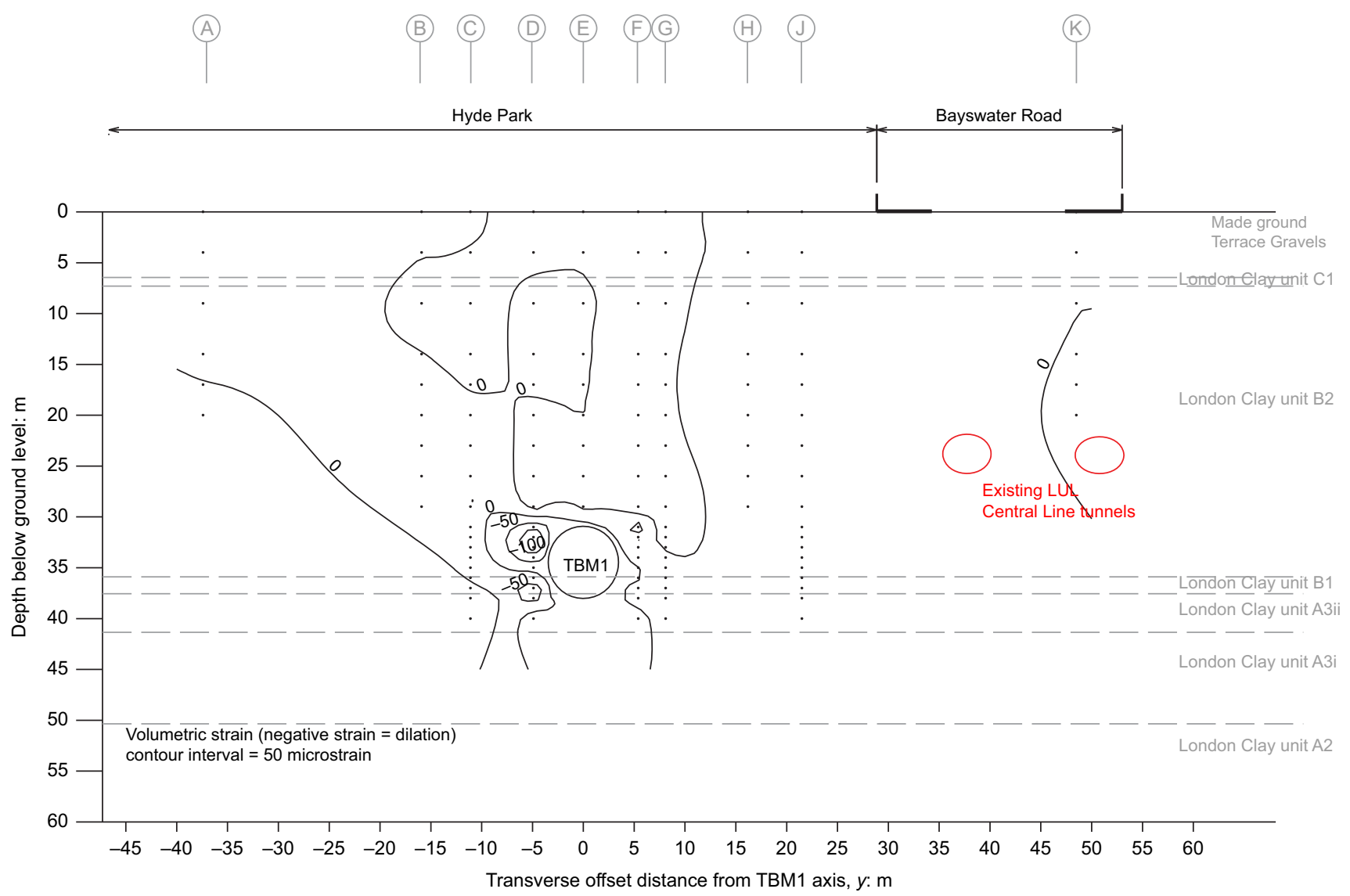

(a)

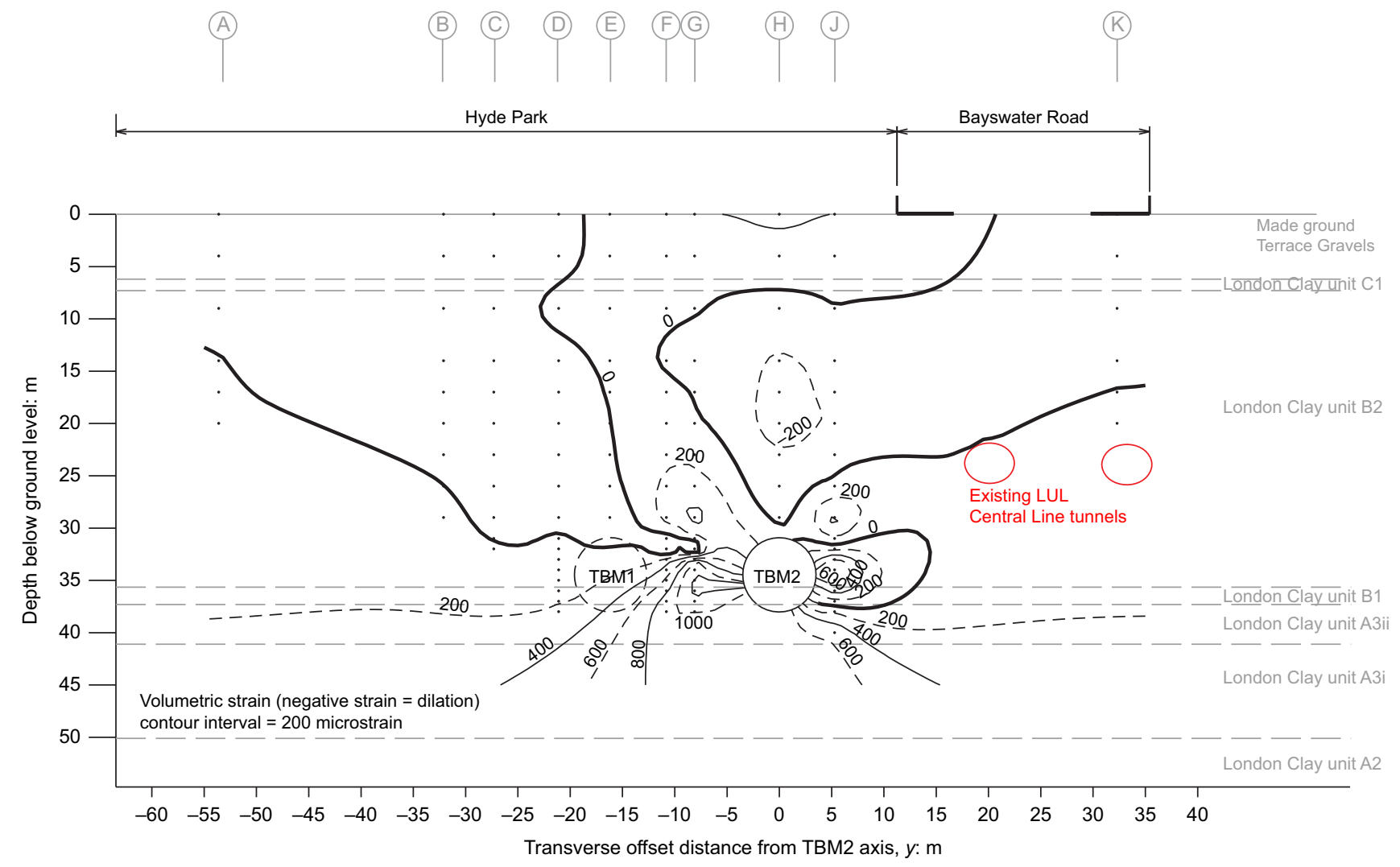

(b)

Fig. 20. Contours of incremental volumetric strain in the vertical transverse plane in response to: (a) westbound construction at the end of period 2; (b) eastbound construction at the end of period 4 


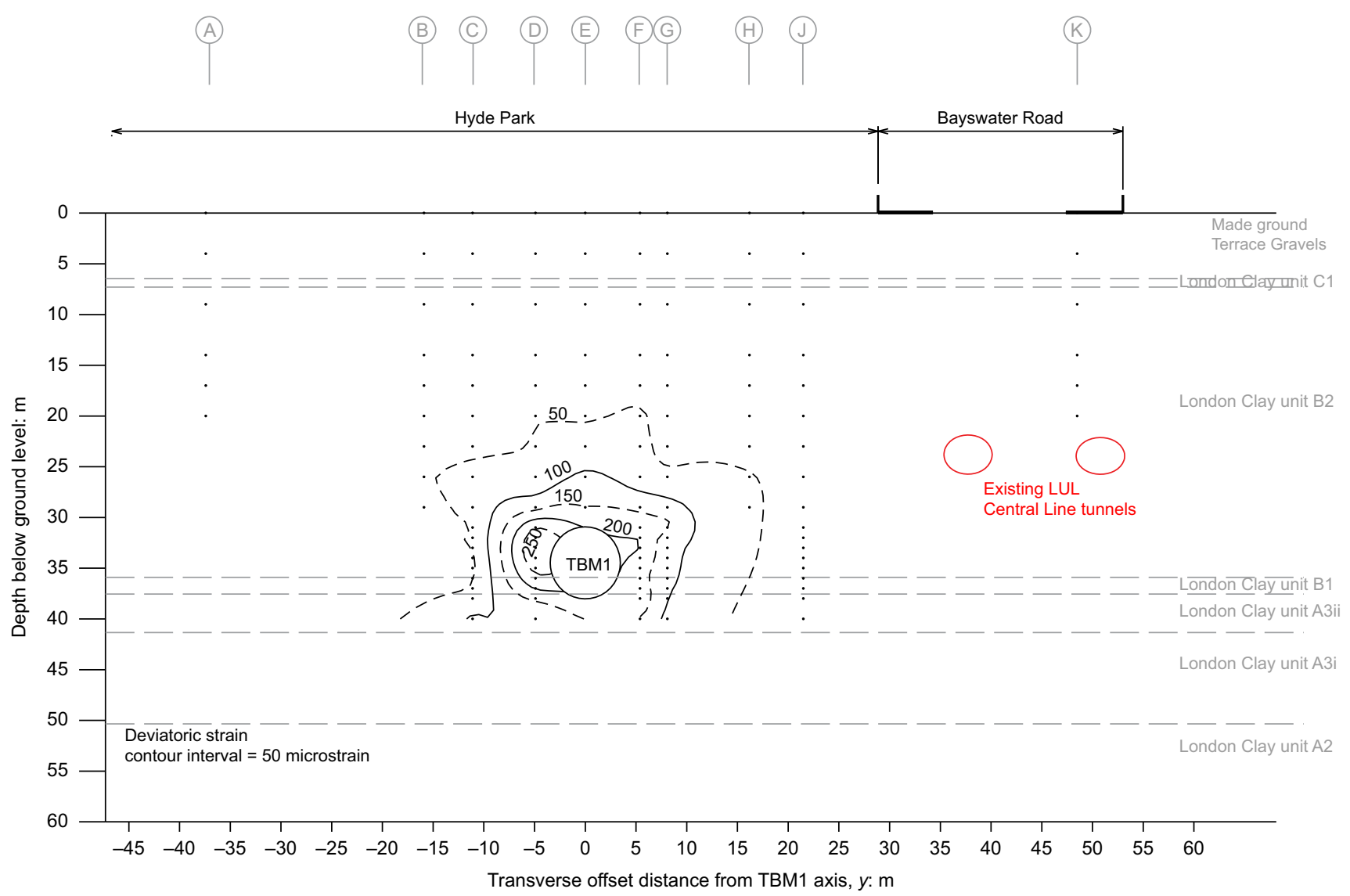

(a)

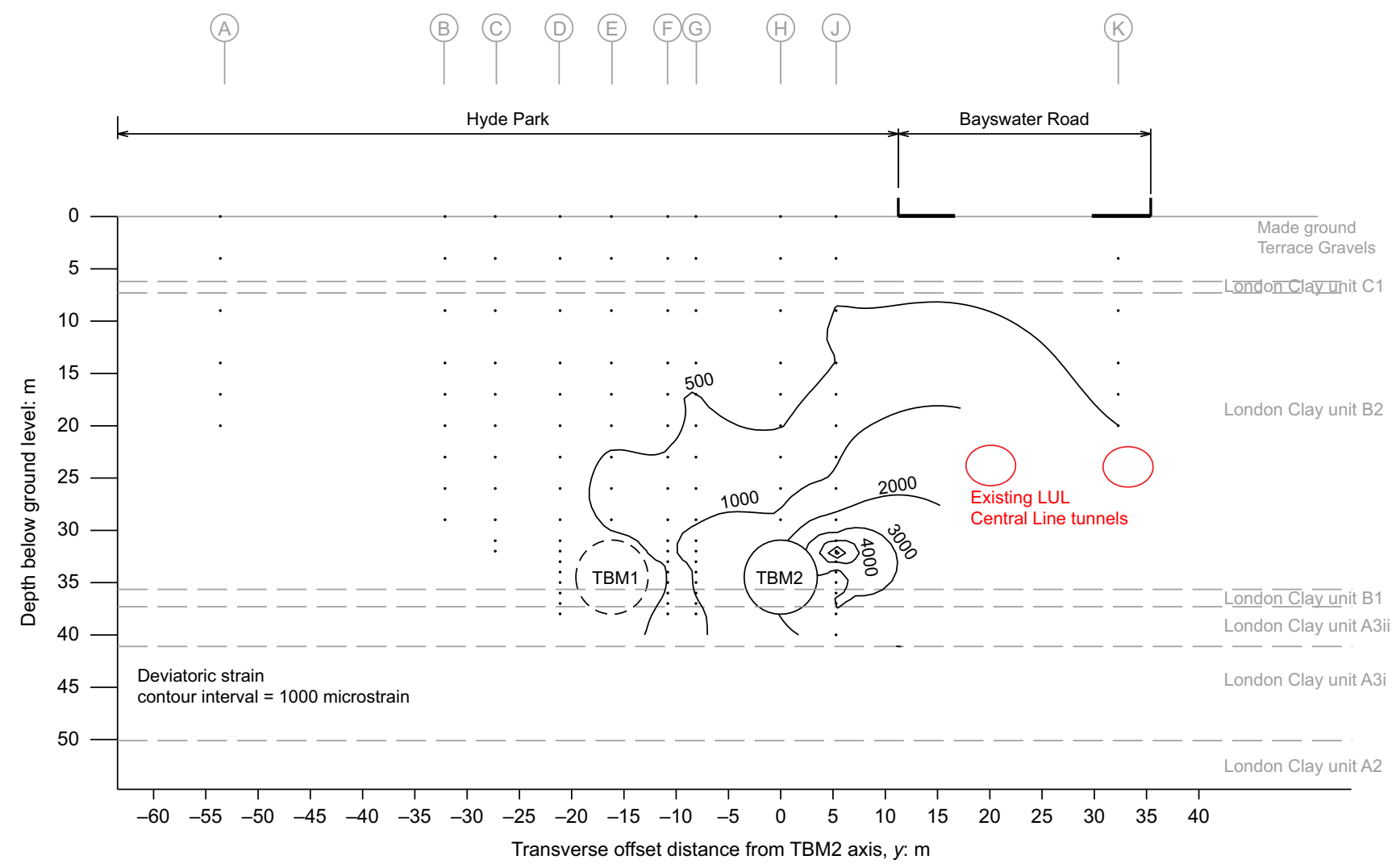

(b)

Fig. 21. Contours of incremental deviatoric strain in the vertical transverse plane in response to: (a) westbound construction at the end of period 2; (b) eastbound construction at the end of period 4 


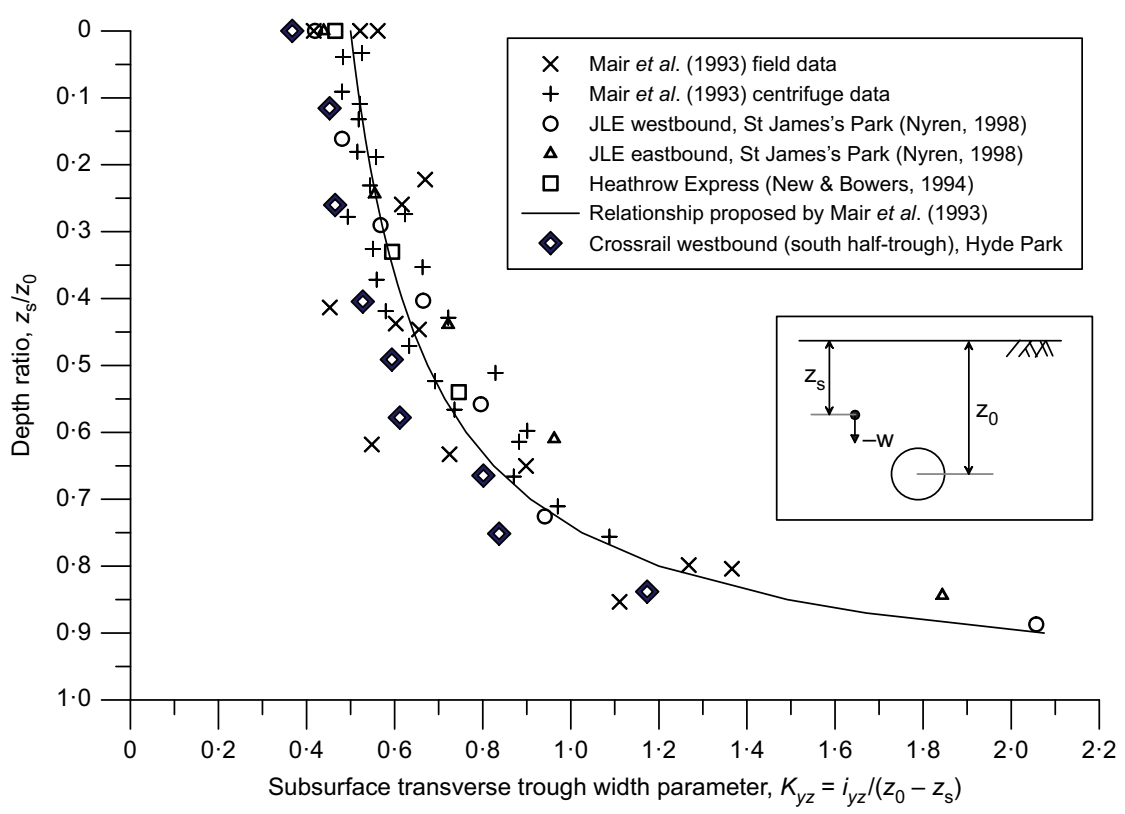

Fig. 22. Greenfield subsurface settlement transverse trough width parameters determined at Hyde Park site, from case histories and centrifuge modelling of tunnelling in cohesive soil

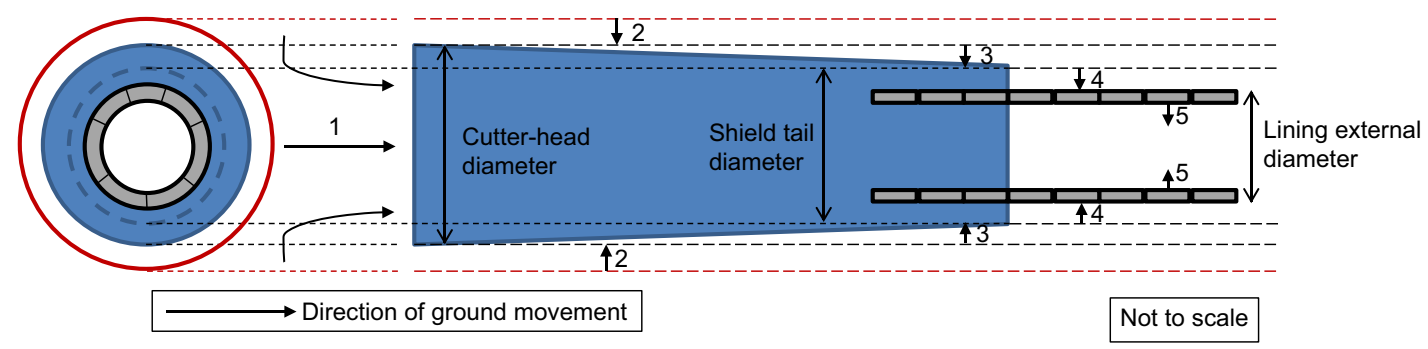

Fig. 23. Schematic diagram of main components of ground loss into tunnel construction by TBM: 1, face movement; 2, over-excavation; 3, shield tapering; 4 , tail void closure; 5 , lining deformation

(d) Subsurface ground losses at different levels above the tunnel crown induced by the passage of TBM 2 were up to $70 \%$ greater than for TBM1. In addition, for TBM2, the southern half-troughs (the side affected by TBM1) were always wider and had greater volume losses than the northern half-troughs. This is attributed to strain softening (with respect to stiffness) of the ground from the passage of TBM1 and is supported by the normal and shear strains derived from the extensometer and inclinometer measurements. Strains of up to $0 \cdot 2 \%$ were developed in the ground within $1 \cdot 5 \mathrm{D}$ of the tunnel axis.

(e) In comparing the greenfield subsurface trough width parameters with other case histories relating to tunnelling in stiff clay, they were generally found to be lower than the range of the earlier field data and less than the relationship proposed by Mair et al. (1993). As with the surface values reported by Wan et al. (2017), this is attributed to the deeper level of the Crossrail tunnels. The measured subsurface trough width parameters matched very well with the power function relationship proposed by Moh et al. (1996) with $m=0 \cdot 4$, when the subsurface trough width parameters were adjusted to the surface trough width parameter. (f) Net 'inward' displacement fields in the ground around the EPBMs were observed after the passage of the two EPBMs, similar to those related to the open-face tunnelling beneath St James's Park during construction of the JLE (Nyren, 1998). However, this contrasts with the net 'outward' displacement field observed for a similar EPBM tunnelling beneath Dagenham for the CTRL (Standing \& Selemetas, 2013). The 'inward' or 'outward' nature of the near-tunnel ground displacement field can be related to the overburden pressure at the tunnel level relative to the TBM face pressure and tail grout pressure.

( $g$ ) Five main components of short-term volume loss related to EPBM tunnel construction are discussed. By studying the development of volume losses determined from extensometer measurements at a level of $2 \mathrm{~m}$ above the tunnel crown during the passages of TBM1 and TBM2, it was established that the greater volume losses measured during the passage of TBM2 mainly originated from the components of face movement and cutter-head over-excavation. Components of volume loss associated with the shield body tapering, tail void closure and lining deformation were of very similar magnitude for both TBMs. 


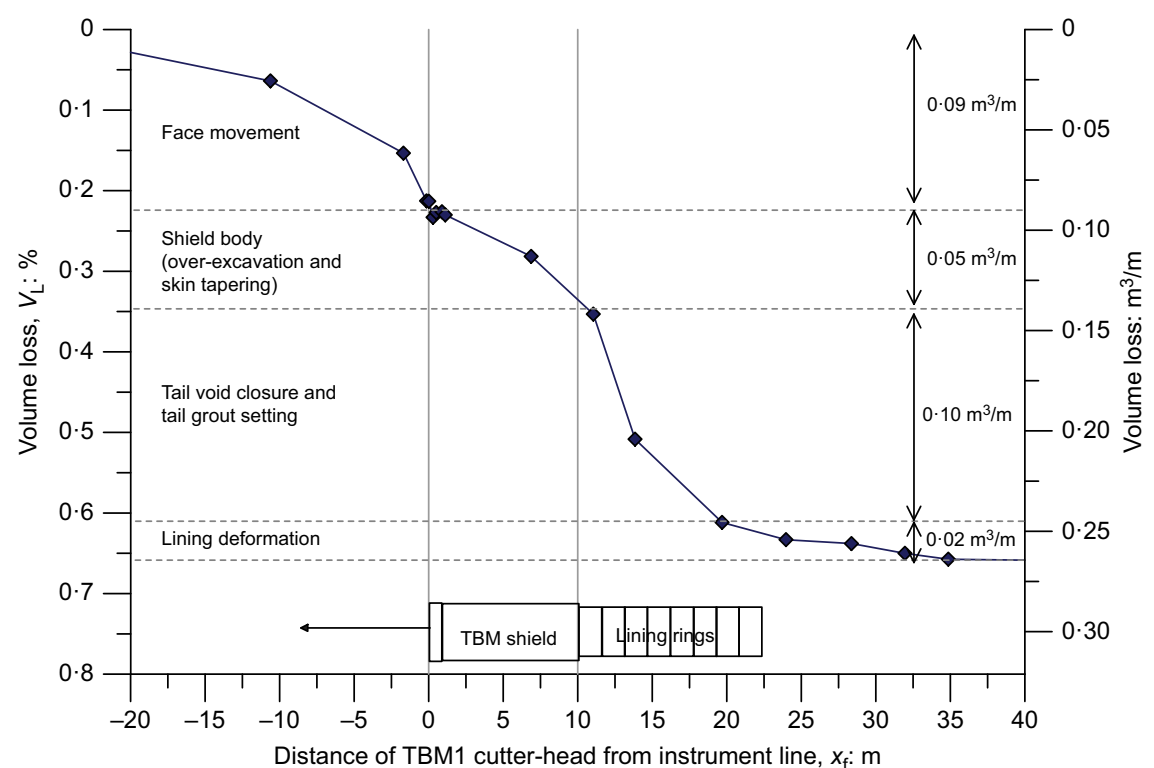

(a)

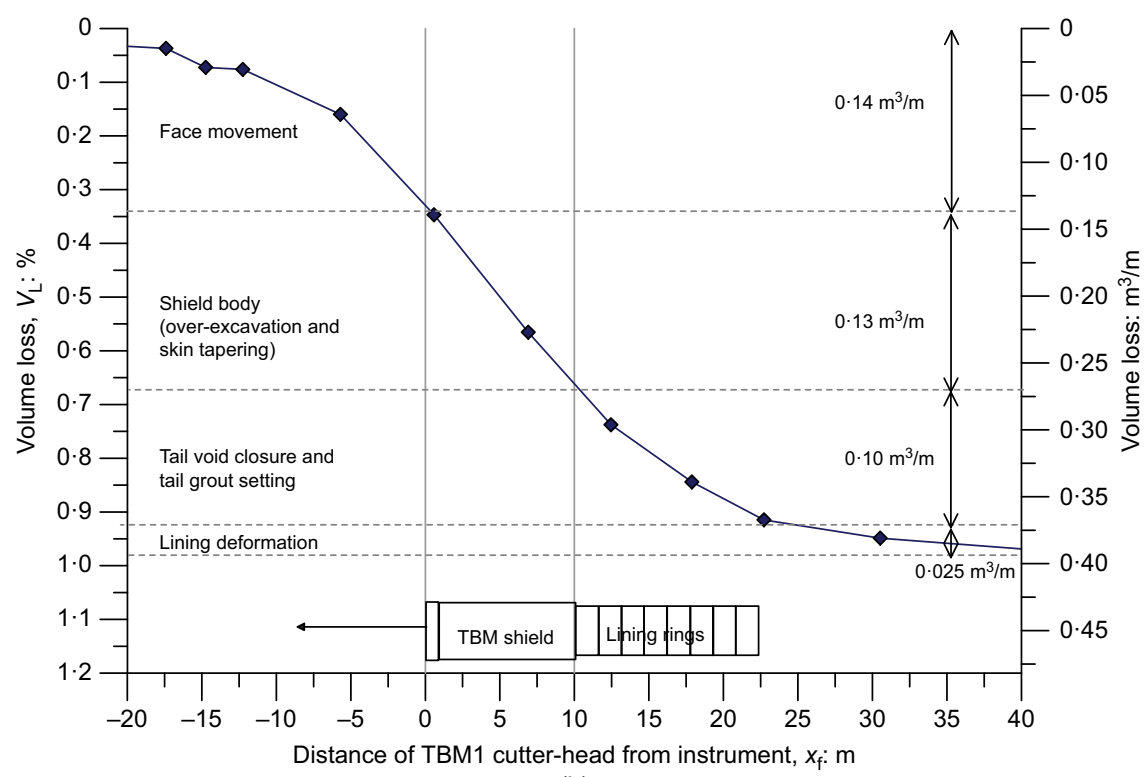

(b)

Fig. 24. Volume loss determined from measured settlement at extensometer anchors at 29.0 $\mathrm{m}$ below ground level during: (a) westbound construction (period 2); (b) eastbound construction (period 4)

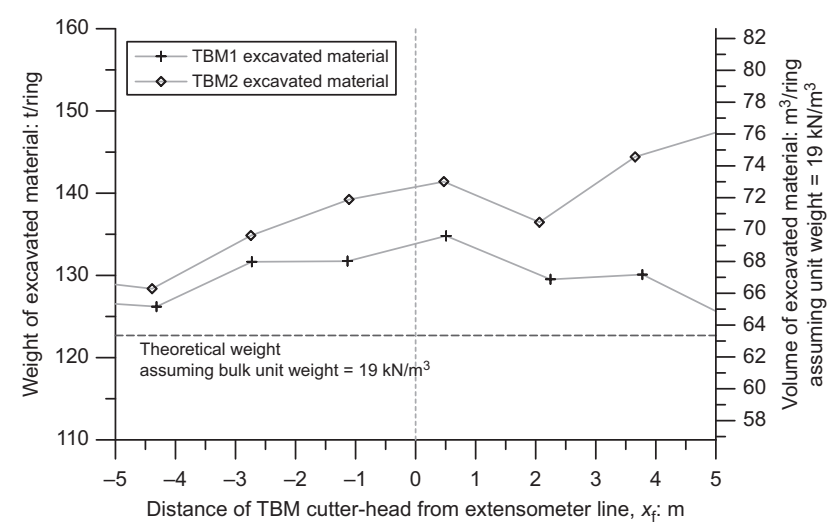

Fig. 25. Weight and volume of excavated materials during tunnel drives beneath the Y-line extensometer line by TBM1 and TBM2

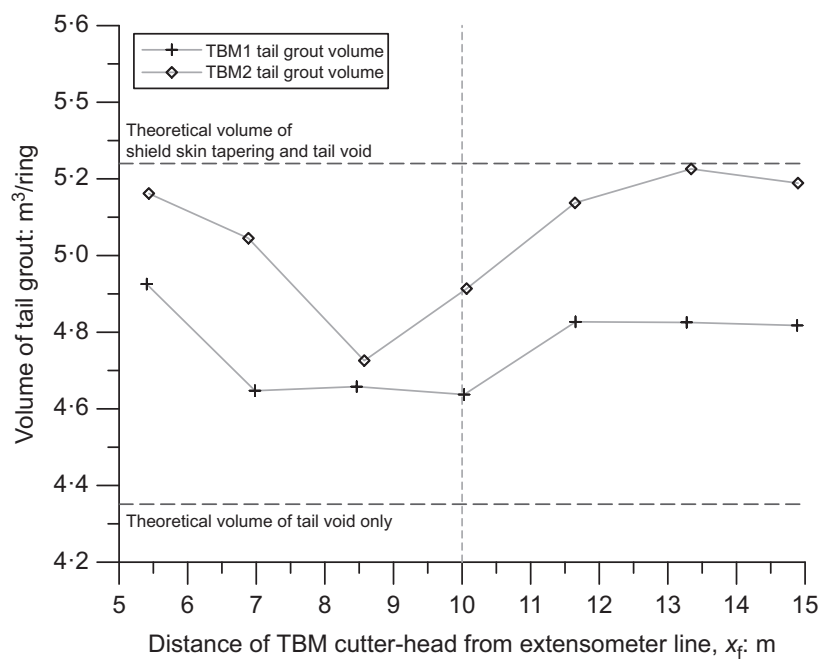

Fig. 26. Volume of tail grout injected during tunnel drives beneath the Y-line extensometer line by TBM1 and TBM2 


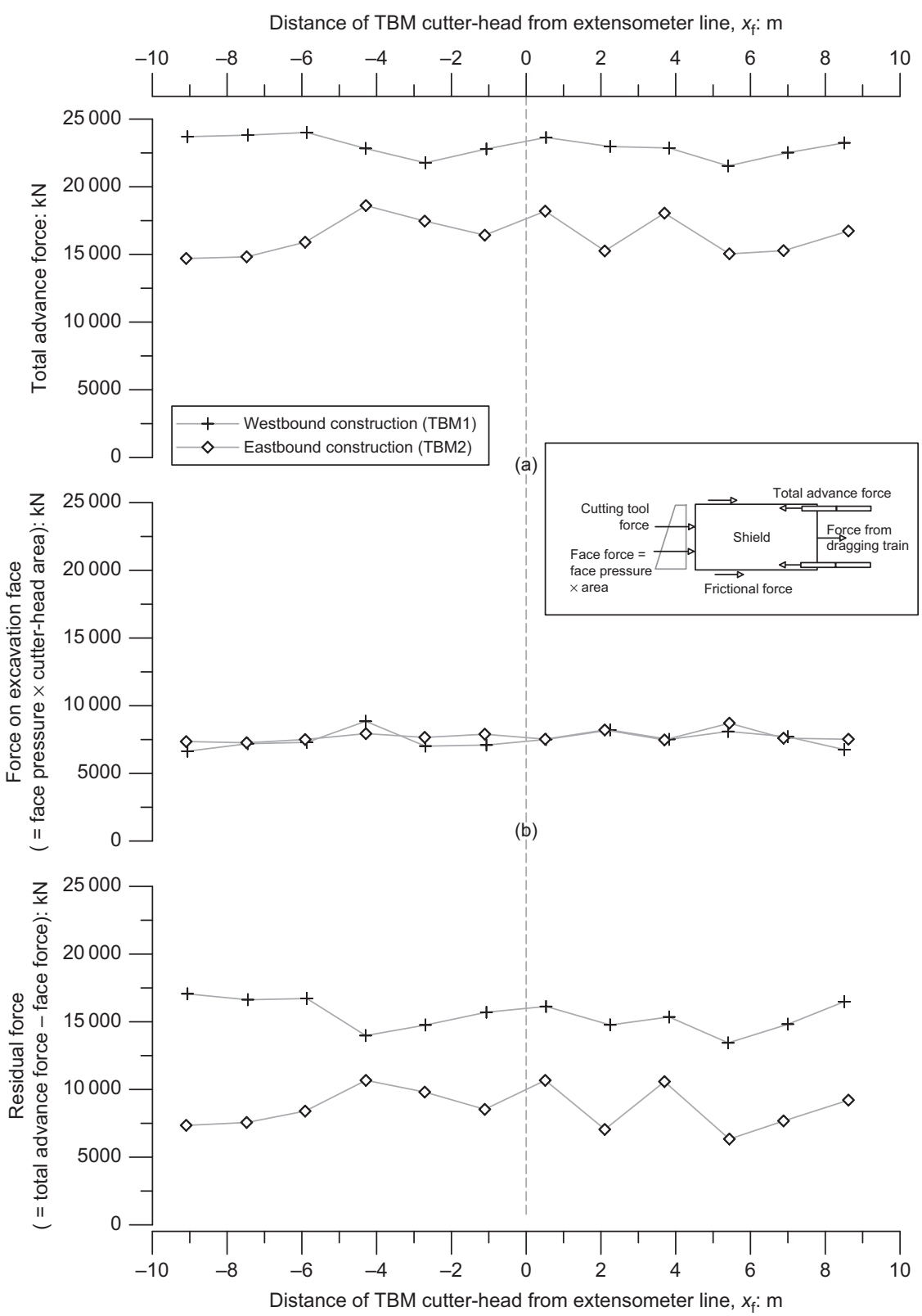

(c)

Fig. 27. Forces acting on the TBM shield during tunnel drives beneath the extensometer line by TBM1 and TBM2

\section{ACKNOWLEDGEMENTS}

The authors gratefully acknowledge the Engineering and Physical Sciences Research Council (EPSRC) (EP/G063486/1) and Crossrail, the major sponsors for this field component of the research project. Many thanks are due to the Imperial College research team, especially technician $\mathrm{Mr}$ Alan Bolsher and others who helped take the field measurements during the $24 \mathrm{~h}$ surveying periods. A thoughtful review of the instrumentation plan by Mr John Dunnicliff is also greatly appreciated. The support provided by the Royal Parks, London Underground Limited and Westminster Council during the installation work is gratefully acknowledged. The specialist input and effort during the subsurface instruments installation by CMCS Ltd and itmsoil are very much appreciated. The authors are also grateful to the main joint venture contractors $\mathrm{BFK}$, in particular $\mathrm{Mr}$ Ivor Thomas, for providing data and information relating to the TBMs and their operational variables.

\section{REFERENCES}

Attewell, P. B. \& Farmer, I. W. (1974). Ground deformations resulting from shield tunnelling in London Clay. Can. Geotech. J. 11, No. 3, 380-395.

Avgerinos, V., Potts, D. M., Standing, J. R. \& Wan, M. S. P. (2017). Predicting tunnelling-induced ground movements and interpreting field measurements using numerical analysis: Crossrail case study at Hyde Park. Géotechnique, http://dx.doi.org/10.1680/ jgeot.16.P.219.

Barratt, D. A. \& Tyler, R. G. (1976). Measurements of ground movement and lining behaviour on the London Underground at Regents Park, Report 684. Wokingham, UK: Transport and Road Research Laboratory.

Clayton, C. R. I., Van der Berg, J. P. \& Thomas, A. H. (2006). Monitoring and displacements at Heathrow Express Terminal 4 station tunnels. Géotechnique 56, No. 5, 323-334, http://dx.doi. org/10.1680/geot.2006.56.5.323.

Dean, A. P. \& Bassett, R. H. (1995). The Heathrow Express trial tunnel. Proc. Instn Civ. Engrs - Geotech. Engng 113, No. 3, 144-156, http://dx.doi.org/10.1680/igeng.1995. 27810. 
Fearnhead, N., Maniscalco, K., Standing, J. R. \& Wan, M. S. P. (2014). Deep excavations: monitoring mechanisms of ground displacement. Proc. Instn Civ. Engrs - Geotech. Engng 167, No. 2, 117-129, http://dx.doi.org/10.1680/geng.13.00047/

Hight, D. W., Gasparre, A., Nishimura, S., Minh, N. A., Jardine, R. J. \& Coop, M. R. (2007). Characteristics of the London Clay from the terminal 5 site at Heathrow airport. Géotechnique 57, No. 1, 3-18, http://dx.doi.org/10.1680/geot.2007.57.1.3.

King, C. (1981). The stratigraphy of the London Basin and associated deposits. Tertiary research special paper, vol. 6 , p. 158. Rotterdam, the Netherlands: Backhuys.

Macklin, S. R. \& Field, G. R. (1998). The response of London Clay to full-face TBM tunnelling at West Ham, London. Proceedings of the international conference on urban ground engineering, Hong Kong, pp. 100-111.

Mair, R. J., Taylor, R. N. \& Bracegirdle, A. (1993). Subsurface settlement profiles above tunnels in clay. Géotechnique 43 , No. 2, 315-320, http://dx.doi.org/10.1680/geot.1995.45.2.361.

Moh, Z. C., Ju, D. H. \& Hwang, R. N. (1996). Ground movements around tunnels in soft ground. In Proceedings of the international symposium on geotechnical aspects of underground construction in soft ground (eds R. J. Mair and R. N. Taylor), pp. 725-730. Rotterdam, the Netherlands: Balkema.

New, B. M. \& Bowers, K. H. (1994). Ground movement model validation at the Heathrow Express trial tunnel. In Tunnelling'94, proceedings of the 7th international symposium of Institute of Mining and Metallurgy and British Tunnelling Society, pp. 310-329. London, UK: Chapman \& Hall.

Nyren, R. (1998). Field measurements above twin tunnels in London Clay. PhD thesis, Imperial College, University of London, London, UK.

Standing, J. R. \& Burland, J. B. (2006). Unexpected tunnelling volume losses in the Westminster area, London.
Géotechnique 56, No. 1, 11-26, http://dx.doi.org/10.1680/geot. 2006.56.1.11.

Standing, J. R. \& Selemetas, D. (2013). Greenfield ground response to EPBM tunnelling in London Clay. Géotechnique 63, No. 12, 989-1007, http://dx.doi.org/10.1680/geot.12.P.154.

Standing, J. R., Selemetas, D. \& Shirlaw, N. (2014). Discussion on Greenfield ground response to EPBM tunnelling in London Clay. Géotechnique 64, No. 7, 581-583, http://dx.doi. org/10.1680/geot.13.D.04.

Standing, J. R., Potts, D. M., Vollum, R., Burland, J. B., Tsiampousi, A., Afshan, S., Yu, J. B. Y., Wan, M. S. P. \& Avgerinos, V. (2015). Investigating the effect of tunnelling on existing tunnels. Proceedings of the underground design and construction conference, Hong Kong, PR China, pp. 301-312.

Van der Berg, J. P., Clayton, C. R. I. \& Powell, D. B. (2003). Displacements ahead of an advancing NATM tunnel in the London clay. Géotechnique 53, No. 9, 767-784, http://dx.doi. org/10.1680/geot.2003.53.9.767.

Wan, M. S. P. (2014). Field monitoring of ground response to EPBM tunnelling close to existing tunnels in London Clay. PhD thesis, Imperial College London, London, UK.

Wan, M. S. P. \& Standing, J. R. (2014a). Lessons learnt from installation of field instrumentation. Proc. Instn Civ. Engrs Geotech. Engng 167, No. 5, 491-506, http://dx.doi.org/10.1680/ geng.13.00054.

Wan, M. S. P. \& Standing, J. R. (2014b). Field measurement by fully grouted vibrating wire piezometers. Proc. Instn Civ. EngrsGeotech. Engng 167, No. 6, 547-564, http://dx.doi.org/10.1680/ geng.13.00153.

Wan, M. S. P., Standing, J. R., Potts, D. M. \& Burland, J. B. (2017). Measured short-term ground surface response to EPBM tunnelling in London Clay. Géotechnique 67, No. 5, 420-445, http://dx.doi.org/10.1680/jgeot.16.P.099. 